\title{
Interesting discussion or tiresome bluster? Exploring the social norms of politics among young people on social media
}

\section{by Harry Chapman}

\author{
A thesis \\ submitted to Victoria University of Wellington \\ in fulfilment of the requirements for the degree of \\ Master of Arts in Political Science
}

Victoria University of Wellington 2015 


\section{(c) (i) (2)}

This thesis is licensed under a

Creative Commons Attribution-ShareAlike

4.0 International License. 


\section{Abstract}

This thesis explores the extent to which talking about politics on Facebook and Twitter is acceptable among young New Zealanders. To investigate the social norms of political discussion on social media, this research has utilised synchronous online focus groups with 27 young New Zealanders aged 16-24.

Participants were positive about the presence of politics on Facebook and Twitter, viewing the platforms as a good way of learning more about politics, although they held quite strong views about the way in which people expressed political views. Through utilising the features of social media platforms, participants had a number of ways of dealing with political material on social media they did not agree with or found offensive. Participants also said they sometimes complained about other people's online political behaviour, primarily offline to people who were not involved in the political conversation.

In investigating both Facebook and Twitter, this research has attempted to tease out differences between the norms of political talk on social media generally, versus the norms specific to each platform. Twitter was seen by participants as a more appropriate place for politics than Facebook, mostly because people's audiences on the respective platforms were very different.

This research has contributed towards a better understanding of an area which has not been well studied, especially outside of North America and Europe. It will be of interest to groups who want to engage young people on social media regarding political issues. 


\section{Acknowledgements}

Thank you to my participants, without whom this research would not have been possible.

Thank you to my supervisor Dr Hilde Coffé, who has been very patient and helpful throughout the process of writing this thesis.

Thanks to Amy and Nick for listening to my progress from afar. To my parents, thanks for hearing me talk far too much about this thesis. Finally, to Sarah, thanks for believing in me, and supporting me, from the beginning to the end. 


\section{Contents}

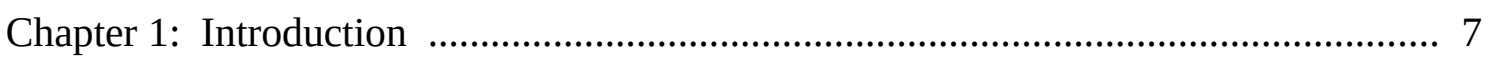

1.1 Outline of the thesis _............................................................................... 9

Chapter 2: Literature review ...…………………………………………………... 11

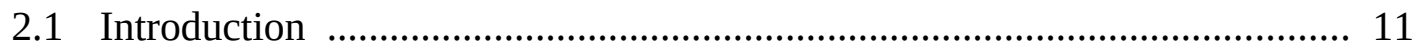

2.2 The relationship between social media and social practices ......................... 11

2.3 Politics on social networking platforms ...................................................... 15

2.4 Social norms ...................................................................................... 17

2.5 Social norms and political talk ………………………………………….... 22

2.6 Research questions .................................................................................. 32

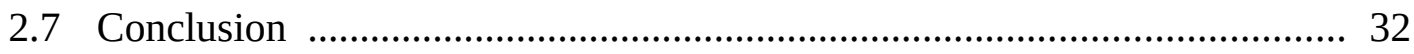

Chapter 3: Methodology, method and analysis ...................................................... 35

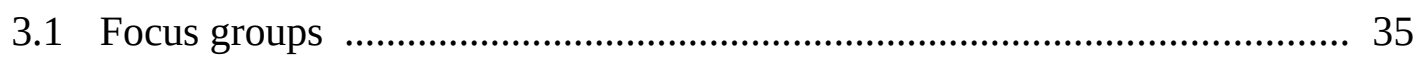

3.2 Description of method ............................................................................ 40

3.3 Analysis ..................................................................................... 45

3.4 Description of participants ……………………………………………...... 45

Chapter 4: Results ……………………………………................................ 47

4.1 Experiences with political content on Facebook and Twitter ……………... 47

4.2 The social norms of talking about politics .................................................. 49

4.3 The relationship between social media and social practices ……………..... 70

4.4 Managing political disagreement on social media ....................................... 79

4.5 Women, feminism and social media ......................................................... 89

Chapter 5: Discussion ...................................................................................... 91

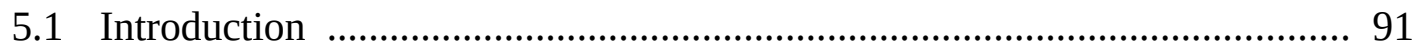

5.2 Norms on social media ……………………………............................ 91

5.3 The way in which appropriate behaviour is determined .............................. 97

5.4 The relationship between social media and social practices ....................... 100

5.5 Feminism and politics online .............................................................. 102

5.6 Research limitations ................................................................................... 103 
5.7 Further avenues for research

Conclusion

References

Appendix 1: Summary statistics

Appendix 2: Information about participants 120

Appendix 3: Example of a political discussion on Facebook 121

Appendix 4: Focus group run plan 122 


\section{Chapter 1: Introduction}

The old adage goes that you should 'never talk about religion or politics with strangers'. This saying reflects the sensitivity of politics as a topic of conversation, and the need to think twice before bringing up politics with family, friends and acquaintances, because people can have strong beliefs and get upset easily.

When thinking about whether or not it is appropriate to talk about politics in everyday 'offline' life, you have to consider your audience, and whether they share your political views. When talking about politics online, however, the social calculations involved in trying to figure out if talking about politics is acceptable are much more complicated. When you talk about politics on social media it is never exactly clear who your audience is, how they are going to react, and whether your political post or comment is going to get taken out of context, or even be reposted by other users. Talking about politics on social media can therefore be a nerve-racking experience.

Despite these difficulties, people do talk about politics on social media, and the connection between social media and politics is a fast growing field of scholarship. While democratic deliberation - which particularly values the discussion of politics among people with different political views - was originally envisaged in offline contexts, scholars interested in democratic deliberation have increasingly examined the potential of online spaces such as social media for political talk (Wright 2012; Freelon 2010). Most scholarship from a political science perspective has focused on the relationship between politics on social media and political participation, exploring for instance, whether being exposed to politics on social media can help to increase the participation of young people in more traditional forms of politics (e.g. Baumgartner and Morris 2010; Vitak et al. 2011; Diesing 2013).

International research in the United States and Sweden has also explored the social acceptability of political talk on social media (e.g. Gustafsson 2012; Van Wyngarden 2012; Thorson, Vraga, and Kligler-Vilenchik 2014; Thorson 2014). This research suggests that there are relatively clear, if unstated, standards about what is considered acceptable in unmoderated social media. We need to know more, however, about these norms of political talk on social media. Are they consistent across countries? Do the 
norms vary across social media platforms? ${ }^{1}$ How do people come to understand the norms, and what are people's reactions when they come across political content they disagree with?

Because this topic focusses on the social norms of political behaviour, it explores a topic at the boundary between political science and political sociology. It is therefore not entirely surprising that it has been somewhat neglected by political science scholars.

The research on politics and social media which has been done in New Zealand explores its role in elections (Marret 2010), as a tool for promotion for politicians (Ross and Bürger 2014), or the potential positive effects of exposure to politics on social media on political participation (e.g. Diesing 2013). This New Zealand research, however, has not looked at any depth into the social acceptability of politics on social media, and this research will help to fill that gap.

The main research question addressed in this study is:

To what extent is posting political content on Facebook and Twitter socially acceptable among young New Zealanders?

Related to this overarching question are a number of sub-questions. The first group of questions explores the practices of young people posting about politics on Facebook and Twitter: what sort of political content do young people see and post on social media?

The second group explores the social acceptability of politics on social media: to what extent do young New Zealanders think there is a place for politics on these platforms? Before they post about politics on Facebook and Twitter, do young people think about the social acceptability of the posts, and do they tweak what they say through humour or impartiality for instance - to make it more acceptable? Are young people particularly concerned with certain people, or groups of people, on social media platforms seeing their political posts?

The third group of questions is related to how young people come to perceive what is socially acceptable. That is, what is the process by which they come to understand what is acceptable? To what extent do direct and indirect complaints about people's behaviour shape people's understanding of what is acceptable? I'll also explore whether

1 I use the term social media platforms (and social networking platforms) instead of social media sites, as the word site does not encompass the different ways users can now interact with Facebook and Twitter. 
people think that standards of what is acceptable vary across groups.

This research has moved beyond the typical focus in existing research on one social media platform, and will examine both Facebook and Twitter. I have chosen to study both platforms for a couple of reasons. Firstly, they are the two most common social networking platforms used by young people in New Zealand (Mills 2013). Secondly, because they are two different forms of social networking which should allow me to investigate the way in which the features of the different social media platforms affect online political talk. If I had only looked at one social media platform, it would be hard to know whether findings are specific to that platform, or could be generalised.

Due to the relative lack of literature on the topic in question, my research is necessarily exploratory, and I have chosen a qualitative methodological approach. I conducted six online synchronous focus groups with 27 New Zealanders aged 16 to 24 . The groups were designed to be heterogeneous in terms of participants' age, interest in politics, and the frequency with which they posted about - and engaged with - politics on Facebook and Twitter. Once the focus groups were finished, to aid in analysis the transcripts were coded using the qualitative data analysis software RQDA.

\subsection{Outline of the thesis}

This introduction has briefly introduced the themes of the research and my research questions.

Chapter 2 is the literature review, which explores a number of areas of pertinent research. Firstly, it investigates the relationship between social media and social practices. Secondly, it explores research which has investigated politics on social media generally. Thirdly, the social norms literature is examined. Finally, research which has explored the social norms of political discussion on social media platforms will be surveyed, before ending with my research questions.

Chapter 3 explores my methodology, method and analysis. Firstly, it investigates the suitability of focus groups for my research. Secondly, it describes the operation of the focus groups and my analytical strategy. It ends with some brief descriptive statistics about participants.

Chapter 4 explores my results. Firstly, it investigates participants' experiences of politics and social media. Secondly, it explores the social norms of political talk. Thirdly, it details how people manage differences of political opinion on social media, 
and finally, explores women's experiences of posting about feminism.

Chapter 5 is the discussion, which places my findings in the context of existing research. It also briefly explores the limitation of my research, and avenues for further research.

Chapter 6 is the conclusion, which briefly summarises the findings and my contribution to the literature. 


\section{Chapter 2: Literature review}

\subsection{Introduction}

Political discussion and deliberation is viewed by many scholars as a crucial part of democracy, being valued for promoting - among other reasons - good governance, good communities, and good citizens (Conover, Searing, and Crewe 2002). As the internet has developed, political talk has increasingly started to take place online, and in more recent years on online social networking platforms. With young people spending significant proportions of their time on social network websites, and with these sites providing a space for non-traditional political participation, the social dynamics of these sites warrant further study.

Research has shown that offline political talk is shaped by the social context in which it occurs (e.g. Eliasoph 1998), but much less is known about the social understanding and acceptability of political talk on social networking platforms. A significant amount of research has been conducted in a number of relevant areas to this topic, for instance looking at the social acceptability of offline talk (Eliasoph 1998; Conover, Searing, and Crewe 2002), how norms operate online (Burnett and Bonnici 2003; McLaughlin and Vitak 2012), and how politics on social media affects offline participation (Vitak et al. 2011; Diesing 2013). However, the research which looks specifically at the crossover of these areas is quite limited (Thorson 2014; Gustafsson 2012).

What follows is a brief exploration of related literature, examining firstly the relationship between social media and social practices, then literature which explores the effects and impacts of politics on social media. I will then introduce social norms, and research which examines the social norms of social media platforms. To finish, I will explore the social norms of political talk, and the limited research which examines the social acceptability of political discussion on social networking platforms.

\subsection{The relationship between social media and social practices}

When doing research on social practices on social media, it is important to understand the way that social media platforms help to shape practices: behaviour is partly shaped by the environment in which it occurs. I will explore two ways of conceptualising the relationship between social media and social practices, firstly through the idea of 
'affordances' and secondly through 'website cultures'.

\subsubsection{Technological affordances}

So-called "affordances" are the interactions and relationships between technology and social practices. The fundamental point is that "technological design can produce political consequences” (Freelon 2010, 1185). In other words, the way physical and virtual spaces are designed in some ways determines the way people engage with the space and act generally (Freelon 2010). In terms of politics and deliberation on the internet, scholars have examined the effect of features such as asynchronous communication, prior moderation, threaded messages, and anonymity (Freelon 2010). However, technological affordances encompass more than just features of sites, and necessarily include "understandings about choice and control” (Young 2012, 20). In other words, affordances help us to explore the way in which the technological construction of these social media platforms shape what users are able to do.

Social media has a number of properties which help to shape social dynamics on the platforms. Boyd (2008) describes social media as "networked publics", which are defined by four properties: persistence, replicability, invisible audiences, and searchability. She argues that "[t]hese properties fundamentally alter social dynamics, complicating the way people interact” (boyd 2008, 120). Social dynamics are complicated because posts or comments on social media can be taken out of context, audiences can be spread across time and space, and the content shared beyond your control.

To draw attention to affordances is to highlight that the technological context, characteristics, and features of social media have an impact on the type of social interactions in general, and political discussions in particular, that will occur on the platforms. In other words, any form of political participation on social networking is shaped by the context of the site, the features it offers, and also how people respond in that environment to content, and the social customs which develop over time. However, one should be careful to avoid falling into the trap of technological determinism when it comes to thinking about how affordances shape norms of behaviour. It is not simply the features of a given social media platform which determine the norms of socialising, but the cultural and social traditions which develop from the use of the platforms. Boyd (2014, 13) argues that: “As people use these different tools, they help create new social 
dynamics”.

It is worth briefly exploring here some of the affordances of Facebook and Twitter, firstly to explain them to readers who are unfamiliar with the platforms. Secondly, in light of fact the platforms are rapidly evolving, detailing the affordances makes it clear how they function at this particular time.

On Facebook, the main way in which people interact with each other publicly is on the 'newsfeed', after people have posted material to all of their friends. It is also possible, but less common, to post on a friend's 'wall' (more recently termed the 'timeline'), in a way which is primarily aimed at the friend, but also visible via the newsfeed to mutual friends. Generally others who see content which has been posted can 'like' it, comment on the post, but also respond to - and like - comments in turn. It is also possible to 'share' other people's posts, recreating the post on your own timeline.

On Twitter, posting material works much the same way except for the 140 character limit. Messages directed to a person, by using their Twitter handle at the beginning of the message, are generally only visible to that person and anyone who follows both of you. 'Retweeting' material is much more common on Twitter than (re)sharing material on Facebook. It is interesting to note neither platforms provide users with the ability to publicly show their dislike for content which has been posted, short of replying to that effect.

An important difference between Facebook and Twitter is that Facebook uses an algorithm to determine which material to show users, whereas Twitter displays to its users all the tweets sent by everyone they follow. The Facebook algorithm is an opaque feature, and is frequently tweaked. It displays material to more people if it receives a number of likes or comments, which has the impact of reinforcing virality, or, from a different perspective, suppressing content which is not popular.

There are a number of options available to Facebook and Twitter users if they wish to hide content or a person, or even block people. The least extreme option is to hide the material on Facebook, or mute the material on Twitter. It is also possible to unfollow people on Facebook, while still remaining 'friends'. More seriously, users of Facebook can 'unfriend' people, and Twitter users can 'unfollow' others. Finally, blocking other users on both platforms is the strongest possible action. 


\subsubsection{Website cultures}

A concept which is similar to affordances, but somewhat broader, is the concept of 'website cultures'. Pasek, more, and Romer (2009, 207)² highlight website cultures, which they define as the interaction of "distinct histories, structural features, and sitespecific attributes”. They argue that website cultures can both influence users of sites, and also affect the recruitment of new users such that only certain types of people are drawn to the site. Studying website cultures is important because websites which appear similar may encourage different behaviour (Pasek, more, and Romer 2009).

Pasek, more, and Romer (2009) explore the differences between MySpace and Facebook as an example of the possible differences in culture between platforms. Facebook has emphasised the link between users of the platform and their offline social world through the network feature, which connects people to fellow students at schools or universities, to fellow employees at their workplaces, and to fellow residents of places (Pasek, more, and Romer 2009). Facebook also has a real name policy which it polices, which states that: "The name you use should be your authentic identity" (Facebook 2015; Pasek, more, and Romer 2009). ${ }^{3}$

Facebook's explicit link to offline social worlds is reflected in boyd's (2014) ${ }^{4}$ research into teenagers in the United States, where she found that Facebook was used by teens in a different way to other social networks, due to the fact that it was the place where different friend groups and family members congregated. Other social networks, such as Twitter, were organised more according to common interests, and hence were used differently by teenagers. Facebook's history and development also partly resulted in a class-based migration of young people from MySpace to Facebook from 2006 onwards, as Facebook opened up membership to non-college students (boyd 2007). Socio-economic differences between users of Facebook and MySpace was established quantitatively by Pasek, more, and Romer (2009). As boyd (2007) has argued: “Social networks are strongly connected to geography, race, and religion; these are also huge factors in lifestyle divisions and thus 'class.'” This research indicates that in addition to

2 No capitals in surname is author's preference

3 Facebook's real name policy has been somewhat controversial, with protests in September 2014 after gay and transgender users protested that they were stopped from using names which were not their 'real' ones (Grinberg 2014; see also Alptraum 2015; Holpuch 2015).

4 No capitals in surname author's preference 
the importance of affordances, we need to be mindful of the ways in which platformspecific history and culture can play a part in shaping people's behaviour.

Now that the relationship between social media and social practices has been explored, I will move on to examining research into politics on social networking platforms.

\subsection{Politics on social networking platforms}

When examining traditional metrics of political participation, young people have typically shown lacklustre and worrying levels of involvement interest (e.g. Baumgartner and Morris 2010). However, it has been increasingly recognised that young people often participate politically in non-traditional ways (Hustinx et al. 2012). Rather than young people participating 'less', they seem to be participating in different ways.

Online political participation is a phenomenon which has important implications for the way in which young people build social capital and participate in politics. If exposure to, and engagement with, politics encourages overall political participation, then social networks could play an important part in encouraging young people to get involved in politics (Vitak et al. 2011).

Research into political participation on social networking platforms has emerged from existing research which explored politics on the broader web, such as on Usenet groups (e.g. Himelboim, Gleave, and Smith 2009). Research into politics and social media has examined the association between social media use and political behaviour (e.g. Park, Kee, and Valenzuela 2009; Diesing 2013), and the link between social media use and social capital (Valenzuela, Park, and Kee 2009; Pasek, more, and Romer 2009). Researchers have also looked at social media as a tool of political promotion, exploring the ways in which community groups and NGOs (Karpf 2010), and politicians (Mason 2011), have utilised Facebook to engage with potential supporters. In addition, a number of studies have examined whether political content on social media is qualitatively different from non-political content (Young 2012; Boynton et al. 2013).

A small amount of research has examined the relationship between the affordances of social media and political talk. Young's (2012) research examined the nature of political discussion among young people on Facebook, through content and network analysis of 25 people’s Facebook walls. She found that political and social posts were 
treated in a similar way, although most posts were social rather than political. She further found that it was common for users to add their own commentary or other information to posts, and that if they did, the post was more likely to start conversations.

Most of the literature on politics and Twitter focusses on either politicians' use of the platform, how everyday people use it, or how Twitter has been utilised in struggles against authoritarian regimes (Larsson and Moe 2012). The role of Twitter in elections has also been studied. It has been established through network analysis that during the 2010 Swedish election, for instance, a minority of users contributed most political tweets, and they were largely from existing political and media elites (Larsson and Moe 2012). Furthermore, most Twitter users in that election engaged in a one-way dissemination of information rather than engaging in discussion (Larsson and Moe 2012). In the 2012 United States presidential elections, Schill and Kirk (2014) found that Twitter had a significant impact in changing the way presidential campaigns unfolded, with the behaviour of the campaign teams, journalists, and citizens all affected.

Overall the literature which explores politics on social media focuses mainly on the political content and its effects on participation, and less on how people perceive the political content. Moreover, most research which has examined politics on social media has focussed on only one social media platform (see however Pasek, more, and Romer 2009; Thorson 2014). Pasek, more, and Romer (2009) explore both MySpace and Facebook's impact impact on social capital. In light of their findings that MySpace and Facebook users were significantly different on a number of indicators relating to politics and social capital, it is dangerous to study politics on only one site, because it would be difficult to determine the impact of a site's culture on results.

\subsubsection{New Zealand research}

Young New Zealanders are intensive users of social media. Approximately 92 percent of young New Zealanders aged 18-29 use Facebook, and 34 percent use Twitter (Mills 2013). Researchers have suggested that using social networking platforms is so ubiquitous in New Zealand's culture that "even those who generally do not use the internet for leisure feel a certain necessity to be on a site like Facebook.” (Gibson et al. 2013, 36)

A substantial number of young New Zealanders also engage with politics on social 
media. The most common behaviour was liking or promoting material related to political or social issues that others had posted, with 54 per cent of those aged 18-29 reporting that they had done that. Forty per cent had posted their own thoughts or commentary on political or social issues, and 26 per cent encouraged other people to vote (Mills 2013). Generally speaking, younger New Zealanders were more likely to engage in politics on social media compared to older groups (Mills 2013).

Exploratory quantitative research into youth online political participation suggests that there are some differences in the extent to which young people use social media for political ends across different countries (Mills 2013). Compared with Australians, young New Zealanders were substantially more likely to participate in politics on social media, and in most activities sampled were more engaged than young Americans (Mills 2013).

Some qualitative research has also specifically explored politics on social media in New Zealand. For example, Marret (2010) investigated how social media interacted with political participation during the 2008 New Zealand general election. Several research projects have also examined the way in which politicians use social media as a tool for self-promotion (Ross and Bürger 2014; Mason 2011). Diesing (2013) explored whether social media is an antidote for declining youth engagement in New Zealand. Overall, her research using mixed methods found that while young people are exposed to politics on social media, political interest still plays an important part in determining whether they engage with that political content (Diesing 2013).

Having explored research which examines politics on social media generally, I will now turn to exploring social norms, the impact of norms on behaviour, challenges involved in studying norms, and finally social norms in online contexts.

\subsection{Social norms}

Social norms are socially constructed 'codes of conduct' which can either encourage or discourage behaviour among members of groups (Lapinski and Rimal 2005). Norms have been called the 'grammar of society', in that they are mostly implicit guides to behaviour which emerge organically rather than being created intentionally (Bicchieri 2006). People learn implicit norms through the observation and imitation of other group members (Burnett and Bonnici 2003; Hooper and Kalidas 2012). It is no surprise that human behaviour is shaped by people's perceptions of the popularity of a prospective action (Lapinski and Rimal 2005) - people generally want to behave in a way which 
will be positively received by others.

Social norms serve a crucial role. Norms can act as the 'glue' which "keeps social groups cohesive” (Burnett and Bonnici 2003, 349) and ensure the group survives (Feldman 1984). Norms also help people to understand each other; without them, "we would be unable to understand each other” (Sunstein 1996, 918). Within a group, norms can help to provide "a sense of balance” for behaviour, so that once individuals have undergone a process of socialisation they can understand the boundaries of acceptable behaviour (Burnett and Bonnici 2003). Norms can therefore help prevent uncomfortable behaviour or interpersonal problems (Feldman 1984). Norms of reciprocity and cooperation, so-called "pro-social” norms, can also help to overcome collective action problems in which an individual's incentives for an action are not aligned with what what benefits the collective (Bicchieri 2006; Sunstein 1996). However, social norms are not always positive forces - some can be inefficient and promote behaviour which is not beneficial for groups or society (Bicchieri 2006; Sunstein 1996).

Within the concept of social norms, a number of conceptual distinctions can be made which facilitate comprehension. For instance, the level at which social norms operate can be differentiated. Firstly, 'collective norms' operate at a high level and represent the prevailing sense of appropriate behaviour for a group. Secondly, norms can also be understood at an individual level. These 'perceived' or 'personal' norms act as the way in which people understand, interpret, and internalise social expectations and use it to guide their behaviour. Norms can be either explicit or implicit, although collective norms are rarely explicit (Lapinski and Rimal 2005).

\subsubsection{The impact of norms on behaviour}

When exploring the impact of norms on behaviour, it is important to note that not all behaviour is governed by norms: norms are generally only relevant when people's behaviour affects other members of a group in some way (Feldman 1984). When norms are relevant, it is clear that they generally have some impact on most people's behaviour, although this is context specific. As Bicchieri (2006, xi) has argued, "the important question is not whether norms affect behaviour, but when, how and to what degree”. Although social norms are frequently referred to in the social sciences, surprisingly "there is no consensus about the power of social norms to direct human action" (Bicchieri 2006, 1). 
There are a number of theories which attempt to explain when, and why, people's behaviour conforms to norms or does not. Sunstein $(1996,916)$ suggests that people weigh up options when they act, balancing the "intrinsic value" of each option, with the benefits or costs to reputation, and also the effect the action will have on "selfconception”. For instance, you might place intrinsic value on talking about politics, and it might boost your self-conception because you like to show off your political knowledge, but it might involve costs to your reputation because talk about politics is disliked by others for the awkwardness it can produce. Social norms are a significant factor in the reputational incentives which make up this calculation (Sunstein 1996). Bicchieri (2006) argues that people use both deliberational and heuristic methods when they are trying to decide how to behave in a particular situation. That is, people both assess the risks and rewards of each course of action and decide on what will maximise their utility, but also use context-dependent mental short-cuts - often unconsciously - to guide them to appropriate behaviour.

There are a number of reasons why people might choose to violate norms. Some people do so because they want to be non-conformists and wish to express their defiance, because they decide that the norm is not worthy of compliance, or perhaps because incidentally their tastes are more important than conforming (Sunstein 1996). Another factor in compliance towards norms is the ambiguity of a given social situation: ambiguity can influence the extent to which individuals rely on their own internal cues. Generally when there is more ambiguity about a behaviour, individuals look to others in the group to see if it is normatively acceptable, whereas if the behaviour is not ambiguous, individuals are more likely to rely on their own personal views (Lapinski and Rimal 2005).

When people choose to not behave in accordance with social norms, there can be a number of consequences. People who disregard norms can be made to feel uncomfortable through disapproval by other group members (Sunstein 1996), face sanctions, or even be expelled from the group (Burnett and Bonnici 2003). Rather than be expelled from the group, those who have disregarded norms may instead display 'behavioural conformity' - attempting to fit in, even if they disagree with the norms. But more than behavioural conformity may be required for a person to truly fit in, as 'attitudinal conformity' is also important (Burnett and Bonnici 2003). The consequences of breaching norms can vary depending on the strength of the norm, and the store of 
good will or social credit which a person has developed over time (Feldman 1984).

It is important to note, however, that deviance from norms is not restricted to individual opposition: groups can also oppose norms and form communities. In any given community, it is likely that there are different views on prevailing social norms. Contested norms within a heterogeneous society can result in the existence of what Sunstein (1996, 919-920) terms 'norm communities', which can be both public and private. People with similar dispositions regarding norms may form groups, as people leave communities which they dislike and are attracted to other communities. For instance, young people at a high school may group together into sub-communities which may even be self-consciously deviant (Sunstein 1996).

The social norms literature has shortcomings which are relevant here. Firstly, it is difficult to determine when people are more or less likely to be influenced by others (Lapinski and Rimal 2005). Some answers to these question have been sought through experimental games, but results are inconclusive (Bicchieri 2006). Secondly, more research is needed into how normative information is shared between people in a group (Lapinski and Rimal 2005).

There are significant methodological challenges to studying collective norms. Although it is easy to conceptualise that there is an overarching guide to behaviour, every individual is likely to have different perceptions of what the norm is (Lapinski and Rimal 2005). Since it is difficult to study collective norms utilising small-scale qualitative methods, this research will investigate the perceived social norms of political discussions on social media, and how individual perceptions feed into people's practices.

Having briefly introduced the concept of social norms, and a useful framework for thinking about them, we now move to a discussion about the way social norms shape online behaviour.

\subsubsection{Social norms in online contexts}

Social interaction is substantially different in online contexts compared to offline contexts. As Burnett and Bonnici (2003, 336) argue, most interaction online is text based, and there cannot be any clear distinction between attitudinal and behavioural conformity: attitudes "can only be inferred through an analysis of textual behaviors.” I will now explore briefly the norms of early online communities, before moving on to 
the norms of social media platforms.

\section{a) The norms of early online communities}

A number of studies have explored the social acceptability of online behaviour. However, early studies such as Burnett and Bonnici (2003) who investigated the implicit and explicit norms of 'virtual communities' in Usenet groups, are very different to more contemporary social networking platforms. Those groups generally had explicit defined norms, whereas a given user of Facebook or Twitter is forced to rely only on interpreting implicit norms through the behaviour of other people.

Some scholars were also optimistic that the pseudo-anonymity of many early online communities could mean the social inequality of the real world would be ironed out, such that people could participate in discussions on more even grounds (Albrecht 2006). However this sort of anonymous environment has largely been partly replaced by platforms like Facebook, in which one's offline and online identities are linked, although a degree of pseudo-anonymity is possible on platforms like Twitter.

\section{b) Social norms on social media}

Given Facebook's dominance among social media platforms, most researchers have focused their attention on it. Scholars have examined what constitutes acceptable and unacceptable behaviour on Facebook, and found that there are implicit norms in operation on the network which discourage people from posting too many status updates, being overly emotional, engaging in "heated interactions” in public, or tagging people in unattractive or compromising photos or content (McLaughlin and Vitak 2012, 307-308).

Hooper and Kalidas (2012) explored through face-to-face interviews with young New Zealanders what is socially acceptable behaviour on Facebook, and also how people come to understand social expectations. The implicit nature of these norms means that they are not always clear, and their participants found that unacceptable behaviour was much easier to describe compared to acceptable behaviour. For the former, participants use their personal beliefs and experiences to guide them, with overly personal or rude behaviour typically being seen as unacceptable. But when it came to articulating acceptable behaviour, participants largely followed the lead of others, and tried to keep their Facebook presence "tame” for family and workmates (Hooper and Kalidas 2012). 
When norm violations do occur, they are normally the result of overlapping audiences with conflicting conceptions of what is appropriate. Litt et al. $(2014,5)$ found that a large proportion of norm violations involved someone else exposing the target "engaged in behaviour that was normatively acceptable to one sub-audience on Facebook, but counter-normative to another.” That is, Facebook users had trouble with other people posting things which did not respect the different contexts in which content might be viewed and understood. For instance, a group of young people could have a running joke, which the parents of those young people might struggle to understand and even find offensive - once it crosses over from the context of friends and is seen by the parents (see boyd 2014). Interestingly, high levels of Facebook skills led people to worry less about face threats, suggesting that once people are more familiar with the settings and tools available to them on Facebook, external threats to their selfpresentation are seen as more manageable (Litt et al. 2014).

There are important reasons to believe that social norms are likely to differ substantially between different social networking platforms. Boyd (2014) notes that the social contexts in which teens operate has important implications for how they behave in and navigate these different social spaces. For the young people she interviewed, Facebook formed the core social infrastructure where all sorts of friend groups come together, whereas other sites such as Tumblr and Twitter were organised more according to interests. Therefore the teens participating in her study had a tendency to act differently when interacting with all of their friends and family on Facebook, compared with when their audience was just those friends who shared similar interests or obsessions on other platforms. Overall, boyd (2014, 39-40) emphasised that "the context of social media sites is socially constructed" such that norms are not simply properties of the site, but reflect the practices which have been created through user interaction.

Having examined social norms, both generally online and on social networking platforms, I turn to examining the role of social norms in political talk, both online and offline.

\subsection{Social norms and political talk}

Talking about politics can often be an uncomfortable experience. Warren (1996, 251) argues that compared to other forms of social behaviour "politics is exceptional and 
difficult: a political stance toward another often indicates a failure of other kinds of social understandings". Political discussion has also been described as "a risky enterprise that carries not only benefits but also potential costs" (Conover, Searing, and Crewe 2002, 53). Politics is a difficult topic of conversation both because strong differences of opinion exist, which are strongly linked to identity, but also because it is embarrassing if you are exposed as not being knowledgeable about politics (Conover, Searing, and Crewe 2002). Although knowledge about any topic of conversation is evidently useful, because knowledge about politics is tied up in ideals of citizenship (Thorson 2012), a lack of knowledge about politics is much more embarrassing.

Social norms serve a useful function when it comes to the discussion of politics, helping to make conversation less risky. Norms go some way towards harmonising expectations regarding political conversations, helping people to avoid avoid awkward social clashes. Conover, Searing, and Crewe $(2002,53)$ argue that norms "can regulate the nature of discussion and thus reduce the likelihood of participants clashing in their expectations.” Nevertheless, different people still understandably have varied - and sometimes conflictual - reasons for participating in political discussions (Conover, Searing, and Crewe 2002).

While it is likely that some aspects of the norms of talking about politics are similar in offline and online contexts, I will now explore research which has examined each context in turn.

\subsubsection{The social norms of offline political talk}

Researchers have established that political discussion - conversations about 'public' issues - are more likely to occur at private fora such as at home or at social occasions where we know the people well, and less likely to occur at large family gatherings and at social occasions where we do not know people well (Conover, Searing, and Crewe 2002). Looking more specifically at public settings, political talk is more common at work or with neighbours, and less common at church or in a bar. Overall, when political discussion "occurs at all, much of it is happening in more private settings." (Conover, Searing, and Crewe 2002, 37) Conover, Searing, and Crewe's (2002) comparative research design allow them to establish that these findings do, however, differ to some extent between the United States and English contexts, with people from the United States generally engaging in more political talk. 
In analysing offline political talk, Eliasoph draws attention to what she calls "civic practices”, “political manners” or "etiquette”. This etiquette represents a "sense of civility" and creates "a comfortable context for [political] talk in the public sphere" (Eliasoph 1998, 21).

Eliasoph (1998) thinks about everyday people engaged in political talk as a process of determining what is appropriate based on 'common knowledge' people share. Determining what is appropriate is a largely subconscious process of intuition based on previous experiences. We rarely think about what we say before we say it, but nonetheless the way we talk in conversations can be adjusted to fit the particular purpose for our talk (Eliasoph 1998).

Eliasoph (1998) also highlights the importance of social context in enabling spaces which are conducive to political discussions. If people are able to consistently socialise within a group, it is possible to create a space characterised by trust, where disagreement - such as over political issues - is not a threat to the group. However groups can also choose not to establish contexts where talking about politics is acceptable. She analyses some groups which "worked together to establish contexts in which debate itself was unpopular” because group members did not want political discussion of systematic problems to make their volunteer efforts seem futile (Eliasoph 1998, 46). Therefore groups can both encourage and discourage the discussion of politics, and researchers must be mindful of the social context of groups and the way in which groups can shape behaviour.

People have varied reasons for choosing to remain silent in political discussions. For instance, whether a person feels competent enough to participate in a political discussion is a significant factor in deciding whether they choose to engage in political discussions at all (Conover, Searing, and Crewe 2002). Conover, Searing and Crewe suggest that people who are unsure of their political competence might "worry that they will be unsuccessful - inarticulate, uniformed, unpersuasive and, in the worst case, simply unheard - in political discussions.” Anticipating the embarrassment of failure, such people avoid participating in discussions altogether (Conover, Searing, and Crewe 2002, 47). People may also choose not to participate in political conversations because they do not want to reveal where they stand on an issue for reasons of privacy, they may anticipate that their opinion will be unpopular, or they simply do not have any opinions to share (Conover, Searing, and Crewe 2002). 
The literature which looks into the etiquette of political talk in offline conversations and contexts typically examines the rules which are found in well-defined groups. For instance, examining the way in which a group of concerned parents talk about political issues (Eliasoph 1998). When doing similar research online, and in particular when looking at social media platforms, it becomes much more difficult to talk about welldefined groups, because the make-up of the people you are interacting with are uncertain and could vary considerably from one day to the next. Hence researching political talk on social media presents interesting challenges.

Finally, given that this research is being conducted in New Zealand, are there any reasons to believe that it has particular characteristics which set it apart? As explored in the introduction, it is possible that the New Zealand social context will produce quite different results to established findings overseas. Anecdotally, New Zealand's political culture seems relatively uneasy regarding political talk. Given that New Zealand shares a cultural and political history with Britain, New Zealanders may have inherited Britain's 'elitist', less deliberative political culture as opposed to the United States' 'populist', more deliberative culture (Conover, Searing, and Crewe 2002, 25). Unfortunately, no research has been done which explores the attitude of New Zealanders regarding talking about politics in everyday conversation, so the attitudes of of New Zealanders necessarily remain conjecture.

\subsubsection{The social norms of political talk on social media}

As described in the previous section, it has been established in the offline world that the social context in which (political) talk occurs determines to a large extent the nature of that talk. Only a few studies have considered the social norms of political talk on social media.

The social norms of political talk become more complicated and ambiguous in the context of social media platforms compared to offline talk. Thorson $(2014,204)$ suggests that social networking sites

increase the uncertainties and risks associated with political talk by increasing the ambiguity of the social setting, both in terms of the potential audience and the context within which a political message will be received ...

She stresses that although this normative difficulty of political talk is amplified online, the ambiguity does not necessarily inhibit behaviour, and could actually encourage 
people to experiment with new forms of political expression. McLauhglin and Vitak (2012) similarly find that although there are certainly social norms in operation on social networking sites, they are not always clear or unambiguous to users, partly as a result of the fast-moving development of the sites. As social networks change in the process of ongoing site development, the norms of acceptable behaviour and affordances will likely change as well, creating uncertainty for users (Thorson 2014).

A relatively small number of studies have investigated the social acceptability of political behaviour on Facebook. For example, examining Facebook in the lead up to the 2008 United States presidential election, Vitak et al (2011) found that participants were moderately accepting of candidates being present and campaigning on Facebook and of people expressing political beliefs on Facebook. However, participants disapproved of Facebook being used as a tool of political persuasion, or to encourage people to vote generally or for a specific candidate. They further found that those who view Facebook as an acceptable place for politics are more likely to participate in politics on Facebook.

More generally, Van Wyngarden (2012) found in her small qualitative study of 20 young (aged 18-24) Facebook users, that although Facebook users might not like or agree with some political posts on Facebook, they nevertheless respected the right of their Facebook friends to post political content. She suggests this belief in the acceptability of political topics might flow from the fact that young people are generally comfortable with extensive sharing (of certain types) in online spaces, and also from a perception that Facebook is a venue for free speech. Furthermore, she found that it was generally acceptable to express beliefs, provide political info or raise awareness, to start a discussion, or to organise and raise money, but generally it was not considered acceptable to release strong emotion or to deliberately start political arguments (Van Wyngarden 2012).

The acceptability of various tones and approaches when it came to talking about politics on Facebook was relatively consistent among different people (Thorson, Vraga, and Kligler-Vilenchik 2014). What varied considerably, however, was the frequency with which people actually engaged in posting or discussing politics on Facebook, as those who post frequently about politics come into contact with those who do not post about politics at all on social media (Thorson 2014).

My previous research (Chapman and Coffé 2015) examined people changing their 
Facebook profile pictures as part of (political) campaigns. A number of participants were wary of being perceived negatively by changing their picture and being written off as a 'hack' by their friends on Facebook. Others mentioned they were wary of their employers, or potential employers, seeing their political activity and viewing it negatively. Some people simply viewed Facebook as an inappropriate forum in which to engage in political talk as it inevitably spiralled into vitriol as well as unproductive and heated backwards and forwards. As part of the research a small experiment was conducted in the survey, which established that people were more likely to change their profile pictures to support the campaign of a community group rather than a political party. This finding suggests that people are reticent about overtly partisan politics.

\section{a) Strategies for increasing the acceptability of political talk}

A variety of strategies which people use to increase the palatability of political talk on social media have been identified. For example, people sometimes present political content in a humorous way (Thorson 2014; Thorson, Vraga, and Kligler-Vilenchik 2014). Thorson (2014) found that of many young-adult participants engaged in selfcensorship as they shied away from controversial topics, and made an effort to appear neutral and avoid the perception of being 'one-sided' when it came to political content. Thorson, Vraga, and Kligler-Vilenchik $(2014,79)$ found that their participants generally thought that “political talk should either be avoided, or be kept tolerant to other's views, up to the point of neutrality.” This strategy can be understood as reflecting a desire to avoid being seen to persuade people or 'push' their ideas onto other people, hoping to avoid becoming the person in their friend group on Facebook who talks about politics in a controversial way.

One way in which people try to avoid conflict is to simply avoid posting - or engaging with - anything political on social media. Diesing (2013) found that some of her participants were wary of posting their political views to Facebook because they were wary of alienating friends and family who did not share their views. She also found that her participants, both young and older, preferred to discuss politics in person, because it could get more in-depth and allowed people to explain their views properly, and was also less prone to name calling. But the preference for offline talk could also be explained by a dislike of the alternative - participants in her study found that in online discussions it was easy to offend others with remarks, people took less care with their comments, and political discussions could get out of hand. 


\section{b) Differences between groups}

While the research into the social acceptability of political content on social media examined above suggests that politics is an area of normative ambiguity for Facebook users generally, a more nuanced approach is to examine the social acceptability of politics for sub-groups of users.

For example, Gustafsson (2012) explores in more depth the social acceptability of political content on Facebook by conducting focus groups whose membership is differentiated according to participants' engagement in political life, such that there were three groups: political party members, interest-organisation members, and the nonorganised. His use of homogeneous focus groups allows him to explore whether there is a marked difference of opinion between political party members and others regarding the appropriateness of political talk on Facebook. He finds that party members were comfortable with political talk on the site, but others were made uncomfortable by the intrusion of politics and 'serious matters' into a social realm.

\section{c) Differences between individuals}

In more recent times, scholars have started to attempt to unravel why it is that some individuals are more willing to engage in politics on social media than others. In other words, why do some people post a significant amount of political content on Facebook while others avoid posting political content altogether (Thorson 2014)? This question about why individuals are different when it comes to considering the acceptability of politics on Facebook has been answered in part by her later work, which suggests that factors such as an individual's political interest and desire to avoid conflict are important factors (Vraga et al. 2015).

Another possible explanation for differences of opinion regarding political content on social media is the degree to which people are concerned with the acceptability of their self-presentation. Litt et al. (2014) distinguish between high self-monitors, who attempt to consistently act in a way which is socially sanctioned, and low self-monitors, who generally are more motivated by “internal thoughts and values”. It could be that people who post a significant amount of political material to social networking sites are low self-monitors and care more about the political issues than the social norms which they might violate by posting such content. Research into “self-censorship” online could provide a useful framework for exploring political inaction (see Das and Kramer 2013; 
Sleeper et al. 2013).

Importantly, it is very difficult to conceptualise or measure the social norms of a social media platform as a whole amongst young people, as the 'group' being analysed will differ depending on each person’s social network (Thorson 2014). Nonetheless, research which has been done on the social norms of political social media use (e.g. Gustafsson 2012; Thorson, Vraga, and Kligler-Vilenchik 2014; Van Wyngarden 2012) has produced relatively consistent results.

One way we can hope to understand the role of social expectations in online political behaviour is to look in more depth at ways in which people think about how content they are thinking of posting is likely to be received by other users of social media. The concept of the 'imagined audience' is one such way of thinking about this process.

\section{d) The imagined audience}

The 'imagined audience' is a useful way of conceptualising the complicated relationship between users of social networking platforms, and the way in which social expectations shape behaviour. Since social networking sites lack the normal social cues from people physically around them, users are forced to rely on their imagination to predict how content will be received. Imagining one's audience is a challenging prospect because of the sheer diversity of different groups who can potentially see one's content on social media; if friends, family and workmates can all see what you post, to whom do you tailor your message (Litt 2012)?

The process becomes more complicated again when it involves one person posting on another person's Facebook page: in that situation the third party creating the content must imagine the possible audience based on not just their mutual friends, but also all the other people which the target knows (Litt et al. 2014). Information which is normative in one context - and hence perfectly harmless - may be transformed in another context in someone else's social circles into a 'face threat'. What determines the perceived severity of face threats is not the size of the audience, but its diversity (Litt et al. 2014).

Thorson (2014) notes that social networking sites such as Facebook create an 'egocentric public': because everyone on the site most likely has unique configurations of friends, the content they are exposed to over time will differ substantially from person to person. Hence although some aspects of imagined audiences are likely to be 
shared, each person is likely to have their own conception of who is looking at their posts on social networking sites.

Perhaps unsurprisingly, given the complexity of the distribution of content on social media platforms, there is evidence that users of social networking sites are not accurately imagining their audiences. Facebook users' imagined audiences often do not correspond to actual audiences as people tend to wrongly view only those people with whom they regularly interact on the platform as their audience (Strater and Lipford 2008). Litt (2012) emphasises the power of imagined audiences to shape our interactions, and also notes that the consequences of a mismatch between imagined and real audiences can be quite significant. We should, therefore, try to understand the processes involved.

Despite these difficulties, there is evidence to suggest that for most topics of conversation on Facebook, users are comfortable with managing their imagined audiences (Thorson 2014). However when it came to politics on Facebook, and managing the audience of political content, many users felt uncomfortable. Thorson hence argues that the "“publicness' of Facebook is contextual, and politics is a topic that makes the public character of the site salient.” (Thorson 2014, 210)

By exploring both Facebook and Twitter, my research will be able to investigate the extent to which the respective features of the platforms shape the process of imagining one's audience when considering political postings. Therefore, my research is focussed on political conversations which occur in public spaces on Facebook and Twitter. For instance, I am interested in a Facebook or Twitter user posting a link to a piece of political news to all their friends or followers, but I am not interested in the conduct of private Facebook groups, or political discussions which occur over Facebook private messages, where the audience is much clearer.

\section{e) Differences between social media platforms}

It is important to keep in mind that the social acceptability of political behaviour can differ substantially between different social media sites. Thorson’s (2014) research usefully focusses on the practices of 'social media curators' rather than the characteristics and impact of a specific platform. Her research examines the practice of political talk across both Twitter and Facebook, and she notes that among the people she interviewed, it was generally believed that politics is more acceptable on Twitter as 
opposed to Facebook, as the former is more interest driven.

Moreover, Thorson (2014) suggests that the way the algorithms of Facebook's news feed operate, it is possible for the worst instances of political discussions to bubble to the surface and be visible to many people - a feature of the social network which might make political content relatively less acceptable.

Whereas early internet communities were drawn together by common interests (Burnett and Bonnici 2003), sites like Facebook create more complicated social dynamics because there is a cultural expectation that people accept practically anyone's friend request if they know them. In this respect, Twitter is much more like these early sites than Facebook is.

\section{f) The impact of social media's asynchronicity}

Evidently there are some significant differences between political talk on social media compared with political talk offline. Significantly, the asynchronous nature of social media means that potentially uncomfortable topics like politics are arguably less confronting online compared with offline, and therefore people will have less inhibitions about posting or engaging.

In the offline world, political talk is necessarily between two or more people, and if someone says something confronting, one may feel obligated to respond, and there is the potential for awkwardness. The "continuous feedback loop” of real-world conversation usually has the effect of steering conversation in the direction of conforming to social norms (Suler 2004, 323). In contrast, the asynchronous nature of social media frees people from the "tyranny of the face-to-face encounter", as they are free to respond in their own time to messages rather than having to respond immediately (Hooper and Kalidas 2012, 266). The absence of real-world social cues in online contexts leads to disinhibition (Suler 2004) and therefore means people are more likely to talk about topics which could be otherwise difficult.

However because politics on social media is - at least initially - a one-way broadcast of opinion, people can say relatively controversial things and people can then just choose to ignore it if they want.

The effects of asynchronicity have also been debated in existing literature. Previous studies have suggested that asychronicity can be beneficial in providing valuable time for reflection and response, but also that it can be damaging that to the formation of 
bonds and hinder understanding (Freelon 2010).

\subsection{Research questions}

The main research question motivating my study is to understand the social norms and expectations of talking about politics on social media. Overall a number of research questions will be addressed, the main research question being:

To what extent is talking about politics on Facebook and Twitter socially acceptable among young New Zealanders?

As part of that question, a number of sub-questions will be addressed.

1: What are young New Zealanders' experiences of politics on social media?

2: What do young New Zealanders perceive as the social norms of politics on social media?

3: How do the social norms of politics on social media come to be understood by young New Zealanders?

\subsection{Conclusion}

Although the literature which examines the social norms of political behaviour on social networking sites suggests that some forms of political expression - such as active persuasion - are less acceptable than simply expressing opinions, overall the literature emphasises the lack of clear social guidelines for users contemplating engaging in politics on social media. It has also been found that in the context of this normative ambiguity regarding discussing politics on social media, people find novel ways of presenting content such that it will be more acceptable to others, such as using humour.

However there still remain significant gaps in the literature, and important questions remain understudied or unanswered: How do young people understand the process by which social norms come to be understood, and do they actively engage in that process? How are the social norms of political discussion complicated by the immeasurable number of different configurations of friends and followers - which have been termed 'egocentric publics' - on social media? Are the findings of overseas studies applicable to the New Zealand context?

Applying social norms theory to the topic, my study will explore both people's observations of what the prevalent behaviours are on social media when it comes to 
politics, as well as what they understand to be normatively acceptable behaviour. Because there are no formal rules for whether people should talk about politics, or talk in a certain way, on social media, the norms at play are also implicit.

By examining both Facebook and Twitter, this research will also expand the limited research, and help us understand whether there are different expectations and social norms regarding political discussions on Facebook as opposed to Twitter, and whether young people are choosing to utilise different sites for different political purposes.

In exploring the part social norms play in influencing political behaviour on social networking sites, this research could potentially help to explain why some young New Zealanders choose to participate politically online while others do not. If it turns out that social expectations are a significant barrier to participation for some people because they are afraid of breaching prevailing social norms, then we can start to understand the social barriers that exist and which prevent young people engaging in politics online. 


\section{Chapter 3: Methodology, method and analysis}

My research has utilised synchronous online focus groups in order to explore the social norms of politics on social media. In this chapter I will firstly analyse the methodology of focus groups. Secondly, I will explore the method of the research project. Thirdly, I will address my analytical strategy, before ending with some information about my research participants.

\subsection{Focus groups}

In this section, I will introduce focus groups as a methodology. I will also assess the appropriateness of offline and online groups, as well as synchronous and asynchronous groups, for my research.

\subsubsection{Introduction to focus groups}

In contrast to other research methods which collect data independently from a number of individuals, focus groups concentrate on group discussion as a data source (Morgan 1996). Focus groups encourage participants to bounce ideas off one another and draw effectively on personal experiences (Burnham et al. 2004). They allow participants to shape the data gathering process to a greater extent compared with other research designs (Burnham et al. 2004). Participants can express their opinions in their own terms while engaging in conversation with others in the group. Hence the group can create its own dialogue rather than simply responding to the researcher (O'Toole et al. 2003). Evidently there will be differences between focus groups depending on the degree of structure, and how quickly the moderator moves the group on from discussions.

The influence of the group context can also be seen as a useful data source. Instead of focus groups simply providing a more efficient method than conducting many interviews, Lunt and Livingston $(1996,85)$ argue that: "the group context may itself be significant to the theoretical framework of the research.” O'Toole et al. $(2003,56)$ similarly argue that group discussions: “more closely reflect the dynamic nature of political participation because they reflect the fact that political beliefs and attitudes are formed and determined in a social context.” While views articulated by participants in 
group contexts will probably differ from those that would have been expressed in an individual interview or in other groups, group interviews allow researchers to "see the ways in which views may be susceptible to cultural or social variables” (O’Toole et al. 2003, 56).

Another advantage of focus groups is that they allow participants to listen to each other, and in turn reflect on their own experiences. Hence this method can help encourage participants to talk about 'non-activity', which is normally very difficult to study (O’Toole et al. 2003). A similar argument is advanced by Gustaffson (2012, 1115), who notes that since politics on social media is a relatively new phenomenon, focus groups are an appropriate methodology because participants interacting in a group can: "react to each other's stories and compare their own experiences". While the more widespread nature of politics on social media in 2015 is such that participants will likely be more familiar with it, the underlying point that a group setting allows participants to be prompted by - and respond to - other people's experiences still stands.

Group interviews also help to reduce possible power imbalances between the participants and the researcher(s), a problem which is particularly relevant when the participants are young people and there may be a significant age difference relative to the researcher (O'Toole et al., 2003).

While focus groups have a number of advantages, the research method also involves a number of potential drawbacks. Focus groups have been criticised because they force participants to report near-instantaneously their opinions and experiences to researchers (Awan and Gauntlett 2013). In addition, the active role the researcher plays in guiding the discussions is often not made explicit, and researchers tend to present findings "as if no choices had been made beyond that of using focus groups in the first place.” (Lunt and Livingstone 1996, 80) In reality, the researcher has necessarily made many decisions about the design of the focus groups, including the physical (or virtual) space where the group will meet, the make-up of the group, how to initiate the discussion, and whether to allow some participants to dominate the conversation (Lunt and Livingstone 1996).

The consequence of participants shaping the process, and the fact that different participants are present in each group, is that it can be difficult to know what the impact of the group context is, potentially muddying results (O’Toole et al. 2003). It is also important to keep in mind that asking people to talk about their experiences can itself be 
complicated by social dynamics. For instance, people's reported recollections of how they went about imagining their audiences on social media might differ substantially from how they really went about posting, due possibly to faulty memories or social desirability bias (Litt 2012).

At a more fundamental level, focus groups have also been criticised on the basis that they do not provide generalisable results due to small samples and issues with reliability (Lunt and Livingstone 1996). These positivist criticisms have been responded to in a number of ways. A strong response is that, in privileging the individual in survey methodologies, researchers overlook the fact that there are many different perspectives on meaning, and that meaning is ultimately context dependent (Lunt and Livingstone 1996). Ultimately, we must keep in mind that “different contexts generate different kinds of data with different meanings”, so we should not dismiss focus groups (Lunt and Livingstone 1996, 91).

While focus groups have traditionally been made up of diverse participants - in terms of sex, social status, and ethnicity for example - conducting studies with homogeneous focus groups has become more commonplace (Lunt and Livingstone 1996). For example, Gustafsson's (2012) model whereby he conducted three focus groups with political party members, interest group members, and non-members respectively allows for useful comparisons between politically active and non-active people. Nevertheless, Lunt and Livingstone (Lunt and Livingstone 1996, 92) argue that heterogeneous focus groups can be more appropriate when the researcher is attempting to "simulate a general public debate within which one expects strong disagreements to exist”, and aid in the generalizability of results. Given that I am interested in differences between people who engage with politics on social media frequently and those who do not, heterogeneous focus groups are more appropriate.

In sum, the use of focus groups enables the exploration, in relatively significant depth, of young people's thoughts and feelings. Using focus groups is an approach which makes sense if the phenomenon one is studying is by nature a social or groupbased one, because it allows researchers in some senses to recreate the social dynamics they are interested in. Focus groups can also provide justification for - or the reasoning behind - inaction, which will be particularly helpful when it comes to exploring why people choose not to engage with politics on social media platforms. Having explored the benefits and drawbacks of focus groups in general, I will now move to analysing the 
differences between offline versus online focus groups, in the process determining which is more appropriate in this case.

\subsubsection{Offline versus online focus groups}

Online focus groups became increasingly popular as a qualitative method in the late 1990s. In conducting online focus groups, researchers initially utilised asynchronous methods such as email discussions, but as time went on real-time online focus groups also became popular (Hooley, Marriott, and Wellens 2011).

Online focus groups evidently have a number of practical advantages: they allow the researcher to recruit individuals from a much more diverse geographical area, and do not require participants to physically travel to the researcher. Online focus groups also allow participants to engage with the research from a comfortable location rather than engaging with the research in an unfamiliar environment. An additional major advantage of running the focus groups online from the researcher's perspective is that they provide ready-made transcripts of the discussions (Hooley, Marriott, and Wellens 2011). It has also been argued that online focus groups might allow participants to frankly discuss topics which they may be uncomfortable talking about offline (Hooley, Marriott, and Wellens 2011). In addition, people are more likely to criticise others and disagree with online focus groups compared with face-to-face focus groups (Liamputtong 2011).

A significant difference between offline and online focus groups is evidently the nature of the interaction itself. When conducting a focus group online, the participants never physically meet each other, and are essentially anonymous. An online focus group is somewhat akin to participants in a face-to-face focus group wearing blindfolds. Hooley et al $(2011,57)$ note that this loss of "most visual and contextual communication and clues" is "perhaps the most challenging of all” the drawbacks of using online focus groups. Related to this lack of cues, another potential negative aspect of online focus groups is that they are less spontaneous in generating interaction between participants. For instance, Gustafsson $(2012,1116)$ established that while the results of asynchronous focus groups were "generally longer and more eloquent”, the offline focus groups produced much more intense “dynamic interaction” between his participants.

While researchers using online focus groups lose the ability to pick up on real life social cues and body language, they gain the ability for people to offer a considered 
response, and put guards against people dominating the discussion because people do not have to wait for others to stop talking before they contribute (Liamputtong 2011). Differences in writing and typing ability, however, may present new challenges to equal participation (Hooley, Marriott, and Wellens 2011).

One of the problems with online focus groups is that the researcher is not guaranteed to have the full attention of participants during the discussion (Hooley, Marriott, and Wellens 2011). Whereas in offline focus groups the environment of discussions can be controlled, for online focus groups the researcher has no guarantee that participants are even looking at the focus group when questions are asked.

Within the debate about the appropriateness of online focus groups, there is also contention surrounding the choice of synchronous versus asynchronous focus groups. Using a real-time online focus group evidently matches more closely the traditional face-to-face focus group model, with the opportunity for participants to interact rapidly, and has been used successfully with groups who are technologically literate (Hooley, Marriott, and Wellens 2011). Synchronous online focus groups, however, run the risk of creating ambiguity as participants potentially submit answers all at the same time and the thread of conversation can be lost. On the other hand, asynchronous online focus groups have been used when it is difficult to coordinate busy people, but can be problematic for researchers trying to maintain the direction of the group interviews over a period of time (Hooley, Marriott, and Wellens 2011). I investigated the possibility of asynchronous online focus groups, but ultimately decided that synchronous focus groups would be more dynamic and allow greater engagement between participants.

\subsubsection{Choosing the right focus group method}

When considering a particular method such as online focus groups, an important consideration is the likely technological capabilities of the participants. Synchronous focus groups using chat rooms are appropriate for this research because most young people are technologically adept and familiar with using instant messaging online. As Hooley, Marriott and Wellens (2011) note, online interviews are "clearly better suited to populations who are digitally literate” and have experience using the online environment utilised in the research. A further reason why online focus groups are appropriate is that this research is focussing on the discussion of politics online, hence an online methodology is fitting. As Hooley, Marriott and Wellens $(2011,14)$ argue: 
"Online research methods are most obviously useful when the phenomenon that is being investigated is strongly connected to the internet.”

Online, synchronous focus groups are simple, time-effective, and allow the recruitment of participants from diverse locations. Given these advantages, I chose to use online synchronous focus groups for my research. Having explored the evidence for this method, I will now detail the method I have employed.

\subsection{Description of method}

The data collection for this research was through online, synchronous focus groups, conducted in September and October 2014. In this section I will detail the preliminary stages of my research, the operation of the focus groups, and finally the post-focus group stage of the research.

\subsubsection{Preliminary stages}

The first step in the research process involved getting ethics approval for the research from the Victoria University of Wellington Human Ethics Committee, which was received in July 2014. ${ }^{5}$ After a funding application to the university, funding for vouchers for participants was approved in August 2014.

Once the funding was approved, the recruitment of participants could begin. Participants were recruited with flyers and posters around Victoria University of Wellington, a number of social media posts on the researcher's Facebook, Twitter, and Tumblr accounts, and lecturers sending out announcements on the learning management system Blackboard to classes with information about the research.

The first stage of involvement for participants was for them to fill out an online survey. The survey asked them for various background and demographic information, and also enabled participants to formally consent to participation in the research. The survey also served as a screening process to ensure that all the participants fit the criteria for the research project, that is, they were aged 16 to 24, living in New Zealand, and had both Facebook and Twitter accounts.

Once I determined that participants fit the research criteria, they were sent them an email asking them to participate in the next stage of the research. The response rate to

5 Ethics approval 21156, approved 16 July 2014 
these emails was relatively high (74.4\%), although multiple reminders were sometimes required. A sufficient number of respondents were however willing to participate (84.4\%, $N=27$ ), enabling me to progressively run the focus groups. ${ }^{6}$ Once participants responded to my email inquiry and agreed to participate, I asked for their Facebook profile address, and added them with a specially created research Facebook account, and messaged them on Facebook chat with a date and time for the focus group. I chose this way of corresponding with people as I anticipated that young people were more likely to check and respond to FB messages as opposed to emails. Participants generally responded to Facebook messages relatively promptly.

The focus groups were arranged in such a way that there was the best possible mix of male and female participants, a range of ages, a mix of students and non-students, and a variety in the extent to which participants posted or engaged with politics on social media. The focus groups were organised to be heterogeneous because at the outset I was interested in the social interactions between different groups of people: particularly between those who were very active in talking about politics on social media and those who were less active. I was interested in whether those who are active in posting and engaging with politics on Facebook and Twitter have different views on what is acceptable to those who do not engage, or whether the two groups shared views about the acceptability of politics, and one group is choosing to disregard them. In other words, the heterogeneous focus group design allowed me to explore the extent to which perceptions of social norms were associated with differences in behaviour.

After doing research to determine the best software solution for running the online focus groups, I chose to set up an Internet Relay Chat (IRC) room. The advantage of using an IRC room was that I could direct participants to the website I had set up, and then they could simply type in a username and start chatting. The other solutions I looked into all seemed to require registering for an account. I considered using Facebook chat for the focus group component, but decided that the environment would be too prone to distractions. ${ }^{7}$

The focus groups were run on a simple Google sites page which I set up, with an embedded Kiwi IRC room, pre-configured to go to a chat channel which was for the

6 Overall, 11 people did not respond to my emails, 11 were excluded because I knew them or they did not meet criteria, five did not want to participate past the survey, and there were 27 participants in the focus groups. 
research. ${ }^{8}$

\subsubsection{Operation of the focus groups}

I chose a semi-structured approach for the focus groups. They were run according to an outline I had prepared, and which provided a number of primary and more discretionary questions (see Appendix Four for the outline). Inevitably, running the focus groups was a process of incremental improvement: sometimes adding questions, removing them, or switching around their order.

The focus groups were held in the weeks surrounding the 2014 New Zealand general election on 20 September, from 7 September to 19 October. Conducting research in the run-up to an election campaign is relatively common (e.g. Thorson, Vraga, and KliglerVilenchik 2014; Diesing 2013), and helps to ensure that politics is more visible than normal.

I ran six focus groups with a total of 27 participants, ranging between three and six participants per focus group. As is common when organising (online) focus groups, I encountered some problems with people not turning up for their arranged focus group (Fox, Morris, and Rumsey 2007). I aimed for group sizes of about four to five people, however non-attendance sometimes resulted in some groups being substantially smaller than others, with one group as small as three participants. While a group of four to five is substantially smaller than a typical offline focus group, I found that generally the smaller groups worked better. With larger groups, it was sometimes difficult to keep track of the thread of conversations, whereas smaller groups enabled participants to respond in more depth to each other's points. This is consistent with findings that online focus groups with more than five participants can stretch the capabilities of a single moderator (Fox, Morris, and Rumsey 2007).

At the outset of the focus groups I did not get the participants to introduce themselves, which in some ways simulates political discussion online. I introduced the topic and outlined some expectations around participants' behaviour and courteousness

7 In my experience, when young people chat on Facebook they are often at the same time browsing Facebook or other parts of the web. While it is also possible to do other tasks while chatting on IRC, the chat room has the advantage of taking up the whole window - in contrast to the small Facebook chat window - and therefore there are less immediate distractions.

8 While in theory this chat room was publicly accessible, due to the nature of IRC, I did not have any problems with non-participants joining the chat room. 
towards each other. I also briefly addressed what I meant by 'politics', suggesting I was interested in whatever the participants considered to be political. To get participants thinking, I gave them examples of political activity on social media such as posting a link to a political news article or expressing an opinion about a political event. I put forward an open definition of politics in the focus groups because I did not want a rigid definition to overshadow what participants conceived as political.

Overall the focus groups were relatively successful. ${ }^{9}$ In some sessions, there was a little less responding and engaging with each other than would have been ideal, but other groups were much more likely to respond to each other. At various points, a small number of participants mentioned that they were engaged in other online activities such as checking emails. This may have contributed to some of the relatively long pauses that I experienced in the process of running the focus groups.

At the end of each focus group, I asked participants about their experiences of taking part in the focus groups, and how they found the fact they were conducted online. The participants mostly reported that they liked the focus groups being conducted online. The most commonly identified benefit was being able to participate in the focus groups remotely. For example Oliver (23) ${ }^{10}$ said it was more convenient having the focus group online "as we can do it from home/don't have to travel anywhere”. A small number of participants also noted that they thought they were better at expressing themselves through typing rather than talking, with Ella (18) commenting that: "I can type a lot better than I can talk”.

Participants liked that there was not an immediate pressure to respond in the online focus groups, which allowed them to think through their ideas better. Hannah (19) commented that the online focus group "does allow us to share our opinions in our own time without being interrupted.” Others noted that pauses in the conversation were not as awkward or confronting as they would have been if they were meeting offline. Lucy (18) argued that: "Digital awkward silences are much more manageable".

9 The only problem which I encountered with the chat room itself was that it did not have a typing indicator, so it was not possible to tell when the participants were typing. This meant that in periods where no answers were forthcoming, it was somewhat difficult to tell whether the participants did not have anything to say, or whether they were typing out a long or complex thought. While this lack of a typing indicator may have been somewhat frustrating - for everyone involved - it meant that the focus group kept up momentum in a way which probably would not have been possible if I had waited for everyone to finish every thought.

10 Names have been changed 
A number of participants commented that the anonymity of the online focus groups meant they felt freer to participate, and less awkward about the whole process. Molly (18) commented that it was "easier to be more open" and "less awkward" to talk online. Similarly Kate (23) noted that the online focus groups were: "Way less threatening and nervous-making for sure”. Zoe (22) likewise thought online discussions were: “Good for shyer people”. Finally, Liam (22) thought it was easier to talk online "because people can voice their true opinion anonymously”.

However, participants were not uniformly positive about the method, with some participants raising doubts about the effectiveness of online focus groups and expressing a preference for face-to-face discussions. For instance, Holly (18) noted: "I usually like to know who I'm talking to". Kate (23) similarly suggested that: "It can be hard when you can't see body language cues that someone wants to talk like if you are all typing away”. Some participants thought there would have been more interaction and responding to each other if the focus group had been run offline. For example, Laura (22) noted that while "it's more convenient" online, "face to face you probably get more dialogue”. Freya (21) said she did not think there were any real differences between online and offline focus groups, "but it would more likely go on longer if we were face to face as people would more likely bounce of one another's thoughts more”. These reservations are broadly consistent with methodological debates regarding the use of online focus groups, and are relatively minor compared to the benefits of using this method.

\subsubsection{Post-focus group}

Once participants finished participating in the focus groups, they were contacted through Facebook chat to organise delivery or pick up of the NZ\$20 voucher they were entitled to. They were also invited to participate further in the research through the optional Facebook group.

As part of the research, I set up a Facebook group which allowed participants to communicate with each other after the focus groups had finished, as they came across interesting and relevant posts or tweets in the process of using Facebook and Twitter. The intention was that the Facebook group might allow the participants to express themselves in a less structured way than in the focus groups. Although many participants were willing to join the group, it was very difficult to motivate people to 
actually engage with it. As such, this component of the research will only be referenced in passing.

\subsection{Analysis}

I used qualitative data analysis software RQDA, which is a package for the open source statistical package R (Huang 2014).

Because the questions in the focus groups reflected the themes of surveyed literature, by coding the results of the focus groups mainly according to the questions asked, I coded the results according to the dominant, recurrent themes, as well as noting themes that were less often referred to.

To aid in the presentation of the results in appendices, engagement levels for participants were calculated based on how often they said engaged with, or posted about, politics on Facebook and Twitter. Participants in the "many times a day”, "once or so every day”, and “most days” categories were assigned 'high', those who were in the "occasionally" category were assigned 'mid', and those who were in the "very rarely/never” category were assigned 'low'.

\subsection{Description of participants}

Overall, 27 young people participated in the focus groups.

There was a relatively even distribution of participants across the age range (16-24), with slightly more clustered between 18 to 23. Amongst the participants, 11 (41\%) were aged under 20 and 16 (59\%) were 20 or over. The overwhelming majority were New Zealand European/Pākehā (23; 87\%), with one Fijian-Indian, one Asian, one Pākehā-Māori, and one Pacific Islander. In terms of geographical distribution, participants were mostly from Wellington (19; 70\%), with three (11\%) from Auckland and the rest from Marlborough, Canterbury, Dunedin and the Manawatu. ${ }^{11}$

Participants generally did not use Twitter as frequently as they used Facebook. Most participants (23; 85\%) used Facebook many times a day, one (4\%) used it once or so every day, and three (11\%) used it most days. In contrast, 12 (44\%) participants used Twitter many times a day, two (7\%) used it everyday, four (15\%) most days, six (22\%)

11 All the participants were resident in New Zealand, and all were New Zealand citizens except one Australian. I use the term "New Zealanders" to refer to all my participants. 
occasionally, and three (11\%) used Twitter very rarely or never.

Participants differed in the extent to which they were interested in, and knowledgeable about, politics. Seven were very interested in politics, nine quite interested, nine somewhat interested, and two were not at all interested. Generally the younger participants - those aged 16 to 19 - were less politically engaged.

Participants also differed in the extent to which they engaged with, and posted about, politics on Facebook and Twitter. On Facebook, no participants engaged or posted many times a day, one (4\%) engaged once or so every day, seven (27\%) most days, nine (33\%) occasionally and ten (37\%) very rarely or never. The pattern was somewhat different on Twitter, with three participants (11\%) engaging or posting many times a day, none once or so every day, three (11\%) most days, five (19\%) occasionally, and 16 $(60 \%)$ vary rarely or never.

Now that I have explored focus groups as a methodology, described the method of this research, and introduced some descriptive data about participants, I will now turn to the results section. 


\section{Chapter 4: Results}

The first section will explore how participants reported behaving in relation to politics on social media, including their own posts, as well as their experiences of other people's political content on the platforms. The second section will then explore participants' perceptions of how people should behave when it comes to politics on Facebook and Twitter. This section will also include an exploration of how people behave when they come into contact with political content they disagree with, and the circumstances in which people complain about that disagreeable content. The third section will explore how people come to understand the social norms of political talk on social media.

Where participants are quoted, they are identified by a pseudonym and their age is given in brackets. A number of corrections and minor changes have been made to quotations from the focus groups. ${ }^{12}$

\subsection{Experiences with political content on Facebook and Twitter}

This section will explore the results in relation to the first research question regarding young New Zealanders' experiences of politics on social media.

\subsubsection{Recent experiences of politics}

There were a mix of experiences when it came to participants' experiences of politics in their social media feeds, with some participants saying they did not see much politics in their Facebook news feeds, while others reported seeing a lot and being "inundated with posts”. Generally, those participants who actively used Twitter saw more political content on Twitter as opposed to Facebook.

Participants noticed a substantial number of jokes and negative comments about John Key and the National Party. Jane (16) said she thought: "People who post things on Facebook about how much they hate John Key without any supporting explanation is pretty stupid”. Leo (21) agreed, noting that much of what he saw on Facebook was: “Oh look, John Key's such a (Insert slur of choice here).”

12 Obvious spelling errors have been corrected, as well as the capitalisation of words such as "I", "I'll”, and "Facebook”. Explanatory notes have been inserted in square brackets where abbreviations or content may be unfamiliar to readers. 
Before the September 2014 general election, participants also noticed a number of comments about voting out the current National Government. For example, Oliver (23) said: "A lot of what I have seen appears to be more about voting out the government, rather than reasons you should vote for X party instead”. After the election, participants noticed people bemoaned the National Party's election win.

Participants saw discussion of various parties and their policies, as well as significant amounts of material from youth wings of political parties on Facebook and Twitter. Some participants saw political debates during the election being live-tweeted. There was some discussion of the Dirty Politics controversy and the resignation of Justice Minister Judith Collins. Maggie (20) and Isaac (24) noticed that their friends' language-style changed around the election, becoming more formal compared with their normal style.

Participants noted a significant amount of political material related to encouraging people to vote. Brooke (23) said the encouragement of voting "was promising to see. University students deserve to have their voices heard, so was chuffed that so many of them got involved this time round”. During the election period, participants noticed a number of people posting their completed ballot papers and also encouraging their friends to vote for certain political parties. After the election they also noticed people highlighting the number of non-voters in the election in an attempt to highlight the costs of non-participation.

In terms of the types of people who posted politics online, Jane (16) noted that it was generally her older friends (18 or older) on social media who posted about politics. Jade (18) said she noticed that it was generally her friends from bigger cities who engaged in politics online; only a handful of people from her high school were interested in politics. Finally, Zoe (22) noted that it was generally people from university or people she had met online who talked about politics, not friends from earlier in her life.

\subsubsection{Experiences of posting about politics}

There were marked differences in whether participants in the different focus groups posted about politics on Facebook or Twitter. Some participants had never posted about politics on either platform, while others frequently posted on one or both about politics.

A substantial number of participants engaged in - and posted about - politics in the 
run up to the New Zealand general election. Some participants shared "lots of election related things" on Facebook and Twitter. Liam (22) posted about how "Labour was incompetent” on election night. Some participants posted encouraging people to vote, and later shared the impact of non-voting with a graph. Some participants live-tweeted election-related events, attempted to give balance to discussions, and tried to correct bias. A small number of participants also re-tweeted screenshots of strange behaviour by politicians on social media.

Other non-election related material that participants posted or shared included social issue petitions, and news items about social issues - which were by extension political such as gay and lesbian, abortion, and sexual violence issues.

\subsection{The social norms of talking about politics}

This section will start to explore the second research question, which addresses what young New Zealanders perceive as the social norms of politics on social media.

Although participants held some reservations about the way social media affected the quality of political discussions, participants were almost unanimous in approving of politics on social media generally. As Jack (23) argued: "If it's a platform for people to talk etc, it's a place for politics”. A number of participants pointed to political content potentially providing a way for people - particularly young people - to engage with politics, and generally to raise political awareness. Facebook and Twitter could also allow young people to communicate directly, and discuss issues with, politicians. Social media was also a good place to promote political issues.

Participants held reservations, however, about certain forms of political content. A common theme which participants expressed in the focus groups was that while people were not adverse to others posting political content on Facebook and Twitter, what they really disliked was people posting uniformed, or badly articulated, arguments on social media. As Leo (21) said in reference to political content: "as long as its not unfounded criticism, or blatantly wrong/false I don't mind”. In addition to the way in which people went about posting political content, participants found it annoying if people posted too often about politics, or posted in a way which was too extreme.

\subsubsection{Politics on social media as a form of education}

In line with existing literature, almost all participants were positive about the 
educational benefits of politics on Facebook and Twitter, which positively contributed towards their perceptions of politics on social media more generally.

Freya (21) commented that Twitter "can be a great source to educate yourself in politics in a more 'modern' way”. Similarly Kate (23) noted that “Twitter is incredible for info gathering”, and that all the major political stories break there first. Zoe (22) argued that politics on social media was a fast, accessible news source, with "a lot more commentary”. Moreover, she emphasised that reading political content on social media is completely voluntary, and hence the content was not particularly objectionable. Jessica (23) argued that politics on social media is:

... a good way to influence friends who are less politically inclined. So, I went to a lower decile high school, and most of them don't keep up with social issues/politics/law etc. I've made the odd 'hey, look at this! Isn't this an interesting idea?' post and I've had replies from them like 'wow, never thought of it that way!' ... and I think, if I'm able to help one person see things in a new way, or maybe question the things we take for granted, then maybe the occasionally harassing message is worth it?...

Asked if Facebook and Twitter were useful in learning about the election, participants were almost all positive about the platforms, particularly highlighting Twitter's benefits. For instance, Freya (21) said, “I would say social media has informed me about $80 \%$ overall in this election. This is not just people's opinions but also links to various debates \& media reporting.” Similarly, Molly (18) said she thought that social media played an important role in educating people:

I know a lot of people whose knowledge of the elections didn't go any further than what was shared on [Facebook], if it wasn't for that then some would know nothing

Participants also noted that Facebook and Twitter were more useful and filled with politics and political discussion in the 2014 general election compared to the previous 2011 election.

Many participants highlighted the way in which Facebook, and particularly Twitter, provided spaces where multiple and diverse viewpoints were presented in a way which was educational. Oliver (23) said social media was especially useful "for the way in which it engages people from all over the political spectrum”. Seeing a range of different opinions on social media was valued by many participants. For example, 
Samuel (19) said: "it is interesting trying to understand how someone comes to a conclusion on their political views". Similarly, Zoe (22) noted: "I'm interested in what others think, questioning my own beliefs, learning more”.

Other participants valued the accessibility of politicians on social media. Jack (23) argued politicians were "a little more human than we see” in the mainstream media, and Zoe noted “it's cool being able to tweet at a politician and actually get a response.” This point was also made by Jade (18): “all the 18 year olds I've talked to said they would be more likely to vote if politicians and policies were more accessible to them”.

\section{a) Incidental exposure to politics on social media}

Rather than having to seek out political information, participants liked the way Facebook and Twitter enabled political content to be brought to their attention serendipitously. For instance, Freya (21) said she would "rarely go to news websites to read political news rather I would read it if someone retweeted the link into my timeline”. Similarly, Jessica (23) noted that:

...it's a great way to keep up with information. Because I have friends who are interested in politics, browsing my wall/feed is like a news feed all on its own! Less work for me :D

Lucy (18) also highlighted the importance of politics being visible even if people did not seek it out: "people are spending more and more time on these platforms, so it makes sense to put the information somewhere people will see it.”

Alice (20) also commented that social media platforms "are news sources for a lot of people, and political news is part of that. People can then engage with that news and discuss”. The simple presence of politics on social networking is useful, in that even incidental exposure can encourage people to participate politically. Holly (18) argued: “The more people talk about politics, the more people voting”.

\section{b) Reservations about the educational impacts of politics on social media}

Some participants cautioned against being too optimistic about the positive effects of politics on social media. Hannah (19) highlighted that while the platforms help "understand the opinions of others around us", "there are also contradictory messages and it takes background knowledge to understand why these are opinions are given.” Some participants also noted the danger that people will uncritically take incorrect or 
biased information as the truth and then act on that information. Leo (21) emphasised the necessity of people having a basic understanding of politics to form proper judgements, and also said that it is "important to differentiate fact from opinion, and acknowledge bias based on the background of the person/organisation you're getting this information from”. Other people also raised concerns about the educational efficacy of social media platforms. Emma (20) thought that "people need to be informed" to be better citizens, but she was not convinced Facebook and Twitter "are the vehicles for that".

A number of participants argued that incidental exposure to political content was not sufficient to really improve young people's understanding about politics, as they also needed the skills and knowledge to decipher that information. Lucy (18) noted that: "People still have to choose to engage with that stuff put out there for them". She also commented that if people did not make the effort to engage with politics: "I think we would end up in a dictatorship”. Jane (16) made the point that people had to be amenable to political content for it to have an effect: "there's lots of information available online if you want to see it" (emphasis added). She earlier commented that she had not seen much political material, but she had not gone looking for it. Others were simply sceptical about the size of any positive effect. Lucas (17) noted that politics on social media “doesn't achieve much really, except maybe gets some people slightly more interested if they find their friend is interested”.

\section{c) The potential of politics on social media to make better citizens}

Participants were asked if politics on social media helps to make people better citizens, for example by making them better informed. Most people did think that seeing politics on social media helped to make people better citizens. Laura (22) explained that she followed activist groups on Facebook which has raised her "level of awareness on issues” and also enabled her to engage in online activism such as petition signing.

A few participants, however, were unsure about politics on social media making people better citizens, even if it could help in educating young people. For instance, Maggie (20) thought that while politics on social media could sometimes keep people informed, at times social media had a negative effect when people posted political content "which is just calling for a fight" and is not going to go anywhere positive. 


\section{d) Social media leading to narrow perceptions}

One danger that participants identified with politics on social media was that instead of having an educational impact it could create more insular communities and narrowed perceptions. For example, Laura (22) thought that the only danger with Facebook was that it: "allows us to tailor what we see to what we already believe, as opposed to a newspaper where you are confronted with all types of views”.

Participants in the sixth group said that due to the insularity of politics on social media, they saw many more left-wing perspectives in the run up to the 2014 election, hence they were surprised when the centre-right National Party won another term in government. Lucas (17) said he mainly saw left-wing perspectives posted around the election, and it made him "forget a little how popular National actually is". Esther (20) similarly said: "I was a little surprised [National] won by so much, considering everything I saw on Facebook”. It is interesting that some participants were surprised that their impression of politics on Facebook was not a representative poll and presented an inaccurate view of reality.

Overall, there was a diverse range of views about the educational impact of politics on social media.

\subsubsection{Factors in determining the acceptability of political content}

\section{a) Being well-informed}

Participants commented that probably the most important factor in determining what was acceptable in terms of politics on Facebook and Twitter was how informed the person posting was. In other words, people were disapproving of people they viewed as not being sufficiently informed to be able to post political opinions, but who had posted them anyway.

For instance, Holly (18) commented that her friends infrequently post about politics, but when they do: "they just posted that they 'love John Key' after the election but when confronted in person couldn't tell me their reasoning behind it”. She also commented that: "A lot of people my age just like to voice their political views on FB and Twitter because we have all just turned 18 so they just like to brag that they can vote and it doesn't matter who for”.

Emma (20) expressed a similar view: "the worst ones are the ill informed. Worse 
than an opposing political opinion". She went on to say "being informed is key.

Whether you're on the fence, or on one side is secondary. If you don't know why you are somewhere, how can you share that opinion?”. This view was supported by others in the group, with Lucy (18) commenting that:

Yeah, it's not so good when you see people of opposite opinions arguing things, but if they're intelligently arguing, then it's the listener's choice. ... They're only frustrating if they refuse to GET INFORMED

Oscar (23) said people should be “informed” and “civil” when talking about politics. Freya found political content annoying when people are "un-educated \& un-balanced with their views”. Jack (23) also noted that it was particularly hard living in Wellington, because: "To have a political discussion you have to assume that the person you are talking to probably has a pretty solid understanding of our political landscape”.

Participants considered that being informed about politics was necessary for not only putting forward a political opinion on social media, but also for participating in formal political processes. For example, Max (17) said "I think people need to be informed to be able to post about policies and to vote”.

\section{b) Competence and coherence}

A number of exchanges in the focus groups suggested that a important potential reason that young people do not participate in political discussions is that they do not have faith in their levels of political knowledge, and are also unsure about their ability to make a coherent argument.

Jade (18)

yeah, I also don't think I'm educated enough to build a solid enough argument

...

Zoe (22)

like I don't want to argue unless I have a strong argument/reasoning

Jade

yeah exactly, too easy to get publicly shamed

Generally the need to be informed and make a good argument was considered critical in political discussions. Lucy (18) highlighted the need for "intelligently arguing” political points, which was a point echoed by Maggie (20): "I think that the best political posts have an engaging arguments that grab attention”. In the first group, there was an exchange on this theme: 
Oliver (23)

I can respect any political opinion as long as they back it up with an argument

Jane (16)

yeah, it has to be justified

Leo (21)

Everyone's got the right to have a political stance. If they can justify it, I can respect that.

One way in which people increased the acceptability of posting political content was to talk about politics in reference to an attached news article. Jade (18) thought that "an article is way better than a rant. An article I actually want to read whereas a rant even if I agree with it is often not worth reading”. Emma (20) argued that posting a news article "provides a safety net I think. If you put yourself out there associating yourself with something, you can alienate yourself”. Liam (22) argued that the acceptability of political content was quite different when one compares "someone's opinion" to a news article: "If it's someone's extreme political views or something, then I am not interested, but if it's a news article that also depends depending on how the article is written.” Lucy (18): "Yeah, linking lets people read the issue their own way, rather than me posting something like "THIS IS S***"”. In the fifth group, participants had conflicting views on whether linking to a news article improved political content:

Connor (19)

I'd prefer "proper" articles than straight opinion, I'm not really friends with most of my friends because of their ability to put forward a political opinion

Ella (18)

I wouldn't say just a news article, cause I tend to just switch off at those, but if someone has an opinion I'd like to see a good source with it

One reason why some participants thought that linking to news articles was useful was that it elevated political discussions above the exchange of subjective opinions. Freya (21) commented that she thought that traditional media organisations were better placed to provide "critical information surrounding politics" rather than just "people's opinions” on social media.

\section{c) Humour}

Previous studies have established that some young people strategically use humour to increase the social acceptability of political content (Thorson, Vraga, and Kligler- 
Vilenchik 2014). Similar strategies were expected in a New Zealand context, however, contrary to expectations, participants' responses were mixed when it came to the appropriateness of mixing humour and political content on Facebook and Twitter. All the groups except one said that while they generally said that humour could sometimes be a useful tool, mixing humour and politics could also be dangerous.

Participants highlighted the value of humour to spark interest in politics and make it more accessible. Hannah (19) suggested: "It's always good to add humour in to it. No one wants a serious, narrow minded person to go on a huge rant.” Max (17) argued that "humour makes many subjects including politics a lot more consumable by the general public”. Hannah (19): “If they add a few puns here and there, their opinion becomes more relatable ... in a way.” Alice (20) similarly noted that humour is “definitely a useful tool", and she also said "some of the more powerful comments on political issues I've seen lately have been satire”. Leo (21) said he thought funny political content was "the most acceptable”. Kate (23) emphasised that humour is an important part of the social practices of Twitter: "I reckon humour has its place for sure. Especially on Twitter where ... it's a big part of the norms of interaction - out-one-linering each other for RTs [re-tweets]”.

However, while a number of participants noted that humour could be a useful tool when done well, humour could also be counterproductive if it was not respectful and good-natured. Some participants said that humour could lead to serious political issues being presented in a way which appeared flippant, did a disservice to serious topics, or belittled others. Jade (18): “if the humour is used to belittle an opinion I don't like it”. Lucas (17) commented "humour can lead to people calling each other stupid and ignorant”. Jessica (23) thought that one of the dangers of political humour was that it would be used to make light of people who are not in positions of power: "There are a lot of "jokes" about marginalised groups that are not helpful at all.” Emma (20) thought humour was useful, but also noted the danger of it potentially making political issues less serious.

At a more basic level, humour could fall flat. Jessica (23) said humour can be useful, “If it's actually funny.” Jack (23): "I've seen some [political] parties post things and have tried to inject humour where it really doesn't belong ... It makes it seem like they're pandering”. When considering posting his own humorous political content, Leo (21) commented that he thinks: "Will people find this hilarious, or do I just have a horrible 
sense of humour”?

\section{d) Civility}

A number of participants in the various groups emphasised the importance of civility, and being respectful, in making political content on social media more acceptable.

For example, Zoe (22) said that when it came to politics on social media she chose her words carefully. She also thought that trying to be respectful was important. Similarly, Alice (20) said she was "mindful of my manner on Twitter ... I'll try not to say anything inflammatory or personal”. She also said that phrasing political content so as to avoid being offensive was an obvious way of increasing its acceptability. Ella (18) said it is easy to post acceptable content: “... BE A NICE PERSON generally works”. Jade (18) emphasised wording political comments "in a non-argumentative way” helped. Finally, Max (17) commented that the way in which people presented themselves when talking about politics was important: “you can't seem overly confident otherwise you will look silly to others”.

In political debates, participants considered that it was important to make sure that they considered both sides, rather than just arguing their side. Esther (20) noted that: "If people are being considerate about other people, then it's fine, but more often than not they're just spitting their opinions without really engaging in any real debate or anything.” Lucas (17) emphasised that people should realise there are inevitable and fundamental disagreements in politics: "people forget to remember this is a debate about economic and social direction of a country and there are different ways of looking at the same issue".

The antithesis of being courteous was engaging in deliberately inflammatory behaviour to provoke a reaction in people, or in other words, 'trolling'. Alice (20) noted: "I think on the internet, a few of my friends from high school give a lot of stock to trolling, and are happy to continually engage in unhelpful ways because they get attention for it”.

\section{e) Bias and neutrality}

Some participants also felt quite strongly about the inappropriateness of 'bias' or 'biased' information when it came to politics. Some participants expressed a concern that Facebook and Twitter "could be damaging if it is ... biased to one party” (Holly, 
18). Similarly, Max (17) said that if social media was "left unbiased it is a great, easy and effective place for political discussion in the younger populous of New Zealand”. Concerns about social media being dominated by one perspective were dismissed by Samuel (19), however, who said that the platforms were not biased and rather "everyone [is] sharing their opinions”.

Participants did not explain in any detail what they meant by biased information, but their aversion to "bias" seems to represent a concern that only one side of a political debate was being presented. In other words, to be biased meant one was an ideologue, and too caught up in the argument to see that there are almost always two sides.

One possible way to avoid bias is to approach the discussion of politics in a neutral way. However, participants in the fifth group were generally not in favour of presenting political content in a neutral way - to do so, they argued, would render it irrelevant. Lucy (18) said that rather than being neutral, it would be better to simply be courteous and "accept that people might disagree”. The fifth group had an interesting exchange about neutrality as a strategy:

Ella (18)

I'm not sure if neutrality really helps anyone's case

$\cdots$

Molly (18)

don’t know many people who post to appear neutral

Emma (20)

neutral = irrelevant post?

just post a sheep video

...

Ella

Like I understand why you'd try be neutral but it just seems pointless

Lucy (18)

Yeah, there's [few] posts you can make that are totally neutral ...

Even if you're posting just a link, the article or whatever is going to be slanted to some extent.

\section{f) Persuasion}

There were a range of views about the appropriateness of political persuasion on Facebook and Twitter. Most of the focus groups expressed conditional support for political persuasion. They thought that people actively trying to persuade others to come around to their particular viewpoint was generally okay in discussions about politics. 
Oliver (23) was positive about persuasion, saying it is "a part of healthy debate". Other participants thought the way people approached persuasion was important. For instance, Freya (21) thought that attempts at persuasion could be useful when they are educating people on different views and leaving them to come to their own conclusions, "rather than persuad[ing] someone to change”. Oliver agreed: “As long as you are not telling them to agree with you - more explaining why your viewpoint is valid”. A number of participants also thought that persuasion was okay, as long as the persuasion was well informed.

The fourth group was less keen on the idea of political persuasion on social media, although some participants recognised that attempts at persuasion could potentially make people think more deeply about their political views. The group generally thought that attempts at persuasion were inappropriate on the basis that they were pushy:

Samuel (19)

No not really it's just forcing your ideas on somebody

Holly (18)

It's like religion, we appreciate that everyone has different views but sometimes we don't want it shoved down our throat Well I don't

Hannah (19)

I dislike persuading people, but I do think giving them a little pressure to actually think about their decision is important.

. $\operatorname{Max}(17)$

I don't think it is someone job to try and persuade someone to vote for a certain party maybe provide information that may persuade but if the person has been following politics they should already know who they want to vote for [when friends post political things I do not agree with] I feel that they are trying to influence my vote and it doesn't annoy me but I feel that its not their job to influence me over social media

Holly also argued that "people need to think for themselves and not let others influence them”.

Finally, some participants in the focus groups mentioned that persuasion can sometimes be uncomfortable when it involves seeing others who do not share one's political beliefs persuading people to come around to their viewpoint. 


\title{
g) Positivity
}

A theme running through a number of the focus groups was the importance of being positive about political issues. In a couple of focus groups, a number of participants commented on what they perceived as a climate of negativity around the general election. Oscar (23) said political posts on social media were "more negative political stuff than it is positive. 'This person sucks' rather than 'This is a cool thing!'” Lucy (18) said she "saw a lot of people just complaining about [the election] in general. Not a lot of discussion, necessarily.”

Participants thought that negativity was a problem, because it “doesn't give you a rounded view on the situation” (Freya, 21). They further suggested that the negativity regarding politics on social media might be caused by the platforms' properties. For instance, Oscar argued that "it's a lot easier to criticize (using the word loosely) something on social media than it is to show support for something." In response to people's hostility to negative content, some participants consciously phrased the political content they posted in a positive way to increase its acceptability and impact. For instance, Jessica (23) said:

No matter how angry or upset you may feel, instead of "look at how women are being discriminated against again", I'd post more stuff like "look at what this awesome woman has done!" on Facebook.

The third group was asked if the need to present things in a positive and palatable way meant that important issues sometimes did not get talked about. Participants emphasised that we have to remember that the issues matter, and not to worry too much about presenting an acceptable face to their audience on social media. In other words, people should not spend too much time trying to figure out how to communicate issues to people in a way which is acceptable:

\author{
Brooke (23) \\ ... I think if you've got something to say, say it \\ Life isn't all about roses and rainbows \\ The truth hurts sometimes - especially with politics \\ But yes, positivity can be good. But not everything is positive
}

Alice (20)

I think the issue is the most important thing to communicate - that should take priority over presenting it in a pleasant way 


\section{h) Moderation}

Some participants did not like how their friends' social media accounts became very political during the election period. There was a sense that some political postings were okay, but posting too much was inappropriate and “overwhelming”. Maggie (20) said she: "had A LOT of stuff that was left wing on my wall because that's the kind of friends I have and after a while it just became a little too much in too little time”. In the sixth group, participants were uncomfortable with the intensity of their friends posting about politics:

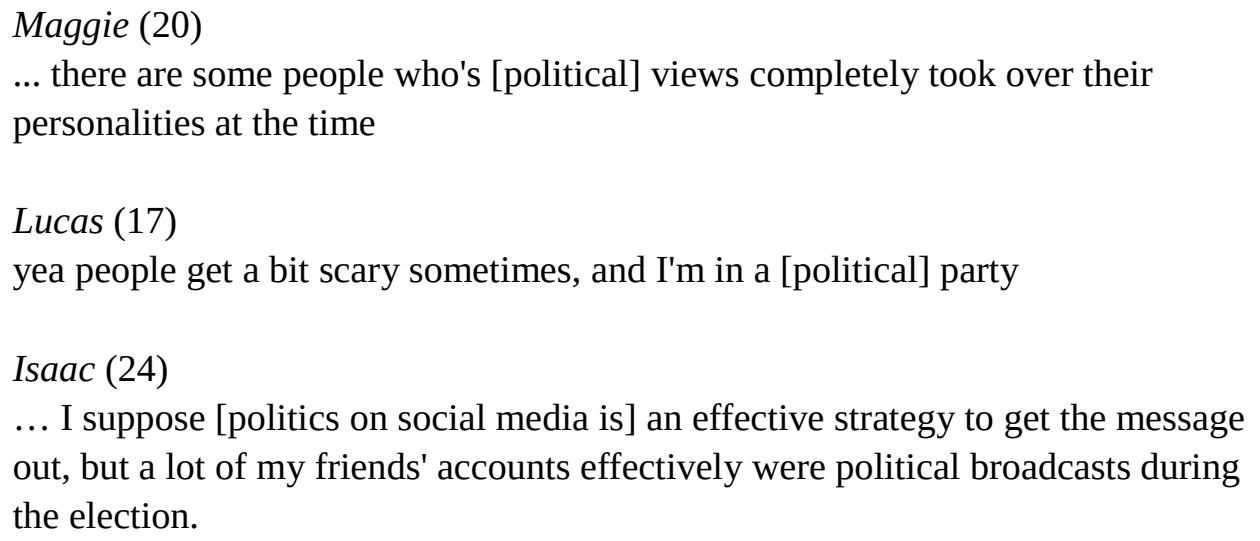

Participants were also wary of friends who approached politics on social media in an extreme way, or who went "way over the top". Jack (23) noted that he had "a few friends who have very strong opinions and can get a bit preachy. With that sort of stuff I just ignore them”. Similarly Lucas (17) said he had a friend who posted "if you vote National defriend me right now”.

\subsubsection{Thinking about acceptability before posting political content}

Participants were asked if they thought about the acceptability of political content before they posted it. Participants reported that they definitely thought about the audience of political posts before they made them, as they were concerned with their self-presentation and how they would be perceived. However, participants were mixed on whether they considered political posts more than non-political posts and tweets.

Overall it seems that some participants were only slightly more concerned with thinking about the appropriateness of political content as opposed to posting nonpolitical content. Oscar (23) said he thought about the appropriateness ahead of time, but: "I do that with any tweet”. Similarly, Lucy (18) said: “I do that before tweeting 
about TV shows, let alone political stuff hahaha”. Connor (19) argued that it "always pays to have a bit of filter”. Holly (18) said she thought about the acceptability of political versus non-political content was about the same, and her main concern was “Just trying not to sound like a dick". Those participants who did not think about the appropriateness of political content before posting it were the small minority.

Participants thought to themselves before they posted about whether their post would be "too negative” or "unconstructive” (Oliver, 23). Participants also highlighted the danger that posting about politics might offend others or start arguments. Lucas (17) said he thinks about: “...who could this offend, will this start a big stupid argument etc”. Laura (22) said she once wanted to comment on a topical issue but refrained "because I figured the risk of backlash wasn't worth it”. Zoe (22) said one danger is simply being "attacked for having an opinion”.

Some participants described thinking about posting politics on social media as a sort of balancing act. Emma (20) noted that: "you have to word it in a way that doesn't rark anyone up, but still communicates your ideals”. On the other hand, some participants chose to remain silent rather than risking an unexpected reaction. For example, Lucy (18) said she was very cautious in posting about politics:

I filter a lot of what I say to the point where I tend not to say it online. Maybe on Tumblr, where no-one whatsoever knows me... but if I know a lot of my friends won't like what I'm thinking about posting, I just won't post it.

Ella (18) said she did not like "deconstructing my views to death, so if it's something that's ridic [ridiculously] abstract I'll probably just leave it”. Samuel (19) noted he did not "want to seem like a twot" by posting about politics.

Others noted that they tried to avoid self-censorship wherever possible. Ella (18) noted that on the one hand, if political content she was considering posting “...might hurt or confuse people or whatevs then I'll try to avoid saying it”. But on the other hand, she said:

I try not to restrain myself too much because it's important to express yourself ... but I try not to be too extremist ... Like, I'm not going to not say something because I think someone might say something mean to me

Molly (18) similarly said “... I'd rather get my point across then worry what people will [think] of me personally”. 
Jessica (23) noted that she crafted her message depending on the particular social media platform which she was posting to, based on a general understanding of the political sophistication of the likely audience:

If they don't know enough about the topic, then we can't really get into the serious, nuanced discussion. You need people who have moved past, like, Feminism 101, to be able to critique things on a deeper level.

so with Facebook, I feel like I have to explain the basics a lot more ... with Twitter (or Tumblr, for longer discussion), I can just get into it

Jessica also noted that political discussions on Facebook involved "extra 'work"” and also the "potential for blowout”. She only posted on Facebook when

there's a goal I'm trying to reach. Like if I want people to think about things a certain way. If the most effective way of reaching that goal is to phrase things differently, then I'd definitely do that.

In addition, Liam (22) commented that the acceptability depended in part on the tools one used to post it, so it depends “... on if you're putting it as your status or posting it to someone".

It is important to note that people did not always consider the acceptability of politics before they posted something. As Maggie (20) noted:

Sometimes you can be angry and just hit send, then realise a few hours later that maybe that wasn't your best moment and deleted it but if you are sound of mind most of the time you'd think about it

She also commented that she was "very open about everything” because her privacy settings were "pretty extreme”.

\section{a) Thinking about who will see political posts?}

Related to the idea of the 'imagined audience', participants were asked if they thought about who would see a political comment on Facebook or Twitter before they posted it, and whether they worried about who might see it.

The first group did not really worry about who might see their political posts, which seemed to largely stem from that fact that they mostly did not post politics on Facebook. Oscar (23) said: “I almost never post political content on Facebook so I don't really worry about who sees it.” Leo (21) noted that: “I probably know about 20 or so of my 
Twitter followers personally, and that's where most of my political views go, so it's not really an issue for me.” Oliver (23) similarly said he did not worry about who sees his posts because:

... I don't post political content on Facebook (which is where I am friends with more friends/family/co-workers), on Twitter it's more about whether it is generally appropriate as I don't really know most of my followers on Twitter personally.

For some participants, thinking about who might see a political comment loomed large when they considered posting on social media. For Jack (23), thinking about who might see a political comment before posting it was his "main concern” when posting on Facebook or Twitter. Many participants were concerned about family (at least those who were friends with their family on Facebook), workmates and bosses, friends who did not share political views, and even friends' parents.

Consideration was also given to the impact political content on social media could have on family relationships. Lucy (18) said that one side of her family was religious, so she avoided posting about topics she thought might upset them. Some commented that they had set up their privacy settings to make family not see all of their posts. Esther (20) said: "I always worry about what my parents will say”. Maggie (20) also said she considered: "My mother and family members, people who would take it out of context and create an argument that uses up all my calling credit”.

Another worry was that posting might prove harmful in terms of employment opportunities in the future. A number of participants commented on the impact political posts might have on their employment or educational opportunities. Kate (23) said she had "been applying for jobs lately. Protected my tweets for a while coz of that concern." Connor (19) noted: "I think of employers etc, I like to keep anything public broadly tolerable”. Lucy noted: "I tried to stop swearing in posts in the weeks when I was applying for Uni, in case someone found them...”. Laura (22) similarly suggested that “there's that slight awareness that anything too radical or left-wing might be damaging in the future regarding reputation, jobs, internships etc”.

Some participants noted that they had to actively think about who to block from viewing their political postings on Facebook. Jessica (23) noted that:

I just posted this status on Twitter actually that got a few agreements: "Whenever I'm about to share a political post on Facebook, I think, hmm, who are the people I need to block from seeing this post..." 
There were also some differences between Facebook and Twitter, with people worrying much more about the audience of their posts on Facebook, despite thinking it was more difficult to imagine who was going to see their posts on Twitter. Max (17) commented that: “Twitter is way more free and open”, and Holly (18) similarly noted it was more difficult to imagine your audience on Twitter "unless you change your privacy settings”.

However, some participants were also unconcerned about people seeing their political posts on Facebook and Twitter. Ella (18) commented that “it doesn't bother me too much if my friends/family know what I think”. She thought about politics on social media in the context of the permanence of everything posted on the internet.

A few participants highlighted the danger of the audience of their political posts not matching up to their expectations, or in other words, unexpected people seeing their posts and perhaps even engaging with them. Brooke (23) recounted a story of a debate she was having about "being involved in relationships with someone who has differing political opinions”. She had talked about how being in a relationship with her exboyfriend who had different political views than her was difficult, and that she probably would not repeat it. She was not aware that a friend of her ex-boyfriend was viewing the post and commented on it, to her embarrassment: "that's the danger with Facebook hahaha”.

Jessica (23) noted the danger of people outside the immediate political conversation having access to her engagement with political postings: “There's ... the danger of exposing yourself to their friends who have access to their page”. Similarly, she noted that "because of the way the wall works, notifications etc. some of my less politically inclined friends will likely see any comments". She also recognised the "danger of people reposting [your material] into an environment you can't control - I've seen it happen”, but overall, she said it was not something she was too worried about. Alice (20) commented that because her political conversations were generally all in private messages she was not concerned about her political comments on Facebook being taken out of context, or being automatically presented to strangers on their feeds.

\section{b) Why participants chose not to post about politics}

The first and fourth focus groups were almost unanimous in not posting about politics on Facebook, although a few people mentioned that they posted about politics on 
Twitter. Freya (21) explained that "my social media doesn't reflect my political views", and she did not post about politics or 'like' political parties. Holly (18) noted: "No I don't post about my political views unless I am directly asked”. Oliver (23) said he did not post anything on Facebook, although on Twitter "I will occasionally respond to political posts to try and give a more balanced viewpoint”. Oscar (23) said: “I don't really post anything political on Facebook or Twitter.” On rare occasions when he did post about politics, he said he normally posts a link or a news article saying “'This isn't cool!' (but more articulate)”.

A number of participants said they generally preferred engaging with existing content rather than posting their own thoughts or starting a new discussion. For instance, Alice (20) said she was "a bit of a lurker on social media in general. I retweet stuff more related to policy issues, or reply, but I don't generally start the political discussion.”

Participants in the other groups provided other reasons for not actively engaging in politics on social media. Connor (19) said:

yeah I don't really share political stuff either as of late, kinda just either preaching to the choir or pissing people off, no-one really wants to critically think on social media

Lucy (18) similarly thought that social media was not a particularly effective place for political discussion: "I prefer to discuss [politics] in person; it's easier to gauge people that way.” Jade (18) was wary of posting about politics because it made her feel like people would stick a label on her: "you're immediately categorised" - the implication being that her subsequent opinions would be disregarded. She also said she did not "want to post anything political because everyone gets very defensive about things they may not know a lot about”. Max (17) said he did not post about politics because he did not think he should be engaged in persuasion:

I don't know if I would ever post stuff political because I feel its something that everyone should have their own feelings and views on and I don't wanna influence anyone to change their vote ... just because of me

Some participants, such as Jessica, were aware that if they posted too much about politics, their behaviour might alienate their audience: "I don't think people like to be lectured to, and there's a risk of that if you post about politics too much.” 


\subsubsection{Differences between individuals and groups}

Participants were aware that significant differences existed in terms of the social acceptability of posting political content both between different individuals, but also between different groups on social media.

\section{a) Individual differences}

Participants seemed very aware that individuals have different political views, and that the same multiplicity of views are present on social media. One aspect of these differences which participants noted was that some people posted frequently about politics, while others were almost always silent. Oscar (23) suggested that "some people almost exclusively post political stuff, while others don't engage with that on social media at all.” He further noted that the acceptability of a person talking about politics depended on the sort of things they had posted in the past, and hence the expectations which other people had built up about their posting patterns:

I think it depends on what kind of person you are - if you've set yourself up as a person who DOES this sort of thing on Facebook/Twitter, then I think it's more acceptable [...] it's still real jarring when somebody I don't expect that kind of discourse or commentary [from] suddenly starts engaging in it.

It was possible, however, for people to mature and post about politics differently. Jessica (23) said that she thought she had "mellowed more over the years" and was "less into arguing and ranting” than she used to be.

A few participants also noted that some people paid little attention to social norms on social media. Jack (23) argued, for instance, that: “There will always be people who will just say whatever is on their mind with no respect for what is 'acceptable'”.

\section{b) Important differences between groups}

In addition to the individual differences explored above, participants also generally considered that perceptions of what was acceptable to post in terms of politics did vary considerably between different social groups present on social media. In other words, participants recognised that what would be considered acceptable in terms of politics on social media in one group would not necessarily be considered okay in another. While perhaps somewhat self-explanatory, this consistent understanding suggests a relatively sophisticated understanding of how social norms operate on social media platforms. 
Participants believed that a big part of what determined the acceptability of political content on social media was the people you interact with, and in Hannah's (19) words, the "groups and 'bubbles'” you are part of. Similarly, Oliver (23) thought that what is acceptable:

depends on who you are friends with/who you follow ... That informs what you think about what you post, and what you think other people will think about what you post!

Emma (20) emphasised "it's going to vary a lot re: what's acceptable regarding your personal opinion and your circle of friends and how they engage with their posts and yours". Brooke (23) commented: "I think we just do what we feel is okay within our own friend groups ... Well I know I do haha”. Jessica (23) provided an example of how a friend group could shape behaviour. She said because she was friends with so many law students and "all we want to do most times is talk politics and social issues", it was difficult to know whether other people had similar views on what was acceptable to post. This point was echoed by Maggie (20), who said that most of her friends online shared her political views, so differences of political opinion were less visible than in her offline life. Finally, Laura (22) took a more expansive view of what determined the social acceptability of political content: “I think what's acceptable varies in different circles, according to class, political beliefs and other social factors”.

Interestingly, Molly (18) commented that either there was no shared understanding of what is acceptable, or alternatively "everyone understands what is acceptable but they don't care about it/take it into consideration”. Similarly, Esther (20) argued that: "I feel like there is a bit of a general idea of what is okay, but sometimes people don't really care and just want to get their opinion across”.

Some commented that the way social media operates often highlights these differences of opinion, with divergent views sometimes colliding together. Isaac (24) commented that differences are especially apparent in "that great moment where, by pure coincidence, two opposing ideas are juxtaposed on a feed.” Ella (18) echoed this comment in arguing that: "I think personally seeing all the different people and opinions on my Facebook newsfeed it's difficult to believe that any of them would think the same way”. Liam (22) commented that differences of opinion were especially visible on “some Facebook groups/pages”.

A few participants noted that the differences between different groups on social 
media sometimes came into sharp relief when they saw something, which they saw as inappropriate, get well received. Alice (20) commented that she definitely thought there was no "shared understanding" of what was considered acceptable on social media, "Purely because I see a lot of offensive jokes made as replies to political posts, and I know this isn't seen as appropriate by me and my friends”. Similarly, Laura (22) argued that:

without sounding horrible, bogans in Christchurch and greenie yuppies will have completely different ideas of acceptability and sometimes I'll see something on my wall and be shocked at how many likes its got, because to me it might be quite offensive or childish

Isaac (24) also commented that he had seen "a quite (well, horribly) offensive post that came up on my feed. But quite a few work colleagues had liked it, but that'll be that group.” Therefore through following a range of people, and due to the way the platforms operate, participants were aware of differences in political views.

Participants noted that there were some differences between Facebook and Twitter in terms of differences in political opinions. Lucy (18) noted that on Facebook what is acceptable is "more variable depending on friend groups" whereas on Twitter "you can offer whatever you want and people can take whatever they want”. She also suggested that

...on Facebook people still can identify their friends who will think certain ways about certain things ... On Twitter, because people choose to follow you, it's easier to assume they will agree with you.

Isaac commented that most of his friends "seem to conveniently fall into groupings around political views. At least on Facebook. Twitter was another story!” Ella (18) compared Facebook to her experience of high school, with both involving "forced interaction with people you barely know or like”. Kate (23) commented that she thought the Facebook algorithm made it difficult to tell if it was only a small group of people who post most of the political content.

Some participants were asked what they thought determined if people belonged to the 'political crowd' on Facebook and Twitter. Oscar (23) said he thought talking about politics online is closely tied to offline political engagement:

you're a lot more likely to engage in online political discourse if you're engaged in it offline, and the opposite is true, if you're not engaged in offline discourse, 
you're probably not going to be super engaged in it online.

Leo (21), however, noted that his offline political engagement did not match closely his online political engagement:

I guess it's just whether you actively choose to engage in politics. I mean, politics isn't really a big part of what I talk about offline, but I tend to tweet about it quite often.

Now that I have explored the social norms of talking about politics on Facebook and Twitter, I will move to examining how the affordances of those platforms affect political talk.

\subsection{The relationship between social media and social practices}

As we have seen in the literature review, scholars have examined the relationship between social practices and technological features, otherwise known as the affordances of technology. This section will explore how the affordances of Facebook and Twitter shape the behaviour of young people in terms of political discussions.

\subsubsection{Social media ill-suited to political discussion}

Participants commented that there were some potentially negative aspects to discussing politics on social media. The barriers to entry on social media were very low. As Oliver (23) said: “Anyone can create an account and start tweeting”. There were also few checks on people spreading incorrect information. Oliver also noted that: "You can say pretty much whatever you want on social media - even if it is wrong and unfounded”. Hannah (19) commented that she was not sure if there was a place for politics on social media:

It's important to share information and opinions, but a lot of what is said is repetitive and many people don't even know what they are talking about: I will put myself in this category.

Political posts and comments on political discussions on social media were sometimes so absurd that some participants found humour in observing political disagreements. Liam (22): "I find some of the comments rather misleading and outrageous to the point of being funny”. Similarly, Emma (20) said it "can often be a bit of a laugh reading 
through the comments”.

There was a sense that people took less care with what they said on social media platforms, and this included discussing politics. Lucy (18):

People care less with online opinion things. They tend to take opinion to extremes, or just not listen to what other people say.... it's an easy way to identify yourself and your opinions, but not so great for discussion

Participants thought that these low barriers to entry, and the freedom to say virtually anything, do not produce an environment conducive to useful political discussions. Therefore any political issues which needed to be discussed in any depth were not suited to social media platforms. Emma (20) noted that any substantive discussions of politics were not particularly well suited to public discussions on social media:

if it's a hey guys, have a wee read of this if your interested then I'll share (if relevant) but if it's something I want to discuss I'll seek it out in person or private message someone for clarification

Laura (22) thought Facebook and Twitter were suited to politics, “... but their role is limited as they're not suited to detailed discussion so it tends to limit discussion to cheap shots or emotional tribalism”. Similarly, Connor (19) argued that: “Facebook is a shitty forum for discourse so no-one really wins”.

Participants in the second group highlighted the danger of a political fight breaking out on Facebook when discussing politics. People felt a strong sense of ownership over their Facebook profiles, and hence did not want a heated political argument breaking out and to be responsible for it:

Jack (23)

For the most part people don't want a massive scrap to break out on their

Facebook

Kate (23)

AMEN

Jack

It's like hosting a party and two of the guests [are] fighting in the front lawn

Zoe (22)

people take things down if it starts getting bad quite often

Participants commented that they often did not engage with politics because it 
simply was not worth the effort to get "caught up in something”. Jack commented that: "Nobody wins when you feed the Facebook trolls lol”. Kate noted that: "If replying publicly won't change minds or further a cause I'm behind, I stay out of it. Limited energy, etc.”

A number of participants highlighted the danger of political arguments online getting out of control, and thought that engaging further probably inflames the situation. There was an exchange in the first focus group on this theme:

Oscar (23)

[engaging makes] it into a bigger thing than it needs to be.

Freya (21)

Yes \& also giving people the attention that they want by reacting to it

Jane (16)

Yeah, it just causes unnecessary issues when people start arguing with you

Leo (21)

Maybe. I mean, everyone's seen those Facebook posts that turn into an unnecessarily massive argument.

Oliver (23)

Arguments online have a tendency to snowball into massive threads

Alice's (20) experience of political discussions was that people often posted unhelpful political content, and then others would not even read the linked content before launching into an argument:

In my experience people will post about an issue with a link to a title that is huge click-bait, and not inform themselves or look into the sources of their information or anything ... And try to establish their position on the issue wholly from the title

To avoid these fraught political discussions from erupting she tried to take "[a]nything potentially inflammatory ... into a private discussion”. Maggie (20) similarly highlighted the potential for people to post about politics "which is just calling for a fight e.g. 'Should New Zealanders be sent to support the USA in the fight against ISIS'.” Oliver (23) said his experience of Twitter was often that someone would post "an opinion that is perhaps not popular, but then the replies are often even more derogatory / more confrontational”.

While many participants were wary of politics on social media getting out of 
control, a minority of participants highlighted the positive effects of people getting passionate about political issues, and noted that for the most part, people stayed good mannered. For instance, in the second group participants were generally positive about people engaging in political debates on Facebook and Twitter. Zoe (22) said that: "I find most of the time people actually stay really respectful”, Jade (18) responded “yeah, at least if it's heated people become interested in it”, and Zoe further commented that she had "seen some really cool discussions from people with opposing views".

Now that I have explored the reasons why social media was viewed as sometimes ill-suited to political discussion, I will explore the differences between Twitter and Facebook, and the effects those differences have on the social acceptability of political content on the respective platforms.

\subsubsection{Differences between Twitter and Facebook}

Most, but not all, participants reported that they considered Twitter to be a more acceptable place for politics compared to Facebook. A number of factors contributed towards the higher acceptability of politics on Twitter, including differences in the sort of people on the respective platforms, differences in privacy, differences in how the platforms are used, and space constraints on Twitter.

\section{a) Differences in the types of people users connect with}

The general consensus among participants was that Facebook and Twitter were quite different social networks, mainly due to the types of people which you normally interact with on the platforms. There was a perception that on Facebook, social obligations mean that people do not have much choice about the people with whom they are friends. This difference in the type of people users of Facebook and Twitter were likely to interact with has an impact on the social acceptability of politics on the respective platforms.

Jessica (23) thought that discussion of politics was more acceptable on Twitter "just because I've cultivated the people I want to follow/who follow me on there - so it's sort of like a relatively safe space. Even though, ironically, it's more public than my Facebook profile.” Hannah (19) suggested that: “It depends completely who you choose to like/follow, and what types of content you choose to read on either platform.”

A number of participants commented that they did not know most of their followers 
on Twitter, whereas on Facebook they knew essentially everyone from their offline social world. Jessica thought politics on Facebook was less acceptable "because it's people from all over my life - ex-teachers, Catholic school friends, non-political people...” She also said that her friends on Facebook were people she knows from general life - non political people, as well as people from the other side of the spectrum. While on Twitter you can pick who to follow and who to share your username with

Isaac (24) explained that he generally ran his Facebook account "as a 'I know you' or to follow some organisations/personalities”, whereas his Twitter account “is a bit more of a free for all”. Finally, Emma (20) suggested that the way people used Facebook was related to the affordances of the platform:

Facebook is designed for people you know. You also have the added profile photos, life events, workplace, hometown etc and usually your family adds you on Facebook and at Christmas bring it up so you have to accept them.

Related to these differences in audience, participants were clear that there were fundamental differences in the platforms. Jack (23) argued that "Facebook is for friends, Twitter is for wider conversation”. Leo (21) thought that Facebook was was for your friends, whereas Twitter is "more public, you're open to a wide range of views". Jane (16) suggested that "Facebook is more for talking friends and family but Twitter is sort of a better place to learn about social and political sort[s] of things”.

Some participants also commented on the influence of the context of other content on the platforms in determining the acceptability of politics. Brooke (23) noted that that politics on Twitter was more acceptable partly because it was “[n]ot generally seen amidst a collage of baby photos like FB”. She also commented that while there is a place for politics on social media, "it becomes too much". She said she would "love to have a Facebook that just had stuff I wanted to see ... And had Twitter for political stuff”.

While on Facebook connections with others depended largely on offline contact, on Twitter connections built up organically over time as users followed people with similar interests. As Kate (23) argued, the

nature of Twitter means you naturally expand your networks even further into groups of people who are interested in the same stuff as you, coz they see you talking and follow or vice versa. So on one hand you [encounter] new people. On 
the other hand, hello-o-o echo chamber

Zoe (22) noted that "I feel like Twitter's more open, easier to jump in and out of different conversations with different people that you might not have talked to before”.

Participants also thought that people on Twitter were generally more interested in politics. For instance, Kate (23) noted that all of her Twitter friends were "super into politics". Alice (20) said that she tends "to follow politically-engaged people on Twitter, and people who have similar policy ideals to myself”. Jessica commented that the differences she noticed between Facebook and Twitter "has to do with the people on there as well”. It is important to note, however, that there is almost certainly a cohort on Twitter which is not interested in discussing politics at all, and hence these perceptions are only reflective of a certain group.

A number of participants noted that most of their Facebook friends were not also on Twitter, and for that reason, some thought that it was appropriate to leave Facebook more for social talk. Alice noted that:

I prefer to see political content on Twitter personally ... I know most of my friends don't have Twitter, and Facebook is their only form of social media, so it's also important that they have a platform ...

Esther (20) explained that: “I'm more likely to post my opinions on Twitter because not many of my friends have it, so there's less chance of it starting an argument”.

A number of participants commented on the relative homogeneity of Twitter versus Facebook. Oscar (23) suggested that politics is probably “... more acceptable on Twitter than it is on Facebook, given that Twitter's more of a place where you can express your opinions easily and to people who probably have similar opinions to you.” In contrast, Esther commented that "Your friends on Facebook are all around the same age as you with the same concerns, [whereas] I feel there is a bit more diversity on Twitter regarding age etc.” Ella (18) said that politics is definitely more acceptable on Twitter, “... since you have more of a choice about who you follow etc. and don't have to make your relatives like you”.

\section{b) Twitter's relative anonymity}

Participants also commented that there was far more anonymity possible on Twitter compared to Facebook. The differences relate to Facebook's explicit link to people's offline identities. Oliver (23) noted that "Facebook is linked to your name - [whereas] 
most people I follow on Twitter I don't know their name/they use nicknames”. Jade (18) similarly commented that “Twitter seems less personal”. The relative anonymity of Twitter was a factor in the platform being perceived as more acceptable for politics than Facebook. Max (17) suggested that "Facebook is very personal you know all the people you are posting to[,] Twitter is open to the whole world”. Similarly, Oscar (23) said:

I think that the fact that Facebook is so closely linked with your image and name makes it a pretty risky place for politics, but with Twitter there's a definite disconnect between what you say and who you are, or there can be.

Lucas (17) thought that Twitter has more "openly political content because there is less of a personal connection attached to it”. Jane (16) noted that: “Twitter is more anonymous and there would be less backlash for an unpopular opinion”. Emma (20) called Twitter "relatively faceless”.

\section{c) Privacy and control over who sees your content}

Alice was less worried about political conversations on Twitter because people have "the option to see the whole conversation, so I'm not too worried about things being taken out of context”.

Some participants commented on the apparently paradoxical relationship between how private respective social networks were and how willing they were to post political content there. Zoe (22) said "it's interesting [that politics is more acceptable on Twitter] because my Twitter is public but my Facebook isn't..”. Jessica (23) said she phrased material quite differently on the two platforms, posting in a more guarded way on Facebook, “[w]hich I find funny, since Twitter is the public site accessible to all, and my Facebook is locked.” This suggests that people are inclined to think that how public the relevant forum is should determine how acceptable politics is, but actually, which people are present on the platform is a more important factor.

Finally, a small number of participants commented that they actively managed who could see their political content. For instance, Lucy (18) noted that: "I have my Twitter linked to my Facebook, but sometimes I turn that feature off to have a rant on Twitter...”

\section{d) The social networks are used differently}

Participants noted that the types of conversations which people had were quite different on the respective social media platforms, and that had an impact on the corresponding 
social acceptability of politics. Max (17) commented that politics was more acceptable on Twitter because it: "seems like more of a social medium that is built to share your opinion on" compared to Facebook. Zoe (22) said that "people post way more to Twitter (normally) ... so that makes sense for the breaking news discussion etc to be there”. Lucy (18) similarly suggested that “Twitter is good for spreading things, Facebook is good for informing people.” Brooke (23) noted that the respective platforms are

... just so different. Like, on Twitter, I'll see lots of soundbites and can grab a bit of a story here and there which I can follow up later. Facebook generally has longer and more engaged posts which can get pretty intense haha

A couple of participants noted that features of the respective platforms made a difference in terms of discussing politics. Jessica (23) felt the need to finish debates on Facebook, but not on Twitter:

[on Facebook] if someone comments on one of my posts with something I really disagree with, I feel sort of an obligation to sit there and finish the debate ... but on Twitter, I don't bother replying, I just block people

Participants also noted that there were different forms of political content posted on the respective platforms. Jessica noted that “...it was mainly "go vote!" on Facebook, while Twitter had more partisan views”. A few participants thought that rants were more predominant on Twitter rather than Facebook. Kate (23) said that "Rants feel like a norm on Twitter tbh [to be honest]" and that it felt like "articles more acceptable on FB, and rants/strongly worded opinions more interesting on Twitter”. Another respondent voiced support for this view, saying on Twitter “almost anything goes”.

For some participants, the differences in the platforms meant they behaved differently when it came to posting and engaging with politics. Jessica said she would phrase things differently on the two sites. [On] Twitter I don't hold back on my opinion. [On] Facebook, I try to be more subtle about it. Either "hmm, isn't this interesting" or I try to phrase the post in a positive way (even if what I really want to do is rant).

Lucas (17) noted that: “Twitter is worse when it comes to ang[ry], thoughtless politics than Facebook ...”. Finally, Brooke (23) said she mainly retweeted political material on Twitter, but on “...Facebook I'm more inclined to have a go”. 


\section{e) Space constraints}

Participants were relatively positive about the effects of space constraints on Twitter, and the way such constraints shaped political behaviour. Isaac (24) commented that space constraints on Twitter can be good:

I feel it forces people (unless they're on a ranty multiple tweet \#ttrttpt [tweet that refers to the previous tweet] style rampage) to be concise, think about what they're saying and where appropriate follow up with a reference, like the linking we were talking about earlier.

Zoe (22) said that political conversations on Twitter would probably be hard "if you have lots to say”, but also noted that people had ways of getting around the space constraint issue: "often people will link to things and then have Twitter conversations about what they linked to". Alice (20): "I think the micro-blogging format of Twitter stops it getting too heated, so makes it a bit more pleasant to read”.

Other participants were unsure about the overall impact of Twitter's space constraints, with Jack (23) commenting that "Twitter is a blessing and a curse ... 140 characters is not enough to rant but often also not enough to express a point”. Jade (18) thought that Twitter's character limit made people "a little more blunt”.

\subsubsection{Feedback mechanisms inform what is considered acceptable}

Most participants were mixed on the impact of social media feedback mechanisms such as likes and favourites on what content was considered acceptable. Some participants compared the Facebook 'like' to a "barometer for the acceptability of your views". Hence through the receiving (or not) of likes, Facebook users are taught what is considered acceptable.

The third group considered that while it was nice to have positive affirmation in the form of likes, favourites or comments, they were ultimately not particularly important.

\section{Jessica}

I think the amount of shares, like, positive comments of support of a post could be an indication [of its acceptability].

If not an indication that the post is "right", maybe at least an indication that it's something to think about

$\cdots$

Brooke

If it got 0 likes or comments I think I'd be up a creek without a paddle lol $\ldots$ 
Jessica

Also the way the algorithm works, if it gets a lot of interaction the post shows up again on your wall. If not, it silently disappears

Brooke

I dunno if it steers it. But I think it's a bit of a reassurance that I've got the right end of the stick haha

Alice

Personally, no.

Jessica

It doesn't steer my behaviour, but I guess it calms nerves.

...

Again, I don't want to get into arguments, and if it looks like it's not heading that way - great! :D

Alice

It's encouraging to have likes/favourites, but if a post has zero reaction, I'm not bothered

Some participants thought that some people might keep posting regardless of reactions on Facebook or Twitter, depending how strongly they believe in their views and how stubborn they were, or as Hannah (19) said: "Until they have cooled down and given up caring about the subject.” Max (17) argued that "some people will never stop campaigning for what they believe in”, even if they do not receive a positive feedback on social media.

Now that I have explored the relationship between social media and social practices, I will explore the ways in which participants managed political disagreements on social media.

\subsection{Managing political disagreement on social media}

It was evident from discussions in the focus groups that participants did come across a significant amount of political content they did not agree with in the course of browsing Facebook and Twitter. This section explores their reaction to disagreeable political content, and whether participants took steps to actively reduce the visibility of the content.

It is important to note at the outset of this section that some participants mentioned that the small amount of disagreeable political content they saw posted on Facebook did 
not annoy them sufficiently for them to take any action. However, the rest of this section largely explores where the political content is disagreeable enough to take action over.

\subsubsection{Assessing the situation}

The first step in reacting to disagreeable political content for many participants was assessing the situation, thinking through the source of the disagreement, how close they are to the person, and whether the material is actively offensive. For instance, Lucy (18) said: "I tend to just scroll past or ignore it unless it's something that's really offensive in particular”.

Some participants highlighted the importance of identifying the source of disagreement before investing time in engaging in an argument or discussion. For example, Alice (20) noted that: "If I think their post comes from a position of (maybe) misinformation, I'll try to figure out why they think that...”. She also said another factor in deciding whether to engage in a discussion was how close they were with the offending actor: "It depends how close the friend is! If it's something they're really passionate about, I don't engage, because it'll just make me angry, and I'm unlikely to change their mind”.

Others mentioned that they assessed whether engaging with the person in question was going to achieve anything. Jessica (23) noted that the people who ended up getting hidden or blocked were "usually people who have in past come onto my posts to argue with me + I can't really talk to because they just don't get it” or people she had reason to believe had opposite views to her. She also differentiated "between people who have something to share, a new way of looking at things, from people who don't have anything constructive to contribute". Alice also noted that "If a stranger is trying to engage on Twitter, I'll always look at their feed before replying. If they seem very set in their ways, I'll ignore (or block)”.

\subsubsection{Trying to understand opposing views}

Many participants emphasised the importance of understanding different political views when they came into contact with them, choosing to keep an open mind rather than taking steps to alter the visibility of the content. For example, Hannah (19) commented that she tries to: "Understand their point of view first. I like to try to understand things I don't understand.” Leo (21) said that he when he saw political content he did not agree 
with, he normally whispers "what a dumbass" under his breath, and scrolls on. However he also said: "I usually try to see where they're coming from before I dismiss it.” Molly (18) said: “I wouldn't defriend or unfollow as I still find it interesting to read their opinion.. even if it is totally opposite to what I think”. Lucas (17) argued:

People are sharing different perspectives for a more well-rounded view, it would be wrong to block off one half of the whole country and if you learn something from what someone posts then it is a good thing definitely

A small number of participants even actively engaged with people with different views in a private way. For instance, Holly (18) said she liked:

...to have discussions with people on private messages. I just like to ask them why they think these views. A lot of the time they are just copying their parents

Another reason why some participants did not limit the visibility of political content they disagreed with on social media was that they thought people should be free to say what they wanted. Holly said she was "all for freedom of speech ... As long as there are no threats”. Samuel (19) thought people could "say what they want ... it's Facebook”. Finally, Esther (20) said: "Most of the time I leave my friends' posts, people are entitled to their opinions and what not”.

\subsubsection{Ignoring content instead of engaging}

Participants highlighted that simply ignoring disagreeable political content was also an option. Rather than actively limiting the visibility of political content they did not like, they had the option of simply not looking at it and scrolling past. For example, Max (17) said: "I just zone out and learn not read their posts”. Esther (20) said she had learnt to "quickly scroll past those friends of mine who were prone to ranting”. Isaac (24) said that he ignored conflictual political content, noting "that is influenced by working in the public sector”.

For some participants, the appropriate response depended on the severity of the disagreement they had with the piece of political content they disagreed with. For political postings they simply disagreed with, most either ignored it or read it without responding. Kate (23): “If it's not oppressive, I just disagree, then usually just ignore.”

Maggie (20) either pretended not to see the content in question, or said she would try and engage in an a discussion to try and get them to see her side of the argument. 
Withholding their attention was not so much a form of sanction, but more along the lines of “'I can't be bothered' rather than I'm deliberately withholding this from you”, in Brooke's (23) words.

\subsubsection{Political content was not worth engaging with}

Many participants chose not to engage with political content, rather than getting drawn into an unproductive and potentially unpleasant conversation. A number of participants highlighted the danger that if they engaged, they would also simply offend people. Lucas (17) said he generally does not engage in political content: "I don't think its worth [engaging] unless I have a point I feel very confident about that won't offend”. Esther (20) commented subsequently that "it's pretty difficult to say something that someone doesn't find offensive”.

Other participants highlighted that the nastiness of political discussions on social media meant they chose to not engage. Fore instance, Laura (22) said she tends not to comment on political content she disagrees with now:

I might have in the past, but its not worth getting into arguments on Facebook where because it's in a public forum, and [with] the like button etc it can get quite nasty, especially if your view is not mainstream

Jessica (23) noted that she mainly chooses not to get involved, especially on Facebook:

A lot of the time it's issues I really, really care about - and "debating" with someone is draining, and often times personally upsetting. I don't think it's worth it in the end and I'm at a stage now where I let it go.

Though! When I see my friends saying something, I try to support them. Because I know who hard it is to speak out

Brooke (23) similarly said she picked her fights on social media when it came to politics. That was not because she got worn out, but was rather because: "I just get annoyed and frustrated and then have a rant to someone else about it that agrees with me”. Sometimes participants felt compelled to engage even when they knew it would not accomplish anything. Brooke also noted that:

I honestly tend to avoid things if I don't agree with them - however, if it's something that is related to something I'm really passionate about, like violence against women, then I'll ... put forward my views on things in the hope that they'll consider things from both sides of the argument 
She later said that she had criticised a person on social media for posting something that was really triggering for victims/survivors of sexual violence. I had a go, but knew that it would go nowhere ... I replied because I felt I had to, I had a duty to. But at the same time, people that post that kind of stuff without thinking, or because that's their worldview or socialisation, I feel like there's nothing I can do to change their views

In terms of the effect of this hesitancy to engage in politics on social media, Zoe (22) thought that it might lead people to be too cautious, and "might stop people from feeling able to engage/discuss/learn more about it ... it's such a tricky thing to talk about without offending people sometimes”. Kate (23) agreed, adding that "I think the quite combative nature of a lot of these discussions means that really useful voices aren't heard sometimes”.

\subsubsection{Taking action in response to disagreeable political content}

Beyond simply ignoring the relevant material, a number of stronger responses are available to users of social media when they come into contact with disagreeable (political) content. Most of the participants had taken steps to manage the visibility of political content they disagreed with or found offensive.

A significant reason why participants chose to take action in response to disagreeable political content was to increase the enjoyability of using the platforms. They were understandably interested in reducing the amount of annoying or offensive content they came across on social media. For instance, Jessica (23) felt well within her rights to manage the visibility of disagreeable political content: "as a private citizen, I don't have to respect their free speech, and if I manage the space, I think it's fine for me to delete their comment." Kate (23) commented that if people were "not adding anything to my life”, and being actively annoying, she was happy to unfriend them. Maggie (20) said she had “... deleted a couple of political rants and at the time tried to decrease the amount of crap my friends posted ... so sort of unfollowed them. They don't need to know that though haha”. Brooke (23) said had unfriended some people on the basis that they what they posted did not fit the content she wanted to see on her newsfeed:

I've deleted a few people that just post radical stuff that is interesting and all but I can't be bothered seeing it - I want to see pics of my godson not their views on the 
establishment.

One respondent mentioned that during the election, someone he knew posted a message asking to be unfriended if anyone was going to vote for the governing National Party, presumably to pro-actively mitigate disagreeable political content before it appeared.

For some participants, if a Facebook friend or someone they followed on Twitter continually posted about politics in a way which was annoying, then that was enough to hide, unfollow, or defriend them. For example, Alice (20) said had not ever defriended someone on Facebook on the basis of political differences, "but if someone's posts are continually making me angry, I'll hide them”. She also said that hiding someone had the advantage that if she was interested in seeing what they were doing, she could always go to their profile when she was "in the appropriate mindset”. Kate (23) said she had taken steps to alter the visibility of both "[p]eople I agree with and people I disagree with. Both can be equally insufferable lol”.

For political postings which crossed the line into being actively offensive and problematic, stronger actions were sometimes appropriate. Zoe (22): “if it's offensive etc just try to ignore", however she also added “I would consider unfollowing/muting or whatever if it's really bad". Asked what pushed her to take action, she reported that it was “probably seeing something I disagree strongly/offended by and thinking I don't want to see this. Particularly if it's something hateful etc”.

Some participants mentioned political and social issues which were so important to them that they were non-negotiable; in other words if their friends did not agree with them on those issues, they were blocked or defriended. Brooke (23) mentioned that she had a "super conservative friend who has stayed blocked after opposing marriage equality.... was a dealbreaker for me”. Oscar (23) said he was most likely to unfriend people "for their opinions on social issues rather than political ones."

Jessica (23) commented that she did not want people who were uninformed, or who did not have facts on their side, “possibly influencing my non-politically aware friends”. Similarly, Jane (16) said she had unfriended people because of their "ignorant political criticisms”. Jessica also said sometimes people aggravated her not because they were not informed, but when they try to argue positions which are unfathomable to her. For instance, she said when people say things like "slavery wasn't that bad”, she thinks "right, there's no point going forward here”. She also argued: 
I don't have a problem with people who have other points of view to share... it's just when they're factually wrong, they're arguing from a position of privilege, and there is no light at the end of this tunnel.

Similarly, Brooke said she finds people who posts things she does not agree with are either uninformed, or "they're just beyond help haha".

Other participants, however, said they avoided unfriending anyone as they wanted to avoid people getting upset if they realised. Connor (19) said he rarely unfriended people, and used the unfollow function on Facebook much more. However, Ella (18) expressed doubts at to the usefulness of the unfollow function, as they noted that their friends on Facebook had an expectation that she would keep up with what they posted:

It's kind of like if you're friends on Facebook you're expected to follow every detail of their lives ... So I don't know if unfollowing is really a viable alternative cause there's always the 'didn't you see my status????' thing

Some participants reported that they mostly terminated their virtual relationships on Twitter rather than Facebook, because they generally did not know the people on Twitter offline. For example, Ella also said users of Twitter are freer "to unfollow people you dislike on there that you know in real life and not have too many repercussions, but unfriending someone on Facebook is a big deal for some reason”.

A small number of participants also noted they sometimes refrained from limiting the visibility of disagreeable content for its comedic value. For instance, Brooke noted that while has deleted some people for their political views, she likes to stay friends or still follow some people because "reading the comments that others post are just hilarious".

Now that we have explored the ways in which participants altered the visibility of disagreeable political content, we turn to exploring how disagreements are strong enough that participants felt the need to complain about other people's behaviour.

\subsubsection{Complaints about political behaviour}

\section{a) Direct, public forms of complaint}

Most participants were cautious about direct, public forms of complaint. Complaining in this way was generally reserved for offensive or problematic political content, or where someone had posted something which was uninformed or obviously wrong.

Some of the participants commented that they "corrected" people rather than 
“complained” about their political postings. Lucy (18) said she had "corrected people, but never complained about it." She went on to say: "If someone's really blatantly wrong about something (often in feminism discussions), I'll try and explain things... Sometimes...”. Ella (18) noted that: "Honestly it depends how close we are but usually I'll try call them out if their opinions are misinformed or prejudiced etc.” Many participants said - or implied - that replying publicly to problematic political content was nerve racking. For instance, Kate said (23): "if [the content is] something really problematic and shit, I might DM/message them to be like "not cool". Or reply publicly if I have the spoons.”

Some participants considered that complaining about others' behaviour on social media when it came to politics was quite significant in terms of shaping people's future behaviour. Isaac (24) commented that he definitely thought "there's a certain amount of self regulation, especially through naming and shaming.” Maggie (20) said she thought complaint "shows people what is and is not acceptable, especially if something gets really out of control and gets reported”.

\section{b) Indirect, public forms of complaint}

'Subtweeting' - short for subliminal tweeting - is a relatively new phenomenon, and is the practice of complaining about other people's behaviour without directly addressing your complaint at them. Boyd $(2014,69)$ notes that subtweeting is a way for young people to 'encode content' to make it difficult to understand from an outsider's perspective. ${ }^{13}$ I was interested in exploring subtweeting as a mechanism by which indirectly enforce norms of political discussion, and also come to understand what was acceptable. ${ }^{14}$ Participants' general impression was that subtweeting was relatively uncommon when it came to complaining about politics online.

Most participants considered subtweeting to be an annoying practice. For instance, Oscar (23) thought that:

subtweeting is more irritating and annoying than the actual thing that is 'not okay' to post ... subtweeting is more passive-aggressive and perpetuates that kind of

13 While any behaviour could be complained about through subtweeting, in my experience most subtweets are aimed at others' behaviour on social media.

14 Some participants were not familiar with the term, but once it was explained they understood the concept and were often familiar with the phenomenon. 
behaviour rather than stops it

Subtweeting was also considered by many participants to be rude. Ella (18) considered subtweeting to be “rude as hell ... and irritating”. Emma (20) similarly commented: “oh god that's so petty ... pull up your socks and go back to class you 12 year old.” Other participants were also dismissive of indirect forms of complaint. Lucy (18) thought that: "People just need to own up to their opinions and shit in general."

A number of participants also considered that it was unfair to complain about people's practices indirectly without giving them a chance to respond. For instance, Leo (21) thought that: "if you're going to call someone out, do it so they've got the opportunity to respond. But I can appreciate that some people aren't as confrontational”.

Indirect complaining also meant that most participants did not consider it to be particularly effective at shaping what people thought was acceptable in terms of politics on social media. Lucy: "Unless you're engaging the person directly, I don't think it makes much of a difference”. Similarly Holly (18) said: complaint has "gotta be direct not indirect otherwise no one gets it”. In contrast, however, some participants did consider that subtweeting and indirect forms of complaint did shape what was acceptable. For instance, Kate (23) argued that "subtweeting is a big way people try to steer the direction of what is acceptable imo [in my opinion]”.

In terms of more general forms of indirect, public forms of complaint, Holly said she had indirectly articulated her "annoyance at people's political ignorance”.

\section{c) Private forms of complaint}

Private forms of complaint about political content on Facebook and Twitter were much more common than public complaints. Participants engaged in two forms of private complaint: direct and indirect.

The first, less common, form was private complaints directly to the person who they were annoyed at, or were offended by. Participants usually had to feel quite strongly about the content in question in order to complain in this way, however. Alice (20) said she quite often "private message[s] my Dad summaries of studies and stuff if he posts something I think it a bit politically ignorant”. Laura (22) noted that she had complained to her Dad after he posted a substantial amount of pro-Palestine material: “...I know it offends people and have suggested he could tone it down”. Jessica (23) said she had both complained about political content privately, but directly, to like-minded friends, as 
well as receiving complaints.

A common reason for complaint about other people posting about politics was for their perceived ignorance. Ella (18) said she had complained privately "only cause they were ridiculously misinformed”. Another frequent reason for complaints was when people posted too often about politics on social media. For instance, Max (17) said he had complained before, "mostly to say I have seen them post way too much”. Similarly, Brooke (23) noted she had "complained to my ex about the stuff he was posting ... But his was CONSTANT".

The more common private form of complaint, however, was participants who said they had complained about - or discussed - annoying political behaviour on social media with others who were not involved in the online conversation. Generally those who had privately complained had done so offline and to friends, flatmates, partners and family.

Participants offered a number of reasons why they had chosen not to complain directly. Emma (20) said that when she had complained, it was "always in private. It'd be rude to rip them to shreds and hang them out to dry for everyone to see”. Participants in the first group explained that their reluctance to publicly complain about people's political postings did not stem mainly from awkwardness, but simply from the belief that complaining online was unnecessary:

Oscar (23)

I think it's not worth the trouble to call people out on their posts, and it might seem like it's the opinion I'm disagreeing with when that might not be the case. Oliver (23)

Yes, it's often not worth complaining about but also that I just don't want to be involved in an online argument

Freya (21)

Na I just don't want to get myself caught up in something that is easier to scroll past \& ignore

Some participants expressed a feeling of embarrassment about the way in which they had complained, suggesting that it was somewhat uncomfortable to admit that they complained about others in private. In reference to their private complaints, Emma (20) said "I’m a bitch ... probably”, and Ella (18) said: "Guilty :I”.

Finally, some participants felt that people should only complain offline. For 
instance, Ella argued: “I get that maybe you need to vent, but don't do that online”.

\section{d) Effects of complaints}

Participants generally considered that complaints - both direct and indirect - about political content on social media was a way in which people come to understood what was acceptable to post. Jack (23) argued that Facebook and Twitter were "selfmoderating” platforms "to a degree”. Jane (16) thought that complaints did "make a difference because nobody wants to post something and be hated on by everyone”. In terms of how people come to understand what is acceptable, Lucy (18) commented “They see other people get shit for posting something, and then don't post those things." One effect of complaints, Max (17) suggested, was that they may "help to weed out the people that know very little about what they are talking about”. More generally, Zoe (22) highlighted that complaints about politics on social media might shape behaviour “a bit” by “reinforcing the caution thing”.

Some participants highlighted that there were always going to be people that disregarded generally held views about what was acceptable to post. For example, Freya (21) commented that complaints about other people's behaviour could only go so far in encouraging people to act a certain way; whether complaints were successful "depends on if you care or not that you might rub someone up the wrong way with your political opinion”.

Now that I have explore how participants manage political disagreement on social media, I will move on to the final section of this chapter, which explores the challenges women face in discussing feminism on social media.

\subsection{Women, feminism and social media}

Some women participants found the intersection between gender, feminism and political discussions particularly challenging when it came to social media. That is, they found that women face particular challenges when it comes to talking about feminist issues on social media.

The third focus group was a small, women-only group of three participants, and brought up the topic of their own accord. Alice (20) noted that she had "seen a lot of tweets about awful replies to feminism (the stuff Anita Sarkeesian's been dealing with specifically, lately)”. Jessica (23) commented that: 
With strangers on Twitter, I find this weird thing where they will find my feminism posts and insist on telling me how wrong I am, or add in something completely unrelated [...] It's always the feminism posts, nothing else political

Alice concurred, pointing out that: "Every terrible tweet I've ever received on Twitter was an inarticulate response to something I've said about feminism”. Brooke (23) also noted that criticism on social media was often gendered:

As a feminist, and a rather vocal one at that, I feel that men, particularly men in positions of privilege, are always discounting my experience as a woman and telling me that gender inequality isn't an issue, also like neither is abortion still being a criminal act - that last one, phwoar that riles me up

While social media presented challenges to feminists from outside the community, social media could also be a powerful and supportive tool for feminist communities. Jessica noted that the "plus side of Twitter is that there are so many active feminists and it's great to see their posts and the links they share”. Participants in the third group also found that the feminist community online formed a valuable supportive network, which made them feel less alone in their feminist activism. Jessica commented that social media

helps you feel less alone. When you talk about things like discrimination, sometimes it can feel rather isolating, and finding other people who /get it/ is really touching and liberating.

Alice agreed, noting that "It's really nice to find people who agree with me on issues I think are important, and encouraging to see their tweets”. Jessica further elaborated that:

I think the more [of a] minority you get, the more important it is. A lot of people care about the large umbrella of feminism. But start talking, queer, WOC [women of colour], transgender - all at once - and it means more to find someone on your wavelength.

Finally Alice responded:

... I think feminism is so broad that it's easy to class it all under that umbrella, and you'd be nearly correct, but the smaller the minority, the more comforting it is to find someone who agrees

Having explored the results of this research project, I will now move to the discussion, which will relate the results to existing research, explore the limitations of this research, and finally suggest avenues for future research. 


\section{Chapter 5: Discussion}

\subsection{Introduction}

In this section, I will briefly summarise the results of my research in relation to my main research question, before moving on to discussion on the sub-research questions in more detail. I conclude with an exploration of the limitations of this thesis, and also avenues for further research.

Most of the participants had experienced substantial amounts of politics on Facebook and Twitter, but were quite varied on whether they had ever posted about politics. Participants were positive about politics on social media, viewing politics on social media as a powerful educational tool, but they had quite strong views on the way in which people posted about - and engaged with - politics on the platforms. Mostly in line with existing research, participants considered political talk on social media as more acceptable if it was well-informed, civil, and expressed in a coherent way. In valuing these qualities, these norms in operation on Facebook and Twitter are very consistent with the deliberative normative model of political talk.

The findings of this research are largely consistent with established findings of the existing literature, which indicate that young people have concerns about political discussion on Facebook, and if they do engage with politics on social media at all, go about sharing their political views at in a self-conscious and careful way as a result (Thorson, Vraga, and Kligler-Vilenchik 2014; Van Wyngarden 2012). Young people are, however, positive about the way in which social media provides information about politics (Thorson, Vraga, and Kligler-Vilenchik 2014; Gustafsson 2012).

\subsection{Norms on social media}

Before moving on to an examination of the results about social norms and political talk on social media and how they relate to the literature, it is necessary to address the applicability of social norms to social media contexts in light of this research's findings.

Participants reported that they were very aware that different groups on social media had different ideas of what was socially acceptable. While participants were sometimes offended by material which they saw on Facebook or Twitter, they were cognizant that the group context in which the comment was made was important. In some ways, this 
awareness of group context meant that participants realised that when people posted offensive things, they were not necessarily aiming to be inflammatory.

As I have explored earlier, studying norms on social media presents some conceptual challenges. One difficulty is that norms are normally thought about in reference to distinct groups, yet on social media groups are encountered together (Hooper and Kalidas 2012). Moreover, each person's social media experience is different, because users create so-called 'egocentric publics' when they curate their friends and those they follow on social media (Thorson 2014).

The findings of this research suggest that there are many virtual norm communities which exist on Facebook and Twitter. The existence of so many groups with different ideas of what was acceptable, which come into contact with each other, means the potential for awkwardness and conflict is quite high. Participants were aware, however, that the political - and other - content they saw as offensive may have escaped a context in which it would be more appropriate. These results are consistent with research which indicates that there are norms of political talk on social media, even if it cannot be said that there are clear groups (Thorson, Vraga, and Kligler-Vilenchik 2014).

\subsubsection{Types of posts which were viewed as acceptable}

The social norms of talking about politics involve a number of different dimensions.

This section will explore findings related to the acceptability of humour, persuasion, and neutrality on social media.

Humour has a number of expressive functions in political discussions (Graham 2010), and posting political content with a humorous slant has been established in previous studies as a way young people can increase the acceptability of their political messages (Thorson, Vraga, and Kligler-Vilenchik 2014; Thorson 2014). Participants were asked in the focus groups about the extent to which humour was a useful tactic to make political content more acceptable for their audience. They were familiar with political humour on social media, and generally reported that while mixing humour and politics could be useful in engaging people and making the content more lively, it could be a double-edged sword. Some participants thought that mixing humour and politics could result in the use of humour where it did not belong, in the process reducing the seriousness of topics which deserves to be taken seriously. Other participants noted that humour could also be used in unproductive ways to make fun of the already 
marginalised, and could simply fail to be funny.

The ambivalent attitude towards humour amongst participants is somewhat inconsistent with earlier findings (Thorson, Vraga, and Kligler-Vilenchik 2014). The question arises as to why political humour is perceived in New Zealand to be less acceptable than in other countries. It may be that New Zealand does not have a very well developed culture and sense of political humour and satire, and this flows on to young people's sense of the acceptability of political humour. Participants noted one somewhat significant stumbling block for humour was that at a basic level it could fail to be funny. Put another way, if New Zealand were to have substantially more effective and funny satire of politics, people may come to accept political humour more on social media platforms. ${ }^{15}$

Participants also had mixed feelings about the appropriateness of people engaged in political persuasion on Facebook and Twitter. Most participants thought that persuasion was acceptable, as long as people went about it with a relatively open mind. A small number of participants were, however, strongly opposed to persuasion, seeing it as inappropriate to try and convince someone to come around to your political position. In one participant's view, persuasion amounted to "forcing your ideas on somebody”.

Previous studies have had somewhat mixed results in terms of the social acceptability of persuasion, with some studies finding in offline contexts that persuasion was mostly not acceptable (Conover, Searing, and Crewe 2002), while studies which explore persuasion on social media finding that people were either mixed on the appropriateness of political persuasion (Van Wyngarden 2012), or that only some forms of persuasion were acceptable (Vitak et al. 2011). Therefore the results of this study in reference to persuasion on social media are broadly consistent with earlier findings.

Most participants felt that neutrality was not helpful when it came to political discussions. While participants were not positive about overly pushy behaviour on social media, participants were not dismissive of people expressing their opinions. They thought that if posts were neutral they did not have much value; in other words, the

15 An example of New Zealanders' attitude towards political humour was the reception of the Civilian Party in the 2014 election. The Civilian Party is a joke political party affiliated with a satirical New Zealand news website, and was criticised in the run up to the election for receiving money from the New Zealand Electoral Commission to produce advertising and promote itself. The Civilian Party was dismissed as a stunt and criticised for mixing humour with the serious business of politics. 
component of political posts they found interesting was generally the opinion. This finding is inconsistent with Thorson, Vraga, and Kligler-Vilenchik's $(2014,81)$ finding that for many young people "polite political neutrality is the only correct political orientation on Facebook.”

\subsubsection{The way social norms shaped behaviour before posting on social media}

Participants generally considered the acceptability of posting about politics before they posted anything. For some participants, however, they were not more cautious in thinking about the acceptability of politics than thinking about the acceptability of other topics and how they would be received. This finding that, for some people, politics is not an especially difficult topic of conversation is contrary to expectations and established findings. Overall, however, the finding that most people take particular care with posting politics on social media is consistent with earlier findings (e.g. Thorson 2014).

Another aspect of norms shaping people's behaviour relates to which groups of people users of social media imagine as their audience. Participants in most instances considered the likely audience of their posts before they posted anything political on social media. Although it varied from person to person, participants thought about how their family, workmates, employers, and friends with different political views would react to their engagement with politics on social media. These findings are consistent with earlier research which examines the imagined audiences involved in more general social media use (Hooper and Kalidas 2012).

\subsubsection{Political knowledge, competence and political discussions}

\section{a) The educational benefits of politics on social media}

Participants were almost uniformly positive about the educational impacts of social media. They showed a surprisingly little amount of cynicism about social media's potential for education young people and engaging them in politics. These educational benefits of politics on social media are consistent with Gustafsson's (2012) findings that his participants - even those not particularly interested in politics - valued the political information which they saw on Facebook. The results are also consistent with Thorson, Vraga, and Kligler-Vilenchik (2014) findings that Facebook was a useful source of 
information.

Participants also believed, however, that the educational benefits of politics on social media were somewhat limited, and that for people to really become better-informed citizens they needed to do more than just reading news articles in their Facebook or Twitter feeds. Participants repeatedly highlighted the importance of digging deeper into political issues, keeping in mind any potential bias both in the social media posts and in the media coverage, and also thinking about the different sides to any debate. The belief among participants that the educational effects of social media were limited by people still needing to be interested enough to engage, and also needing the skills and knowledge to interpret new information, is also consistent with earlier findings. As Nisbet and Scheufele $(2004,879)$ note, the "availability of information does not necessarily lead to its use”, and people still need the personal resources and motivation to take advantage of these new opportunities.

A small number of participants also highlighted the danger for politics on social media to lead to narrowed perceptions. They thought that the way social media operates, people could get trapped simply seeing viewpoints which were already similar to their own. For instance, some participants commented that the postings they saw around the election led them to believe that left-wing parties would perform much better than they did. The views of these participants was in contrast to others in the focus groups who valued the way social media led to their exposure to different political views online. The literature on this topic, mainly in the democratic deliberation field, similarly has reached somewhat mixed conclusions, highlighting the possibility of politics on social social media both leading to insular communities, but also potentially exposure to different viewpoints (e.g. Albrecht 2006; Wojcieszak and Mutz 2009).

\section{b) Earning the right to participate in political discussion through political knowledge and competence}

In some of the focus groups, there was a sense that being informed had to come before expressing an opinion. One of the worst things which someone could do was to express a political opinion without having a good level of knowledge about the things they were talking about. In some ways, political discussion was a practice engaged in by a visible but exclusive club, where membership involves knowing a certain amount about politics. 
Related to participants' dislike of those who were uninformed about politics was their belief that some people had very superficial political beliefs. A couple of participants noted that they sometimes pushed their friends to explain their views, which often resulted in friends being unable to explain themselves. Participants also reported that they were quite likely to intervene in - or complain about - political discussions if someone was talking about politics in a way which was obviously ill-informed or incorrect. A related perception was that some people were very susceptible to persuasion because they did not really have any firm political beliefs of their own. Participants were somewhat concerned that these people ran the risk of being manipulated into voting a certain way, with worrying effects for the quality of democratic processes. This dislike of uninformed people voicing political opinions on social media is consistent with earlier findings (Thorson, Vraga, and Kligler-Vilenchik 2014).

These findings about the desirability of being informed are strongly related to conceptions of what it means to be a good citizen. Thorson $(2012,81)$ notes that: "Historically, news media have narrowly portrayed civic obligation in terms of “informed citizenship” and other passive modes of engagement”, while other more "alternative" forms of political action were viewed with suspicion.

This social norm surrounding the necessity of being informed seems to act as a barrier to more participation. Some participants mentioned that they were wary of engaging in political discussions because they did not know enough, and might be called out by their peers on social media for their ignorance if they were to voice an opinion. This is consistent with earlier findings that lacking confidence (Diesing 2013), and not feeling competent (Conover, Searing, and Crewe 2002), are significant barriers in people’s decision to participate in political conversations.

It is somewhat contradictory that on the one hand participants see Facebook and Twitter as a valuable tool for educating people about politics, while on the other they dislike uninformed people from voicing opinions. Participants were effectively saying that while political discussions on Facebook and Twitter could play an educational role, people had to be educated to a certain level before they participated in politics on social media in the first place. Therefore, political discussions on Facebook and Twitter could only play a limited role in educating and informing people about political issues, if they excluded a large number of people to begin with.

While higher level of knowledge might improve the quality political discussions, the 
impact of this norm regarding political knowledge and conversation might be producing counter-productive outcomes from a societal perspective. Discussing politics has been causally linked to higher levels of political knowledge (Eveland and Thomson 2006). Therefore even if one starts from a position of not knowing much about the politics, discussing politics is probably an effective way of learning more.

The findings of this research complicate Vitak et al's (2011) suggestion that Facebook could be a forum for experimenting with political views: Facebook and Twitter seem only to be forums for experimentation for those who are already somewhat knowledgeable about politics and who feel competent enough to participate on the platforms.

This issue of whether people are excluded from participating in politics on the basis that they are not knowledgeable enough is important because it relates to one the fundamental characteristics - and necessary preconditions - for democratic deliberation: the need for substantive equality among participants (see Conover, Searing, and Crewe 2002). If young people are unable to participate in political discussions on an event footing then than poses a serious challenge to the worth of the deliberation in question.

Before moving on, it is worth considering the possible link between participants antipathy to uninformed opinions and class dynamics. In other words, shutting out people who are not informed might be having a disproportionate impact on lesseducated, more socio-economically deprived people. By restricting, through the enforcement of social norms, those who should talk about politics to only those with political knowledge - by proxy higher educated people - the norm might shut out lower socio-economic groups from the discussion. The intention of encouraging only those informed to participate in political discussion may not be classist, but the effect of excluding many uneducated people from politics may well be.

Having explored the relationship between political knowledge, competence, and political discussions, I will now move on to a discussion of the way in which the norms of political talk are determined on social media.

\subsection{The way in which appropriate behaviour is determined}

I will now move to exploring my third research question, which explores how the social norms of politics on social media come to be understood.

Some participants considered that feedback mechanisms on social media (such as 
likes, favourites, and the number of comments users receive) was a way of determining what was acceptable in terms of politics. A few of the participants who posted about politics, however, said that they did not pay much attention to these feedback mechanisms, and that even if they were to receive no positive feedback they would continue to post about politics. These results are broadly consistent with Thorson's (2014) findings that many of her participants used reactions to their posts to guide their behaviour. She notes that her participants were reluctant to admit that they paid attention to the reception of their posts, and it may be that I did not question my participants directly enough to get an accurate sense of their practices in this respect.

\subsubsection{Political disagreement on social media}

Almost all participants mentioned that they had witnessed political discussions turn into heated disagreements, which they often found uncomfortable. One participant in the post-focus group Facebook group provided an example of such a fraught exchange (see Appendix Three).

Before moving to an analysis of the way in which participants managed the visibility of disagreeable content, it is worth emphasising that participants articulated a strong belief in free speech when it came to politics on Facebook and Twitter. While participants did believe that people were free to say more or less whatever they wanted on the platforms, they did identify some limits to free speech. Participants thought that social media users had a responsibility to at least listen to other perspectives, and try not to be offensive. Participants also sometimes criticised other's social media behaviour when they did not like it, or when it strayed into problematic territory. This research's results in this area are broadly consistent with Van Wyngarden's (2012) research that young people hold relatively permissive attitudes towards politics on social media..

\section{a) Managing visibility of disagreeable political content}

The general view among participants was that they were well within their rights to manage the visibility of content on social media. So if they encountered political content on Facebook or Twitter which they disagreed with, while they could simply ignore it, many used the tools at their disposal to hide the content, unfollow the person in question, or even defriend them. Participants were understandably interested in reducing the amount of annoying or offensive content they came across, and the principle factor 
which got in the way of this cathartic pruning was the desire to avoid offending people. These results are broadly consistent with McLaugh and Vitak's (2012) findings regarding non-political social media use.

Participants did consider that there were some differences between the platforms in this regard. Twitter was seen as a place better suited to encountering different political views. Whereas on Facebook, while some people make a point of trying to understand opposing political views, the default option usually seemed to be to just ignore the political content, or perhaps even hide it or unfollow the person involved.

There were two reasons why people sometimes did not take action to reduce the visibility of disagreeable political content. One reason was that some participants valued encountering differences of political opinion on social media, even if they did not want to actually engage in discussions. A small number of participants enjoyed encountering discussions on social media where intense differences of political opinion were unfolding, finding it to be entertaining and humorous. This result is in consistent with the findings of Conover, Searing, and Crewe (2002). The second reason that some participants mentioned was that they felt a social obligation to monitor what their Facebook friends were doing and posting. A compromise in this situation was choosing to unfollow them, which provided a way to avoid awkwardness and still keep up with what the person posted when they felt like it.

It is interesting to note that some of these tools participants used to manage the visibility of disagreeable content - such as the ability to unfollow someone on Facebook - are relatively new, and might reflect the meeting of demand for more options to deal with uncomfortable behaviour online.

\section{b) The process by which norms of politics online are enforced}

Most people who had seen political content had found at least some of it annoying, and participants frequently reported that they had complained about their friends posting annoying content. Interestingly, participants said that they almost exclusively complained about other people's behaviour offline. This can be largely attributed to the fact that they found that complaining about other people's political postings online was too confrontational. For controversial political topics, respondents either ignored the content, or if it was actively offensive or oppressive, they sometimes took the time to let the poster know through private means, either online or offline. 
Eliasoph $(1998,12)$ notes that more than just being nice to each other, good friends have a role in helping us to become better people. This raises an interesting question in regards to the themes of this thesis: does this role of friendship stretch to good friends letting others know that their behaviour is annoying on social media?

Existing research has not addressed in much detail the process by which social norms are created and enforced for behaviour on Facebook and Twitter. As far as I am aware, no research has been done which explores the way in which the norms of politics on social media are enforced. That is, how and where do people complain about behaviour on social media they do not like. Hence the finding that people primarily complain about other people's political social media practices offline or through private channels has added to the existing literature.

It has been established that enforcing norms can serve an "expressive function for groups” (Feldman 1984, 48). In other words, by enforcing norms, group members can help to establish more clearly the group's values and identity (Feldman 1984); through showing people they are on the outside of an acceptable boundary, the boundary is made clearer to all the members.

\subsection{The relationship between social media and social practices}

It has long been established that the social environment "plays a crucial role in affecting the social flow of political information” (Huckfeldt and Sprague 1987, 1198). However much less is known about the impact of socio-technological environment of social media platforms and how it affects political talk (Thorson, Vraga, and Kligler-Vilenchik 2014). I was interested in exploring the relationship between social media and social practices: how do the affordances of Facebook and Twitter affect the way young people act in terms of politics and social media?

While participants were positive about politics on social media generally, they did express a number of reservations about the impact of social media on the quality and temperament of political discussions. Many participants said that they preferred to not get involved in political discussions because they could easily spiral out of control. There was a sense that people talked past each other rather than properly engaging in reasoned debate. A small number of participants, however, did say that they had seen good discussions on social media. These findings are consistent with earlier research 
that people have reservations about social media's impacts on political discussion (e.g. Diesing 2013).

\subsubsection{The differences between Facebook and Twitter}

In this section I will explore some of the differences between the two platforms, and why participants thought that Twitter was generally viewed as a more appropriate place for political talk than Facebook.

Somewhat contrary to expectations, participants posted about - and engaged with politics on Facebook somewhat more than on Twitter. This pattern is seemingly inconsistent with participants' view that Twitter was a more acceptable place for politics than Facebook. Some of this difference in frequency with which participants posted about or engaged with politics on Facebook versus Twitter can be likely be explained by the differences in usage between the two networks. That is, because participants generally used Facebook much more intensively than Twitter, they have many more opportunities to engage with - and post about - politics. The other possible explanation is that the acceptability of political content was not the most important factor in determining whether people posted about - or engaged with - politics.

Participants expressed that a crucial factor in determining the acceptability of politics on the Facebook and Twitter respectively was in the different nature of the audiences. This stemmed in large part from people having many more connections with real-world friends, family, and workmates on Facebook than on Twitter. The offline world intruded and complicated things on Facebook, whereas Twitter was organised more according to shared interests. Therefore, the acceptability of political talk had less to do with the technological features of the respective platforms and more to do with who is going to see your political posts. In this sense that one posts messages to potential strangers, Twitter is much more public than Facebook; the latter is anchored more to users' offline social networks. ${ }^{16}$ Despite Twitter generally being more public, participants thought that because it was more anonymous and freer from the constrains of offline relationships, politics on the platform was more appropriate.

These results are consistent with earlier ethnographic research that teenagers use

16 It is important to acknowledge that while generally Twitter is more public than Facebook, there can exist a wide degree of variation in people's privacy settings and the way in which they use the platforms. For instance, some people choose to have private Twitter profiles. 
Facebook quite differently to other social media platforms, because it is the place online where different friend groups and family members gather (boyd 2014; see also Gustafsson 2012, n. 2). This difference likely stems from Facebook's explicit connection to users' offline worlds (Pasek, more, and Romer 2009). Gustafsson's (2012) participants also expressed that they found the interplay of different audiences - and the associated juggling of identities - on Facebook quite difficult and frustrating. The findings are also consistent with Diesing's (2013) research which found that many young people view Facebook as a social - not political - tool, and they want to "keep politics separated from their social life” (Diesing 2013, 72). In contrast, on Twitter people can choose who to follow, and which hashtags to engage with (Freelon 2013).

Participants viewed Twitter as less personal and more anonymous than Facebook, and this contributed to the increased acceptability of politics on the platform. This difference likely stems in part from Facebook's real name policy (Facebook 2015). This finding conforms to Suler's (2004) findings that anonymity and invisibility, among other factors, produce the 'online disinhibition effect' whereby people are less reserved and restrained when engaging online. The finding is also consistent with Freelon's (2010) suggestion that relative anonymity online means people act with less restraint than offline contexts, leading them to potentially view topics such as politics as more acceptable.

Finally, participants were relatively positive about the impacts of Twitter's 140 character limit for political talk. They suggested that space constraints meant that people could not rant easily, exchanges might stay less heated, and people were sometimes forced to link to external material to bolster their argument. If political discussions are kept relatively civil and rant free, and privilege the marshalling of evidence, then they conform to deliberational norms of political talk (Freelon 2010).

\subsection{Feminism and politics online}

As I have explored earlier, while this research did not set out to explore issues at the intersection of gender, politics, and social media, the third focus group in particular talked a substantial amount, initially unprompted, about their experiences of feminism and social media. In line with the existing literature, participants explored both the benefits and costs of engaging with feminist issues online.

One benefit of social media which the participants in the third focus group 
highlighted was the value of finding a like-minded community online. This is in line with Schuster's (2013) findings that young feminists in New Zealand turn to community-organisation online, which can be an easy and relatively safe space for discussing issues which do not 'fit in' elsewhere.

However, while participants in the third focus group valued the opportunities provided by social media, they also talked about the challenges of operating in an online environment where people were hostile towards discussions of feminism. In particular, they highlighted the way in which talking about feminist issues quite often resulted in personal and hugely offensive comments being directed at them. This result is also in line with Schuster's (2013) findings that feminists often encounter the ugly side of anonymity and the freer speech of the internet through their repeated experiences of intense criticism and even outright harassment. The result also fits into an emerging criticism of social media platforms in the media, which argues that on many platforms women face unacceptable levels of harassment and a worrying number of threats to their safety, which the companies that operate these platforms do little to address (Buni and Chemaly 2014).

Now that I have explored how my results relate to the existing literature, I will examine the limitations of my research, and some further avenues for research.

\subsection{Research limitations}

\subsubsection{Sample}

As is common with many convenience samples, there were a number of problems with some groups being over-represented, and others under-represented. As a result, any generalisations arising from this research should be made cautiously.

It is important to note that because this research was primarily interested in young people who used both Facebook and Twitter, and that these participants are not necessarily representative of young New Zealanders as a whole. As of 2013, of those aged between 18-29, approximately 92 per cent used Facebook, and 35 per cent used Twitter (Mills 2013). While figures are not available concerning how many young people use both Facebook and Twitter, it is likely to be slightly less than 35 per cent of young New Zealanders. The sample is therefore likely to be more technologically engaged than average young people in New Zealand. 
In terms of educational status, the sample largely consisted of people who were attending university (63\%), or who had attended university but were now working (19\%), with the remainder studying at high school (19\%). Those who were attending or had attended Victoria University of Wellington were also over-represented. Evidently, the sample was therefore over-represented by people with high levels of education, with no participants who had gone straight to employment without studying at university.

This research's over-reliance on tertiary education students is consistent with longstanding practice in the social sciences of using tertiary education students in convenience samples. Associated with this use, however, has been a methodological debate about whether students are similar to non-student populations, and hence over the generalisability of student-based research's findings (Peterson 2001). It is hence best practice to either include non-students in research to begin with, or replicate research with non-students prior to attempting to generalise findings to broader populations (Peterson 2001).

Finally, two other limitations in the sample are worth commenting on. First, the over-representation of participants from Wellington may have also skewed the results somewhat. Wellington is generally seen as a very political place and that may have changed the way participants thought about politics and hence the findings I have reached. Secondly, the number of participants reporting that their friends on social media were opposed to the National Party suggests that the sample is relatively leftleaning ideologically.

\subsubsection{Context}

\section{a) The election period}

The fact that the research was conducted in a general election period is another factor to consider. Previous studies have found that people understandably encounter more political content, and talk more about politics, around elections (Diesing 2013). In terms of the effects on the acceptability of politics, elections make politics unusually visible, which might make people more annoyed with political content. Vraga et al. (2015) chose to conduct their study during an election period because they were interested in gauging opinions about politics during a period of intense exposure. Vraga et al. (2015, 288) further note respondents might have felt: 
very differently about the appropriateness of political content being shared via Facebook and its potential to produce negativity during a period when passions are running less high and the competition between parties is not so intense.

Alternatively, the election may have meant that participants were more accepting of politics on social media because they wanted to learn more about the election. While the direction of the impact is not entirely clear, it seems clear that conducting this research during the 2014 election period must have had some effect on way participants felt about politics on social media.

\section{b) The impact of changing technology}

As I have explored, the design and features of social media can have an impact on users behaviour. It is also important to note that the technological features of Facebook and Twitter are constantly undergoing a process of change. These changes create a potential barrier to applying the findings of research such as this to other time periods, because norms about the acceptability of behaviour likely shift as features change (Thorson 2014). This is a challenge scholars studying the internet have faced for many years, as they struggle to gain "an ontological footing within rapidly obsolescing technologies” (Wilson and Peterson 2002, 451).

Changes in the features of social media platforms might also equip users to manage more effectively the content they come across. For instance, the ability to unfollow people on Facebook while still remaining friends with them, and to decrease or increase the amount of visible material about or by a particular person, are relatively new features on Facebook, which may have flow on effects for prevailing social norms. If it is easier to manage the visibility of disagreeable political content, then users of these

platforms might have less strong views about the appropriateness of posting the material in the first place and adopt more permissive attitudes.

\subsection{Further avenues for research}

By focussing on both Facebook and Twitter, this research has helped expanded existing research beyond its primary focus on Facebook. The comparison has also allowed deeper analysis of the relationship between social practices and the respective social media platforms, in an attempt to disentangle the extent to which practices are specific to a certain platform. Future research should also attempt to be explicitly comparative in 
terms of social media platforms.

Further research could investigate social media platforms beyond just Facebook and Twitter. Participants sometimes mentioned that they encountered interesting political discussions beyond simply Facebook and Twitter. For instance, Tumblr was mentioned as a place where activist communities could have interesting, and often in-depth discussions about political topics.

There are a couple of areas of literature which I have not explored which may be useful in further research. One area is the research which has explored the impact of the heterogeneity of networks on social media. Such heterogeneity could have quite big impacts on how people view the acceptability of political content. Theoretical insights from social cognition theory and herding behaviour theory could also be useful in advancing the exploration of the social norms of political talk on social media. These related theories seem quite relevant in suggesting that people follow the behaviour of others in determining what is socially acceptable.

While it was not the focus of this research, increasing attention is being paid to the individual level characteristics which determine whether people view political content on social media as acceptable and also post about it. Political interest and sensitivity to disagreement has been determined to be a significant factor (Vraga et al. 2015). Gustafsson (2012) found that the factor which largely determined whether people posted about politics was whether they were members of a political party or an interest organisation.

It has been established that people are more likely to talk about (Conover, Searing, and Crewe 2002) and engage with politics on social media (Vitak et al. 2011) when they consider it to be acceptable. The direction of the causal relationship, however, is not entirely clear. Does a higher perception of the social acceptability of political talk facilitate more political talk, or does engaging in political talk increase your perception of its social acceptability? The most likely relationship is that engaging in political talk, and individual's perceptions of the acceptability of political talk are mutually reinforcing.

At a methodological level, the themes and expectations in terms of exploring the social acceptability of politics are becoming clearer, and it is perhaps time to complement qualitative research methods with large-scale quantitative work. The themes are beginning to be established enough that it would be interesting to know what 
is happening on a large scale, and in more rigorous way. 


\section{Conclusion}

Through exploring the social acceptability of political content on Facebook and Twitter, this research has contributed towards a better understanding of an area which has not been well studied. Little is known about the way in which people come to understand what is acceptable to post when it comes to politics on social media, people's responses to political content they disagree with on social media, or the way in which complaints about political postings on social media shape behaviour. This research has helped to fill those gaps.

This research has been innovative in a number of areas. It has gone further than previous studies in looking not only at the norms of political discussion on social media, but also at the process by which people come to understands these norms, and what happens when people encounter disagreeable political content on social media. It has confirmed that a number of findings in offline contexts - such as the importance of being informed - are applicable to online contexts. This research has also been one of the few studies in this area to look at both Facebook and Twitter. In doing so, it has allowed a more nuanced examination of the factors which determine the social acceptability of political content online.

The other innovation, relative to the existing literature is in explicitly exploring and contrasting two social media platforms - Facebook and Twitter. Most of the existing literature focusses on just one platform (although there are some exceptions, such as Thorson (2014)), which does not enable comparisons between the platforms in terms of the acceptability of political content. Looking at both social media platforms enabled me to explore the extent to which the social acceptability of political content was an overarching factor, or whether it was dependent on the social network itself. In other words, exploring two platforms has allowed an exploration of the accordances of social media and the way in which social practices around politics interact with the technological features of the platforms in which people choose to interact.

This study is also filling the gap of non-North American and European research, by exploring whether the existing findings in the literature are consistent across international borders. The results suggest that the norms of political discussion on social media are consistent internationally.

In addition, this research has used an innovative research method within political 
science. While focus groups have been used for some of the research which has explored the social acceptability of political talk on social media, online focus groups are much less common (see however Gustafsson 2012). The real-time online focus groups were generally well received by participants, who liked the convenience of being able to participate from wherever they liked.

In addition to the novelty of the online focus groups, this research also utilised a follow-up Facebook group as a way of gathering more in-depth information about the topic. The intention was that the Facebook group would allow participants to talk more about the themes of the focus groups in an unstructured way. For instance, if participants came across political content on social media which annoyed them after the end of the focus groups, they could talk about their experience with other participants. Although this part of the method was not successful, in that it was not well used by participants, it may represent an interesting area for methodological experimentation in the future.

At a broad level, this research topic is important because we need to better understand the factors which play a part in ordinary people discussing politics. The discussion of politics - particularly among people with different views - has been viewed by democratic deliberation theorists as an integral part of a well-functioning democracy (Pattie and Johnston 2009). Without the relatively equal participation of everyday people in the political process, democracy loses its legitimacy, and it is through everyday people discussing politics that people develop ideas and viewpoints.

Political deliberation can occur wherever people gather and talk. Therefore, as people have started to socialise more online, most recently through social media platforms, scholars have turned their attention to those places and their potentially positive effects for stimulating political talk and broader political engagement (e.g. Vitak et al. 2011; Diesing 2013). Therefore it is important to understand the social norms which govern these relatively new social contexts.

Understand the ways in which people understand and enforce social norms is also important in itself. These processes of social enforcement in various aspects of our lives are frequently occurring around us, yet we seldom think about and analyse them enough to understand what is going on. By exploring implicit social rules and norms, which are not initially obvious, we can start to understand the way in which the social world operates. 
If we can understand the ways in which people find political content and discussions more acceptable, it is possible that we can design better ways of encouraging people to participate in politics. As Bicchieri $(2006,7)$ argues: "Without a better understanding of the mechanisms through which norms control our actions ... there is little hope of predicting and this influencing behavior.” The findings of this study indicate that by using particular language, or by framing and delivering content in a particular way, people will be more amenable to political messages. Put simply, if people are not annoyed by the way in which political messages are articulated, they are more likely to be receptive to their contents. Therefore this research might be of interest to nongovernmental organisations, government officials, and politicians interested in engaging with people in these new social contexts online. 



\section{References}

Albrecht, Steffen. 2006. "Whose Voice Is Heard in Online Deliberation?: A Study of Participation and Representation in Political Debates on the Internet.” Information, Communication \& Society 9 (1): 62-82. doi:10.1080/13691180500519548.

Alptraum, Lux. 2015. “Facebook’s Real Name Policy Is Still a Huge Problem.” The Verge. February 19.

https://web.archive.org/web/20150219192717/http://www.theverge.com/2015/2/19/806 9211/facebook-real-name-policy-problem-account-suspension.

Awan, Fatimah, and David Gauntlett. 2013. "Young People’s Uses and Understandings of Online Social Networks in Their Everyday Lives.” Young 21 (2): 111-32.

Baumgartner, Jody C., and Jonathan S. Morris. 2010. "MyFaceTube Politics: Social Networking Web Sites and Political Engagement of Young Adults.” Social Science Computer Review 28 (1): 24-44. doi:10.1177/0894439309334325.

Bicchieri, Cristina. 2006. The Grammar of Society: The Nature and Dynamics of Social Norms. New York: Cambridge University Press.

boyd, danah. 2007. "Viewing American Class Divisions through Facebook and MySpace." Apophenia. June 24. https://web.archive.org/web/20150213045040/http://www.danah.org/papers/essays/ClassDivisions.html.

2008. "Why Youth (Heart) Social Network Sites: The Role of Networked Publics in Teenage Social Life.” In Youth, Identity and Digital Media, edited by David Buckingham, 119-42. John D. and Catherine T. MacArthur Foundation Series on Digital Media and Learning. Cambridge, MA: The MIT Press.

http://papers.ssrn.com/abstract $=1518924$.

2014. It's Complicated: The Social Lives of Networked Teens. New Haven: Yale University Press.

Boynton, George Robert, James Cook, Kelly Daniels, Melissa Dawkins, Jory Kopish, Maria Makar, William McDavid, Margaret Murphy, John Osmundson, and Taylor Steenblock. 2013. "The Political Domain Goes to Twitter: Hashtags, Retweets and URLs." Open Journal of Political Science 4: 8.

Buni, Catherine, and Soraya Chemaly. 2014. "The Unsafety Net: How Social Media Turned Against Women.” The Atlantic. October 9.

https://web.archive.org/web/20150114004416/http://www.theatlantic.com/technology/a rchive/2014/10/the-unsafety-net-how-social-media-turned-against-women/381261/.

Burnett, Gary, and Laurie Bonnici. 2003. "Beyond the FAQ: Explicit and Implicit Norms in Usenet Newsgroups.” Library \& Information Science Research 25 (3): 333-51. doi:10.1016/S0740-8188(03)00033-1.

Burnham, Peter, Karin Gilland, Wyn Grant, and Zig Layton-Henry. 2004. Research Methods in Politics. Political Analysis. Houndmills, Basingstoke, Hampshire ; New York: Palgrave Macmillan.

Chapman, Harry, and Hilde Coffé. 2015. "Changing Facebook Profile Pictures as Part of a Campaign: Who Does It and Why?” Journal of Youth Studies. doi:10.1080/13676261.2015.1083962.

Conover, Pamela Johnston, Donald D. Searing, and Ivor M. Crewe. 2002. “The Deliberative Potential of Political Discussion.” British Journal of Political Science 32 (1): 21-62. 
Das, Sauvik, and Adam Kramer. 2013. “Self-Censorship on Facebook.” http://sauvik.me/papers.

Diesing, Juana. 2013. "Social Media: A Solution to Declining Youth Engagement in Politics?” Master's thesis, University of Otago. http://otago.ourarchive.ac.nz/handle/10523/4764.

Eliasoph, Nina. 1998. Avoiding Politics: How Americans Produce Apathy in Everyday Life. Cambridge Cultural Social Studies. Cambridge, UK ; New York, NY, USA: Cambridge University Press.

Eveland, William P., and Tiffany Thomson. 2006. "Is It Talking, Thinking, or Both? A Lagged Dependent Variable Model of Discussion Effects on Political Knowledge.” Journal of Communication 56 (3): 523-42. doi:10.1111/j.1460-2466.2006.00299.x.

Facebook. 2015. "What Names Are Allowed on Facebook?” Facebook Help Centre. Accessed February 17. https://www.facebook.com/help/112146705538576.

Feldman, Daniel C. 1984. "The Development and Enforcement of Group Norms.” Academy of Management Review 9 (1): 47-53. doi:10.5465/AMR.1984.4277934.

Fox, Fiona E., Marianne Morris, and Nichola Rumsey. 2007. "Doing Synchronous Online Focus Groups with Young People: Methodological Reflections.” Qualitative Health Research 17 (4): 539-47.

Freelon, Deen. 2010. “Analyzing Online Political Discussion Using Three Models of Democratic Communication.” New Media \& Society 12 (7): 1172-90.

doi:10.1177/1461444809357927.

2013. "Discourse Architecture, Ideology, and Democratic Norms in Online Political Discussion.” New Media \& Society, December, 1461444813513259. doi:10.1177/1461444813513259.

Gibson, Andy, Melissa Miller, Philippa Smith, Allan Bell, and Charles Crothers. 2013. "The Internet and New Zealand 2013.” World Internet Project New Zealand. Auckland, N.Z.: Institute of Culture, Discourse \& Communication, AUT University. wipnz.aut.ac.nz.

Graham, Todd. 2010. “The Use of Expressives in Online Political Talk: Impeding or Facilitating the Normative Goals of Deliberation?” In Electronic Participation, edited by Efthimios Tambouris, Ann Macintosh, and Olivier Glassey, 26-41. Lecture Notes in Computer Science 6229. Springer Berlin Heidelberg. http://link.springer.com/chapter/10.1007/978-3-642-15158-3_3.

Grinberg, Emanuella. 2014. “Facebook 'Real Name’ Policy Stirs Questions around Identity.” CNN. September 18. https://web.archive.org/web/20150219214543/http://edition.cnn.com/2014/09/16/living/facebook-name-policy/index.html.

Gustafsson, Nils. 2012. "The Subtle Nature of Facebook Politics: Swedish Social Network Site Users and Political Participation.” New Media \& Society 14 (7): 1111-27. doi:10.1177/1461444812439551.

Himelboim, Itai, Eric Gleave, and Marc Smith. 2009. "Discussion Catalysts in Online Political Discussions: Content Importers and Conversation Starters.” Journal of Computer-Mediated Communication 14 (4): 771-89.

Holpuch, Amanda. 2015. “Native American Activist to Sue Facebook over Site’s 'Real Name' Policy.” The Guardian. January 19. https://web.archive.org/web/20150219164832/http://www.theguardian.com/technology/ 2015/feb/19/native-american-activist-facebook-lawsuit-real-name.

Hooley, Tristram, John Marriott, and Jane Wellens. 2011. What Is Online Research? Using the Internet for Social Science Research. Bloomsbury Academic. http://www.blooms- 
burycollections.com/book/what-is-online-research-using-the-internet-for-social-scienceresearch/.

Hooper, Val, and Tarika Kalidas. 2012. “Acceptable and Unacceptable Behaviour on Social Networking Sites: A Study of the Behavioural Norms of Youth on Facebook.” Electronic Journal of Information Systems Evaluation 15 (3): 259-68.

Huang, Ronggui. 2014. "RQDA: R-Based Qualitative Data Analysis - R Package Version 0.27.” http://rqda.r-forge.r-project.org/.

Huckfeldt, Robert, and John Sprague. 1987. "Networks in Context: The Social Flow of Political Information.” The American Political Science Review 81 (4): 1197-1216. doi:10.2307/1962585.

Hustinx, Lesley, Lucas C.P.M. Meijs, Femida Handy, and Ram A. Cnaan. 2012. “Monitorial Citizens or Civic Omnivores? Repertoires of Civic Participation among University Students.” Youth \& Society 44 (1): 95-117.

Karpf, David. 2010. “Online Political Mobilization from the Advocacy Group’s Perspective: Looking Beyond Clicktivism.” Policy \& Internet 2 (4): 7-41.

Lapinski, Maria Knight, and Rajiv N. Rimal. 2005. “An Explication of Social Norms.” Communication Theory 15 (2): 127-47.

Larsson, Anders Olof, and Hallvard Moe. 2012. "Studying Political Microblogging: Twitter Users in the 2010 Swedish Election Campaign.” New Media \& Society 14 (5): 729-47. doi:10.1177/1461444811422894.

Liamputtong, Pranee. 2011. Focus Group Methodology: Principles and Practices. Los Angeles: SAGE.

Litt, Eden. 2012. “Knock, Knock. Who’s There? The Imagined Audience.” Journal of Broadcasting \& Electronic Media 56 (3): 330-45. doi:10.1080/08838151.2012.705195.

Litt, Eden, Erin Spottswood, Jeremy Birnholtz, Jeff Hancock, Madeline E. Smith, and Lindsay Reynolds. 2014. "Awkward Encounters of an 'Other' Kind: Collective Self-Presentation and Face Threat on Facebook."

Lunt, Peter, and Sonia Livingstone. 1996. "Rethinking the Focus Group in Media and Communications Research.” Journal of Communication 46 (2): 79-98.

Marret, Alexandra. 2010. "Participating Online: The Internet and Its Role in Political Participatory Behaviour in the Context of the New Zealand General Election 2008.” Master's thesis, Christchurch: University of Canterbury. http://ir.canterbury.ac.nz/bitstream/10092/4962/1/thesis_fulltext.pdf.

Mason, Annastasha. 2011. "Perceptions of Use: Social Networking Sites, MPs and Citizens.” Master's thesis, University of Otago. http://otago.ourarchive.ac.nz/handle/10523/1891.

McLaughlin, Caitlin, and Jessica Vitak. 2012. "Norm Evolution and Violation on Facebook." New Media \& Society 14 (2): 299-315. doi:10.1177/1461444811412712.

Mills, Stephen. 2013. "Use of Social Media in Politics by Young People in Australasia.” In Social Media and Elections in Asia-Pacific - The Growing Power of the Youth Vote, edited by Alastair Carthew and Simon Winkelmann, 13-28. Singapore: Konrad-Adenauer-Stiftung. http://www.kas.de/wf/doc/kas_35939-1522-2-30.pdf?131105090222.

Morgan, David L. 1996. “Focus Groups.” Annual Review of Sociology, 129-52. 
Nisbet, Matthew C., and Dietram A. Scheufele. 2004. "Political Talk as a Catalyst for Online Citizenship.” Journalism \& Mass Communication Quarterly 81 (4): 877-96.

O’Toole, Therese, Michael Lister, Dave Marsh, Su Jones, and Alex McDonagh. 2003. "Tuning Out or Left Out? Participation and Non-Participation Among Young People.” Contemporary Politics 9 (1): 45-61.

Park, Namsu, Kerk F. Kee, and Sebastián Valenzuela. 2009. "Being Immersed in Social Networking Environment: Facebook Groups, Uses and Gratifications, and Social Outcomes.” CyberPsychology \& Behavior 12 (6): 729-33.

Pasek, Josh, eian more, and Daniel Romer. 2009. "Realizing the Social Internet? Online Social Networking Meets Offline Civic Engagement.” Journal of Information Technology \& Politics 6 (3-4): 197-215. doi:10.1080/19331680902996403.

Pattie, C. J., and R. J. Johnston. 2009. “Conversation, Disagreement and Political Participation.” Political Behavior 31 (2): 261-85.

Peterson, Robert A. 2001. "On the Use of College Students in Social Science Research: Insights from a Second-Order Meta-analysis.” Journal of Consumer Research 28 (3): 450-61. doi:10.1086/323732.

Ross, Karen, and Tobias Bürger. 2014. "Face to Face(book) Social Media, Political Campaigning and the Unbearable Lightness of Being There.” Political Science 66 (1): 46-62. doi:10.1177/0032318714534106.

Schill, Dan, and Rita Kirk. 2014. "Issue Debates in 140 Characters: Online Talk Surrounding the 2012 Debates.” In Presidential Campaigning and Social Media: An Analysis of the 2012 Campaign, edited by John Allen Hendricks and Dan Schill, 74-93. New York: Oxford University Press.

Schuster, Julia. 2013. “Invisible Feminists? Social Media and Young Women’s Political Participation.” Political Science 65 (1): 8-24. doi:10.1177/0032318713486474.

Sleeper, Manya, Rebecca Balebako, Sauvik Das, Amber Lynn McConahy, Jason Wiese, and Lorrie Faith Cranor. 2013. “The Post That Wasn't: Exploring Self-Censorship on Facebook.” In Proceedings of the 2013 Conference on Computer Supported Cooperative Work, 793-802. ACM.

Strater, Katherine, and Heather Richter Lipford. 2008. "Strategies and Struggles with Privacy in an Online Social Networking Community." In Proceedings of the 22nd British HCI Group Annual Conference on People and Computers: Culture, Creativity, InteractionVolume 1, 111-19. British Computer Society.

Suler, John. 2004. “The Online Disinhibition Effect.” CyberPsychology \& Behavior 7 (3): 32126. doi:10.1089/1094931041291295.

Sunstein, Cass R. 1996. “Social Norms and Social Roles.” Columbia Law Review 96 (4): 903 68. doi:10.2307/1123430.

Thorson, Kjerstin. 2012. "What Does It Mean to Be a Good Citizen? Citizenship Vocabularies as Resources for Action.” The ANNALS of the American Academy of Political and Social Science 644 (1): 70-85. doi:10.1177/0002716212453264.

. 2014. "Facing an Uncertain Reception: Young Citizens and Political Interaction on Facebook.” Information, Communication \& Society 17 (2): 203-16.

Thorson, Kjerstin, Emily K Vraga, and Neta Kligler-Vilenchik. 2014. “Don’t Push Your Opinions on Me: Young Citizens and Political Etiquette on Facebook.” In Presidential Cam- 
paigning and Social Media: An Analysis of the 2012 Campaign, edited by John Allen Hendricks and Dan Schill, 74-93. New York: Oxford University Press.

Valenzuela, Sebastian, Namsu Park, and Kerk F. Kee. 2009. "Is There Social Capital in a Social Network Site?: Facebook Use and College Students’ Life Satisfaction, Trust, and Participation.” Journal of Computer-Mediated Communication 14 (4): 875-901.

Van Wyngarden, Katherine E. 2012. "New Participation, New Perspectives? Young Adults' Participation Engagement Using Facebook.” Master’s thesis, Fort Springs, Colorado: Colorado State University.

Vitak, Jessica, Paul Zube, Andrew Smock, Caleb T. Carr, Nicole Ellison, and Cliff Lampe. 2011. "It's Complicated: Facebook Users' Political Participation in the 2008 Election." Cyberpsychology, Behavior, and Social Networking 14 (3): 107-14. doi:10.1089/cyber.2009.0226.

Vraga, Emily K., Kjerstin Thorson, Neta Kligler-Vilenchik, and Emily Gee. 2015. "How Individual Sensitivities to Disagreement Shape Youth Political Expression on Facebook.” Computers in Human Behavior 45 (April): 281-89. doi:10.1016/j.chb.2014.12.025.

Warren, Mark E. 1996. "What Should We Expect from More Democracy?: Radically Democratic Responses to Politics.” Political Theory 24 (2): 241-70. doi:10.2307/192116.

Wilson, Samuel M., and Leighton C. Peterson. 2002. "The Anthropology of Online Communities.” Annual Review of Anthropology 31 (January): 449-67.

Wojcieszak, Magdalena E., and Diana C. Mutz. 2009. “Online Groups and Political Discourse: Do Online Discussion Spaces Facilitate Exposure to Political Disagreement?” Journal of Communication 59 (1): 40-56. doi:10.1111/j.1460-2466.2008.01403.x.

Wright, Scott. 2012. "From 'Third Place' to 'Third Space': Everyday Political Talk in NonPolitical Online Spaces.” Javnost - The Public 19 (3).

Young, Jennifer Marie. 2012. "Political Conversations on Facebook: An Exploration of Practices.” Master's thesis, Georgetown University. Georgetown University Institutional Repository. http://hdl.handle.net/10822/557538. 



\section{Appendix 1: Summary statistics}

\begin{tabular}{|c|c|c|c|c|c|}
\hline \multicolumn{2}{|l|}{ Variable } & \multirow{2}{*}{$\begin{array}{c}\text { Percentages } \\
37 \%\end{array}$} & \multirow[t]{2}{*}{ Range } & \multirow[t]{2}{*}{ Mean } & \multirow[t]{2}{*}{$\begin{array}{l}\text { Standard } \\
\text { Deviation }\end{array}$} \\
\hline & Male & & & & \\
\hline & Female & $63 \%$ & & & \\
\hline Age & & - & $16-24$ & 20.3 & 2.31 \\
\hline \multirow{3}{*}{ Education } & $\begin{array}{l}\text { Studying at } \\
\text { university }\end{array}$ & $63 \%$ & & & \\
\hline & $\begin{array}{l}\text { Graduated } \\
\text { university }\end{array}$ & $19 \%$ & & & \\
\hline & $\begin{array}{l}\text { Attending } \\
\text { high school }\end{array}$ & $19 \%$ & & & \\
\hline \multirow{2}{*}{ Occupation } & Working & $19 \%$ & & & \\
\hline & Studying & $81 \%$ & & & \\
\hline \multirow{4}{*}{ Interest in politics } & $\begin{array}{l}\text { Very inter- } \\
\text { ested }\end{array}$ & $26 \%$ & & & \\
\hline & $\begin{array}{l}\text { Quite inter- } \\
\text { ested }\end{array}$ & $33 \%$ & $0-3$ & 1.78 & 0.93 \\
\hline & $\begin{array}{c}\text { Somewhat in- } \\
\text { terested }\end{array}$ & $33 \%$ & & & \\
\hline & $\begin{array}{l}\text { Not at all in- } \\
\text { terested }\end{array}$ & $7 \%$ & & & \\
\hline \multirow{6}{*}{$\begin{array}{l}\text { Engagement } \\
\text { with politics } \\
\text { on } \quad \text { Twitter }\end{array}$} & High & $30 \%$ & & & \\
\hline & Mid & $33 \%$ & $0-2$ & 0.93 & 0.83 \\
\hline & Low & $37 \%$ & & & \\
\hline & High & $22 \%$ & & & \\
\hline & Mid & $19 \%$ & $0-2$ & 0.63 & 0.84 \\
\hline & Low & $59 \%$ & & & \\
\hline
\end{tabular}




\section{Appendix 2: Information about participants}

\begin{tabular}{|c|c|c|c|c|c|}
\hline \multirow{2}{*}{ Pseudonym } & \multirow{2}{*}{ Group } & \multirow{2}{*}{ Age } & \multirow{2}{*}{ Interest in politics } & \multicolumn{2}{|c|}{ Engagement with politics on } \\
\hline & & & & Facebook & Twitter \\
\hline Leo & 1 & 21 & Very interested & mid & high \\
\hline Oliver & 1 & 23 & Very interested & mid & mid \\
\hline Oscar & 1 & 23 & Somewhat interested & low & low \\
\hline Jane & 1 & 16 & Not at all interested & mid & low \\
\hline Freya & 1 & 21 & Somewhat interested & low & low \\
\hline Zoe & 2 & 22 & Very interested & mid & high \\
\hline Jade & 2 & 18 & Quite interested & low & low \\
\hline Jack & 2 & 23 & Quite interested & low & high \\
\hline Kate & 2 & 23 & Quite interested & high & high \\
\hline Jessica & 3 & 23 & Very interested & mid & high \\
\hline Alice & 3 & 20 & Not all interested & low & low \\
\hline Brooke & 3 & 23 & Quite interested & high & high \\
\hline Holly & 4 & 18 & Somewhat interested & low & low \\
\hline Max & 4 & 17 & Quite interested & low & low \\
\hline Hannah & 4 & 19 & Somewhat interested & mid & low \\
\hline Samuel & 4 & 19 & Somewhat interested & mid & low \\
\hline Emma & 5 & 20 & Somewhat interested & mid & mid \\
\hline Connor & 5 & 19 & Quite interested & high & low \\
\hline Lucy & 5 & 18 & Somewhat interested & low & low \\
\hline Liam & 5 & 22 & Somewhat interested & high & low \\
\hline Ella & 5 & 18 & Quite interested & high & mid \\
\hline Molly & 5 & 18 & Very interested & high & low \\
\hline Isaac & 6 & 24 & Quite interested & low & low \\
\hline Lucas & 6 & 17 & Very interested & high & mid \\
\hline Maggie & 6 & 20 & Somewhat interested & mid & low \\
\hline Laura & 6 & 22 & Very interested & high & low \\
\hline Esther & 6 & 20 & Quite interested & low & mid \\
\hline
\end{tabular}




\section{Appendix 3: Example of a political discussion on Facebook}

The following is an excerpt from a fraught political conversation on Facebook which a participant uploaded to the Facebook group after the focus group was finished.

$23 \mathrm{hrs}-24$

What The Fuck!! You either quit or you dont! Its quite clear you're not wanted, wanker

Like - Comment - Share

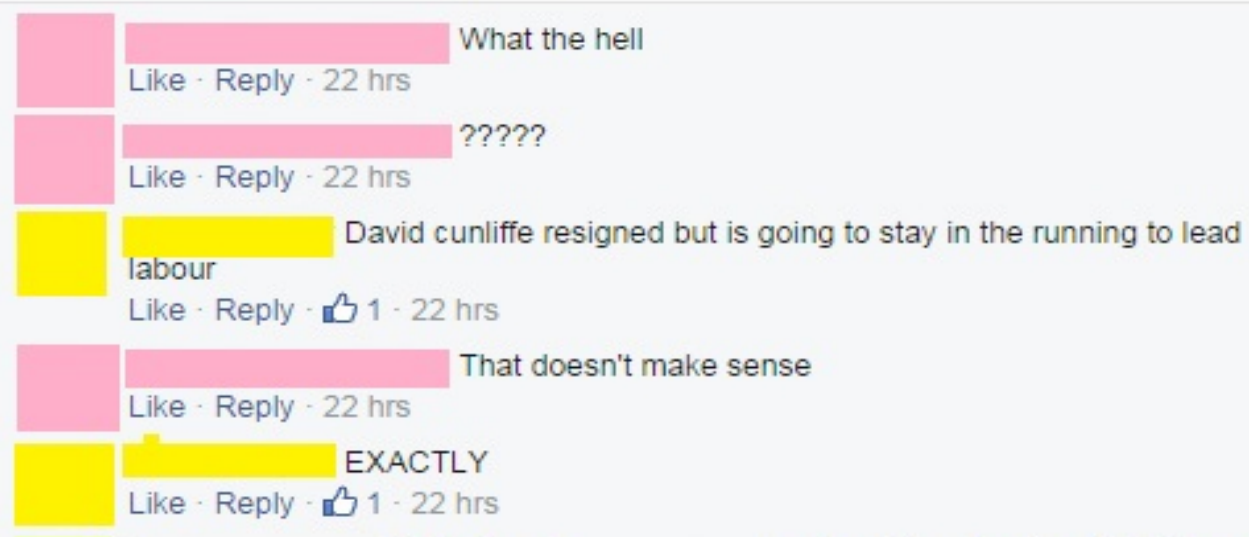

not good for digestion this labour politics. Have a coke and smile.

Like - Reply - 22 hrs

Like - Reply - 1 - 22 hrs

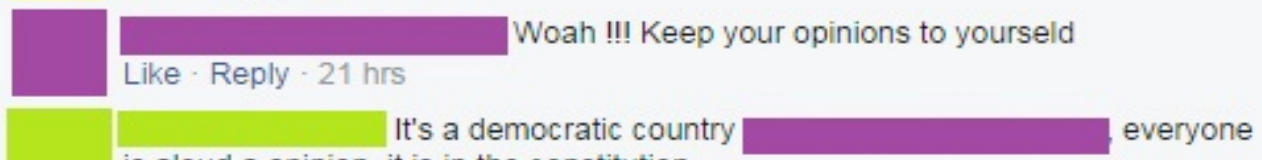
is aloud a opinion, it is in the constitution.

Like - Reply - 21 hrs

Let me start of by saying that I have been brought up as a Labour supporter. But all through this election, ur opinions have been bombarding my newsfeed and I have said nothing about it. You don't have to like my opinion, but I have a right to express it. Just the same as you. Like - Reply - 3 - 21 hrs

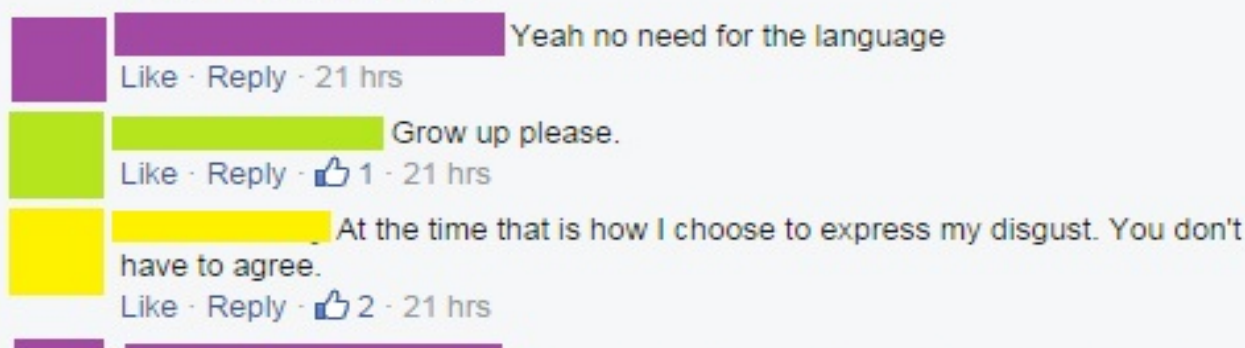

You grow up. No need for bad language towards people in any way !! And its disgusting swearing comming from a female. Just saying. (:) thats how I was brought up.

Like - Reply - 21 hrs 


\section{Appendix 4: Focus group run plan}

Note: The focus group run plan changed somewhat throughout the course of running the groups. For instance, question order was tweaked, and questions were edited or added. The below run plan is the one used in the last focus group.

Questions in the second level of bullet points were optional questions which I included where further probing was needed. Sometimes the natural flow of questions meant that the order of questions did not match the run plan. The headings were for my purposes only.

Hello everyone and thanks for participating in this online discussion. In a minute I will start asking some questions and start the discussion. But first, I would like to lay down a couple of ground rules.

1) It would be fantastic if you could engage and respond to what others have to say. However, if you disagree with something someone else says, don't dismiss it, but rather try and explain why you experience it differently or why you have a different opinion. There's no such thing as a wrong opinion! Yet, please be respectful of everyone's opinions.

2) Please keep everything that is talked about in this chat room confidential.

I'll just give a quick outline of the discussion we're going to have. We'll start with your experiences of politics on Facebook and Twitter, and also look at how you manage talking about politics personally. Before we finish we'll also take a step back and think about social norms on social media more broadly.

When I say "politics", I'm interested in whatever you think political things are on Facebook and Twitter. Here are a few examples just to get you thinking about what counts as "political”: posting a link to a national or local political news article, expressing an opinion or engaging in a conversation about political events, asking someone to vote, linking to a petition about a political issue etc.

All up, our discussion should take around 60 minutes, maybe up to 90, depending on how much everyone has to say. If you do not understand a question, please feel free to ask what I mean or to clarify the question.

\section{Experiences of politics on Facebook and Twitter}

First we're going to talk about your experiences of politics on Facebook and Twitter.

- What experiences have you had of political discussions on Facebook and/or Twitter? Did you notice lots of posts around the election?

- Are you friends with people who regularly post political arguments/content?

- What do you do (and what is your reaction) when a friend posts political 
content you don't agree with?

- Would you become friends or follow someone on Facebook or Twitter if you knew they were going to talk a lot about politics?

- Have you posted anything political on Facebook or Twitter recently?

- Can you tell me about a time you posted something political and people reacted - or maybe they didn't.

- Do you believe there is a place for politics on Facebook and Twitter?

- Do you think certain types of political posts on Facebook/Twitter are more socially acceptable than others? For example, is a link to a political news article better than a rant?

- Is having an open-ended discussion about a piece of political news more appropriate than posting a partisan political message?

- Does the political discussion have to be constructive for it to be acceptable? Is it the act of persuasion which is distasteful?

- Do you think it's okay to try and persuade people to say, vote for a certain party or candidate?

- Does the right to free speech mean people should be allowed to post whatever they want?

- Have you ever taken steps to alter the visibility of political discussions? E.g. have you ever hidden a post, or defriended or unfollowed someone because they talk too much about politics, or they talked in a particular way you did not like?

- For those of you have done something, can you remember what pushed you to do it?

\section{Differences between Facebook and Twitter}

- Do you think political content is more or less acceptable on Twitter versus Facebook? Why do you think that is?

- Do you think Facebook is different to Twitter in terms of politics because you might know more people from the offline world?

- Are there features or limitations of Twitter and Facebook which make either platform good or bad for politics?

- Do space constraints on Twitter make a difference? 


\section{Personal experience of posting politics and strategies for posting acceptable (political) content}

- Do you think about the appropriateness of posting political content before you hit publish or tweet?

- Do you think more about how people are going to react when you post a political comment rather than a non-political one? (or think less....)

- Do you think about who might see a political comment on Facebook or Twitter before you post it?

- To what extent do you worry about the people who might see your political messages on Facebook/Twitter? How well do you think you can estimate the audience of a post?

- Are there ways in which people can approach the posting of political content on Facebook or Twitter which could make it more acceptable?

- For example, do you think humour is a useful tool?

- Is it better to post politics without taking an explicit position?

\section{Thinking about norms on social media}

Now let's talk about your understanding of social norms on social media, or in other words, what people understand is “okay” or socially acceptable. More particularly, I'm interested in how you think people figure out what's okay.

- How do you think people come to understand what's okay to post on Facebook and Twitter in terms of politics?

- Do you think it's more people seeing positive stuff others are doing and copying it, or seeing bad things others are doing and avoiding it?

- Do you think people share an understanding of what's acceptable? Or are different people and groups likely to think differently about what is okay to post on Facebook and/or Twitter in terms of politics?

- Do you think it's easy to forget sometimes that not everyone thinks alike when it comes to politics?

- Do you think "subtweeting”, or more generally complaining about other people's behaviour on social media, plays a role in enforcing what is--or is not-okay to post on Facebook/Twitter in terms of politics?

- Have you ever complained about other people posting political content on Facebook/Twitter? Either in public or private, and not necessarily directly to them 
- Do you think political content on Facebook and Twitter can help to make us better citizens?

- For example, was politics on Facebook and Twitter a useful way of learning about the election?

- Would it be good or bad if politics were more readily accepted on Facebook or Twitter for instance?

- Do we lose something when people are afraid to express their real political opinions, or when they present their opinions in a somewhat bland, neutral way? Could we instead engage in civil debates where everyone isn't afraid to say what they believe?

\section{Wrap up and methodology question}

Does anyone have any final comments about politics and social media?

Before concluding, I would like to ask what you thought about this online focus group.

- Do you think talking online is easier than talking face-to-face, for a group discussion?

Okay, thanks very much everyone for coming. I greatly value your input and your time.

I'll be in touch with information about your vouchers via Facebook chat :-) 